Organizadores

Gissele Carraro Loise Cristina Passos Drumond Valmin Ramos-Silva

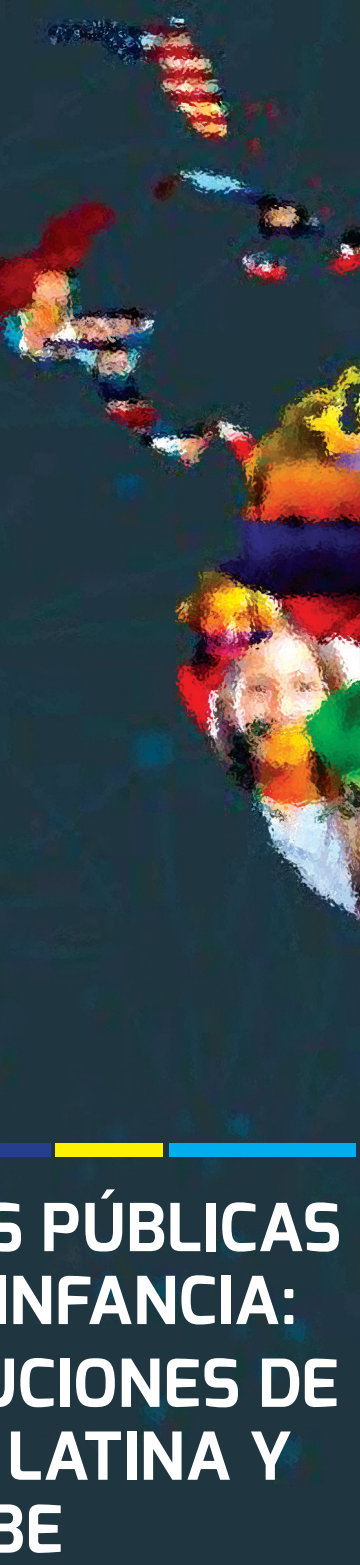

POLÍTICAS PÚBLICAS PARA LA INFANCIA: CONTRIBUCIONES DE AMÉRICA LATINA Y DEL CARIBE 

Gissele Carraro

Loise Cristina Passos Drumond

Valmin Ramos-Silva

Organizadores

\section{POLÍTICAS PÚBLICAS PARA LA INFANCIA: CONTRIBUCIONES DE AMÉRICA LATINA $Y$ DEL CARIBE}

DOI: 10.5935/978-65-88041-02-4.0001 (http://dx.doi.org)

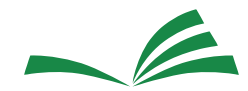

e ditora EMESCAM

Vitória, ES - 2020 
(c) 2020 Editora EMESCAM

Todos los derechos reservados. La reproducción de cualquier parte de la obra, por cualquier medio, sin la autorización del editor, constituye una violación de la LDA n 9.610/98

\section{Portada}

Sector de la comunicación del EMESCAM

\section{Revisión y preparación de originales}

Valmin Ramos-Silva

\section{Publicación}

Edson Maltez Heringer | 27 98113-1826

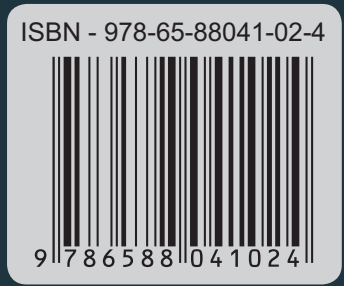

Disponible en https://www.editoraemescam.com.br/editora-2/

Datos de catalogación internacional en publicación (CIP)

(Biblioteca Central da EMESCAM, Espírito Santo, ES, Brasil)

P769 Políticas públicas dirigidas a la niñez : aportes de América Latina y el Caribe / Gissele Cassaro, Loise Cristina Passos Drumond e Valmin Ramos-Silva (organizadores). - Vitória: Emescam, 2020.

Traducido de: Políticas públicas dirigidas à infância: contribuições da América Latina e do Caribe.

134 p. : il.

Incluye bibliografías

ISBN: 978-65-88041-02-4

1. Políticas públicas - niños. 2. Niños - aspectos sociales - América Latina Caribe. 3. Derechos de los niños. I. Carraro, Gissele, org. II. Drumond, Loise Cristina Passos, org. III. Ramos-Silva, Valmin, org. IV. Escuela Superior de Ciencias de la Santa Casa de Misericórdia de Vitória, EMESCAM. V. Título. 


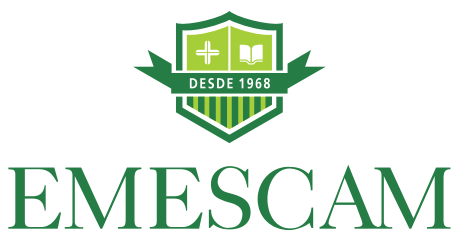

Irmandade da Santa Casa de Misericórdia de Vitória

Proveedor

Maria da Penha Rodrigues D’Avida

Proveedor adjunto

Cláudio Medina da Fonseca

Escola Superior de Ciências da Santa Casa de Misericórdia de Vitória

Director

Cláudio Medina da Fonseca

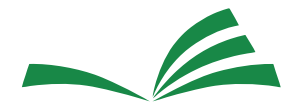

e $d$ i tor a

EMESCAM

Editora Universitária Emescam

Editor jefe
Valmin Ramos-Silva

Consejo editorial

Jane Prates (PUCRS) - Presidente

Cristina Ribeiro Macedo - EMESCAM - Vitória/ES

Marcela Souza Lima Paulo - EMESCAM - Vitória/ES

Renato Lirio Morelato - EMESCAM - Vitória/ES

Roberta Ribeiro Batista - EMESCAM - Vitória/ES

Rubens José Loureiro - EMESCAM - Vitória/ES 


\section{Autores}

\section{Gissele Carraro}

Doctora en Servicio social por el Programa de Postgrado en Servicio Social por la Pontificia Universidad Católica de Rio Grande do Sul (PUC-RS). Profesora y Coordinadora del Programa de Postgrado en Políticas Públicas y Desarrollo Local de la Escola Superior de Ciências da Santa Casa de Misericórdia de Vitória (Emescam). Líder del Grupo de Estudio Capitalismo, Estado y Políticas Públicas en la Sociedad Contemporánea (GECEPP).

Correo electrónico: gissele.carraro@emescam.br y gcarraro5@gmail.com ORCID https://orcid.org/0000-0002-3143-9708

\section{Loise Cristina Passos Drumond}

Graduado en Letras por la Universidad Federal de Espírito Santo; Especialización en Lingüística Aplicada al Texto por la Universidad Federal de Espírito Santo; Maestría en Extranjería y Formación en Psicoanálisis Clínico de la Universidad Iguaçu, RJ; Licenciada en Pedagogía por la Facultad de Educación Regional Serrana. Actualmente estudia Psicología en la Asociación Victoriana de Educación Superior (FAVI). Profesora de los cursos de Fisioterapia, Enfermería y Medicina de la Escola Superior de Ciências da Santa Casa de Misericórdia de Vitória (Emescam).

Correo electrónico: loise.drumond@emescam.br

\section{Valmin Ramos-Silva}

Biólogo. Pediatra. Máster en Biología Vegetal. Doctor en Pediatría. Postdoctorado en Educación. Profesor del Programa de Postgrado en Políticas Públicas y Desarrollo Local de la Escola Superior de Ciências da Santa Casa de misericordia de Vitória (Emescam). Coordinador de Investigación y Postgrado Stricto Sensu / (EMESCAM).

Correo electrónico:valmin.ramos@emescam.br; Valmin.silva@gmail.com https://orcid.org/0000-0003-1574-0266 


\section{Autores contribuyentes}

Adelma Alves de Figueirêdo (Brasil)

Amarilis Then-Paulino (República Dominicana)

Ana María Aguilar Liendo (Bolivia)

Ana María Lozano Alemán (Honduras)

Asha V. Badaloo (Jamaica)

Blenda Avelino García (Brasil)

Camilo Adauton Mariano da Silva (Brasil)

Carolyn Taylor-Bryan (Jamaica)

Daniel Thomas (Jamaica)

Denise Abreu Cavalcanti (Brasil)

Enrique O. Abeyá-Gilardon (Argentina)

Eugênia Aguilar Lema de Las Mercedes (Equador)

Faride Esther Rodríguez Díaz (Panamá)

Gerardo Weisstaub (Chile)

Gustavo Cediel (Colômbia)

Inocencia Palmira Peralta López (Paraguai)

Israel Ríos-Castillo (Panamá)

Janine Pereira da Silva (Brasil)

Joel Alves Lamounier (Brasil)

Maressa Cristiane Malini de Lima (Brasil)

María Elena Díaz Sánchez (Cuba)

Matilde Peguero Payano (República Dominicana)

Priscila Campos de Matos Lacerda (Brasil)

Shelley McFarlane (Jamaica)

Valmin Ramos-Silva (Brasil)

Wendell Costa Bila (Brasil) 


\section{Resumen}

Capítulo 1 LA DOBLE CARGA DE LA DESNUTRICIÓN,

LA DESIGUALDAD Y EL SISTEMA ALIMENTARIO

Gerardo Weisstaub, Enrique O. Abeyá-Gilardon, Gustavo Cediel,

Ana María Aguilar Liendo y Israel Ríos-Castillo

Capítulo 2 DESAFíO E INNOVACIÓN EN POLÍTICAS PÚBLICAS

PARA LA NIÑEZ EN SITUACIONES DE VIOLENCIA

EN BRASIL: VIOLACIÓN DE DERECHOS

Adelma Alves de Figueirêdo, Blenda Avelino Garcia, Priscila Campos

de Matos Lacerda y Denise Abreu Cavalcanti

Capítulo 3 DESAFÍOS DE LAS POLÍTICAS PÚBLICAS PARA EL

CONTROL DE LA OBESIDAD INFANTIL EN AMÉRICA

LATINA Y EL CARIBE

Asha V. Badaloo, Shelley McFarlane, Carolyn Taylor-Bryan y Daniel Thomas

Capítulo 4 POLÍTICA DE SEGURIDAD ALIMENTARIA Y NUTRICIONAL

EN BRASIL: ENFOQUE EN LA LUCHA CONTRA LA

DEFICIENCIA DE MICRONUTRIENTES

Wendell Costa Bila, Joel Alves Lamounier, Inocencia Palmira Peralta López,

Ana María Lozano Alemán y Camilo Adauton Mariano da Silva

Capítulo 5 POLÍTICAS PARA COMBATIR LA POBREZA INFANTIL

EN AMÉRICA LATINA Y EL CARIBE

Matilde Peguero y Amarilis Then-Paulino

Capítulo 6 POLÍTICAS PÚBLICAS DE NUTRICIÓN EN AMÉRICA

LATINA Y EL CARIBE: REFLEXIONES SOCIALES Y

ANTROPOLÓGICAS

María Elena Díaz Sánchez

Capítulo 7 MORTALIDAD INFANTIL EN AMÉRICA LATINA Y EL CARIBE:

INTERFAZ CON LAS POLÍTICAS PÚBLICAS Y SOCIALES

Maressa Cristiane Malini de Lima; Janine Pereira da Silva,

Eugenia de las Mercedes Aguilar Lema, Faride E. Rodríguez Díaz,

Helder Gomes, Valmin Ramos-Silva 


\section{Presentación}

Para los niños trabajamos, porque los niños son los que saben querer, porque los niños son la esperanza del mundo. [...] Lo que queremos es que los niños sean felices, como los hermanitos de nuestro grabado; y que si alguna vez nos encuentra un niño de América, por el mundo nos apriete mucho la mano, como a un amigo viejo, y diga donde todo el mundo lo oiga: '¡Este hombre de La Edad de Oro fue mi amigo!'. (José Martí, a los niños que lean La Edad de Oro).

Esta Colección está compuesta por textos de autores brasileños y extranjeros, productos de la reflexión conceptual, teórica e indicadores de América Latina y el Caribe, que involucran el análisis de propuestas en el ámbito de las políticas públicas, posibilidades, obstáculos de desafíos en su proceso de materialización en los países latinoamericanos.

Cabe mencionar que autores extranjeros y algunos brasileños forman parte de un grupo de investigación que aborda temas alimentarios, nutricionales y otros que comprometen la niñez, le quita la oportunidad de acceder a bienes y servicios, con pérdidas a salud de los niños. El grupo está vinculado a proyectos de cooperación técnica internacional, con la participación de países de América Latina y el Caribe, aprobados, coordinados y financiados por el Organismo Internacional de Energía Atómica (OIEA) y por las Agencias de Energía Nuclear de los países involucrados. En estos proyectos participan docentes de la Escuela Superior de Ciencias de la Santa Casa de Misericórdia (EMESCAM) y del Programa de Posgrado en Políticas Públicas y Desarrollo Local de esta institución, coordinado por el profesor Valmin Ramos-Silva.

Estas producciones de conocimiento son el resultado de investigaciones que articulan varios dominios del conocimiento, a través de la interfaz entre diferentes áreas del conocimiento, en particular, Ciencias de la Salud, 
Ciencias Humanas y Ciencias Sociales Aplicadas, contribuyendo así a análisis amplios de la realidad concreta y de políticas públicas dirigidas a la niñez en países de América Latina y el Caribe. Se enfatiza que las políticas públicas tienen una interdisciplinar, Por constituir un campo de estudio y trabajo para investigadores de distinta formación, lo que da lugar a concepciones distintas en relación con ellos, convergentes y divergentes en determinados aspectos. La complementariedad y la construcción de nuevos conocimientos, propósitos comunes, acciones colectivas e integradas permiten producir cambios y respuestas a las demandas y necesidades sociales.

Reside aquí, uno de los impactos de esta producción bibliográfica para diferentes áreas en relación a la difusión del conocimiento, la mejora de los procesos de formulación, ejecución y evaluación de políticas públicas, y aportes para realizar análisis de fenómenos y procesos históricos y sociales relevantes a nivel local, regional, nacional e internacional, y en la propuesta de alternativas de intervención a los problemas socioeconómicos que afectan a la población, salvaguardando la diversidad de cada realidad concreta y formación social que interfieren en los planes de acción, propósitos y medios especificados para la realización de derechos y políticas, especialmente los centrados en la infancia, definidos como campo analítico en esta Colección.

El reconocimiento internacional del imperativo de brindar plena protección a la infancia, con miras al desarrollo de la autonomía y personalidad de cada ser humano, ha demandado una atención especial y sistemática por parte del Estado y la Sociedad Civil. Su incorporación como prioridad en la lista de derechos exigibles y políticas públicas dirigidas a la niñez en América Latina y el Caribe y, en el mundo, es resultado de las luchas sociales e históricas que libran los movimientos colectivos que reclaman la constitución, defensa y materialización de los derechos de la niñez. que se destaquen en acciones cooperativas e intersectoriales, considerando las necesidades sociales y las diferentes demandas que surgen de la realidad concreta de cada país.

La expansión de las desigualdades, la pobreza, el hambre, la obesidad y la desnutrición, de la violencia que afectan a la infancia en diferentes países, incluidos los latinoamericanos, han provocado graves pérdidas en el proceso de desarrollo cognitivo/lingüístico, psicomotor, afectivo/social, puntualiza. estudios e investigaciones de instituciones y organismos nacionales e 
internacionales, como la Organización Mundial de la Salud (OMS), la Organización Panamericana de la Salud (OPS), el Fondo de las Naciones Unidas para la Infancia (UNICEF), la Organización de las Naciones Unidas para Alimentación y Agricultura (FAO), Organización de las Naciones Unidas para la Educación, la Ciencia y la Cultura (UESCO), Sistema de Información sobre la Primera Infancia en América Latina (SIPI).

Al constituir una responsabilidad pública de todas las personas y un deber ético irrenunciable, compromete tanto al Estado como a la Sociedad a garantizar la satisfacción de las necesidades sociales, imprescindibles para la vida material y subjetiva de todo ser humano. Así, la lucha por afirmar la protección de la niñez como un derecho, así como el reconocimiento de que son "sujetos de derechos" y "personas en peculiar condición de desarrollo" requiere el establecimiento de parámetros para su regulación y aseguramiento, a través de instrumentos. normativas, organismos públicos, mecanismos de promoción, con miras a su implementación.

En este sentido, la importancia de los tratados internacionales adoptados y ratificados, a lo largo del siglo XX, por diferentes países del mundo, en los que los Estados-Partes asumieron un conjunto de compromisos políticos, que deben orientar la formulación y ejecución de políticas públicas orientadas a protección infantil. Así, destacan los siguientes: Declaración de Ginebra de los Derechos del Niño (1924); Declaración de los Derechos del Niño (1959); Declaración Universal de Derechos Humanos (1948); Pacto Internacional de Derechos Civiles y Políticos (1966); Pacto Internacional de Derechos Económicos, Sociales y Culturales (1966); Pacto de San José de Costa Rica (1969); Convención sobre los Derechos del Niño (1990).

Sin duda, estos hitos históricos y normativos han sido y siguen siendo el motor de los avances en varios países del mundo, de América Latina y el Caribe en materia de protección a la niñez, los cuales difieren y dirigen a: la regulación de derechos en la Constitución y en instrumentos normativos específicos. (leyes, resoluciones, decretos, etc.); establecimiento de un marco conceptual, lineamientos y estrategias integrales en el diseño e implementación de diferentes políticas públicas; constitución de políticas públicas específicas para la niñez, materializadas a través de servicios, programas, proyectos y beneficios. Sin embargo, aún es necesario avanzar cualitativamente para que estas iniciativas se conviertan en acciones 
concretas, que permitan a todos los niños disfrutar de un desarrollo pleno y de una infancia con plena protección. Esto depende de la voluntad política de priorizar recursos para las políticas públicas hacia el acceso y cobertura universal, la integralidad, la equidad y la eficiencia. Lo que constituye uno de los mayores desafíos, dada la crisis de capital y las medidas de ajuste fiscal para enfrentarla, que generan inflexiones en la materialización de las políticas públicas.

Esta colección busca estimular la discusión sobre políticas públicas dirigidas a la niñez, que permita mostrar el estado actual del tema, intercambiar lecciones aprendidas y reflexiones para avanzar en las arduas luchas que se avecinan, con el objetivo compartido por todos (as): que los niños de la región de América Latina y el Caribe puedan disfrutar de una infancia plena en todos los aspectos de la vida. Dicho esto, se presentan los siete capítulos que componen la producción de conocimiento.

El primer capítulo, titulado "La doble carga de la desnutrición, la desigualdad y el sistema alimentario", de los autores: Gerardo Weisstaub, Enrique O. Abeyá-Gilardon, Gustavo Cediel, Ana María Aguilar Liendo, Israel Ríos-Castillo, analiza la coexistencia de desnutrición con sobrepeso y enfermedades crónicas ligadas a dietas inadecuadas, compuestas por alimentos ultraprocesados y la inactividad física a lo largo de la vida, como consecuencia del modelo económico de desarrollo. Llama la atención sobre el avance de las formas de malnutrición en los países en desarrollo, que son los que sufren más inequidades vinculadas a los determinantes sociales.

El segundo capítulo, Desafío e innovación en políticas públicas para niños en situaciones de violencia en Brasil: violación de derechos, de las autoras Adelma Alves de Figueirêdo, Blenda Avelino García, Priscila Campos de Matos Lacerda, Denise Abreu Cavalcanti, aborda las formas de violencia niños, con insumos de datos sobre la realidad internacional y brasileña y en este punto cambios en la visión y prácticas que involucran a la niñez, en relación al texto constitucional y legislación infraconstitucional en la realización de los derechos de los niños, niñas y adolescentes, aseguradores de protección social. En este texto, los autores discuten las políticas públicas, concretando conceptos y normas que las instituyen, con ejemplos de experiencias concretas, explicando desafíos e innovaciones para enfrentar la violencia en sus diferentes configuraciones. 
El tercer capítulo, Desafíos de las políticas públicas para el control de la obesidad infantil en América Latina y el Caribe, de los autores Daniel Thomas; Carolyn Taylor-Bryan; Shelley McFarlane; Asha V. Badaloo, analiza la obesidad infantil, sus expresiones e implicaciones para la infancia. Contextualizan esta problemática en la región estudiada, utilizando indicadores para retratar el tema de la obesidad y estrategias y planes de acción para superar, a nivel mundial, que involucran diferentes políticas públicas, como salud, educación, seguridad alimentaria y nutricional, además de los desafíos que se les plantean en su proceso de ejecución, seguimiento y evaluación, involucrando a gobierno, mercado y sociedad civil.

El cuarto capítulo Política de seguridad alimentaria y nutricional en Brasil: Enfoque en la lucha contra la deficiencia de micronutrientes, por los autores Wendell Costa Bila, Joel Alves Lamounier, Inocencia Palmira Peralta López, Ana María Lozano Alemán y Camilo Adauton Mariano da Silva, centro la discusión de los principales temas relacionados con las necesidades nutricionales y las consecuencias de la falta o exceso de macro y micronutrientes en la salud, especialmente para el crecimiento y desarrollo saludable del niño, estableciendo una asociación con las desigualdades sociales y la pobreza. También acerca las principales políticas públicas de seguridad alimentaria y nutricional de América Latina y el Caribe para enfrentar el hambre, la desnutrición y la obesidad.

El quinto capítulo Políticas para combatir la pobreza infantil en América Latina y el Caribe, de las autoras Matilde Peguero y Amarilis Then-Paulino, está dedicado a las principales políticas públicas dirigidas a la niñez en los países de la región, con foco en la reducción de la pobreza y las inequidades, en el desarrollo de la primera infancia y la protección ofrecida en forma de sistemas, políticas, planes, programas y estrategias gubernamentales. Se propone hacer explícitos sus objetivos, el público destinatario, los límites y desafíos planteados para su realización, debido a las inflexiones que produce el apego a la política dictatorial neoliberal de los países y gobiernos externos.

El capítulo sexto, Políticas públicas de nutrición en América Latina y el Caribe: reflexiones sociales y antropológicas, de la Antopóloga María Elena Díaz Sánchez, esboza su análisis de los obstáculos para la formulación e implementación de políticas públicas desde contextos institucionales y socioculturales, lenguaje y desde el discurso de los formuladores, desde 
las decisiones que se toman, las reglas que las originan, el impacto y la forma en que responden a las demandas que se proponen atender, incluida la alimentación y la nutrición. En su lógica de análisis, aborda aspectos políticos, económicos y sociales que contribuyen a la permanencia de la inseguridad alimentaria de la niñez en la región latinoamericana. También destaca la importancia de la soberanía alimentaria como derecho de los pueblos en la definición de políticas y estrategias para la producción, distribución y consumo de alimentos para toda la población.

El capítulo séptimo, Desafíos de las políticas públicas para reducir la mortalidad infantil en América Latina y el Caribe, de las autoras Maressa Cristiane Malini de Lima; Janine Pereira da Silva, Faride E. Rodríguez Díaz, Eugenia de las Mercedes Aguilar Lema y Valmin Ramos-Silva, presenta un panorama de la mortalidad infantil em algunos países de la región, con una discusión sobre las causas de este problema. El enfoque desarrollado toma en cuenta los sistemas políticos neoliberales y las políticas implementadas con base en las directrices del Fondo Monetario Internacional, lo que ha resultado en un aumento de la mortalidad infantil. Además, los países se incorporan con mayor frecuencia y acciones para reducirlos.

Brasil - Vitória (ES), noviembre de 2020

Gissele Carraro Loise, Cristina Passos Drumond y Valmin Ramos-Silva (Organizers) 


\section{Capítulo 1}

\section{LA DOBLE CARGA DE LA DESNUTRICIÓN, LA DESIGUALDAD Y EL SISTEMA ALIMENTARIO}

Gerardo Weisstaub ${ }^{1}$, Enrique O. Abeyá-Gilardon², Gustavo Cediel ${ }^{3}$, Ana María Aguilar Liendo ${ }^{4}$, Israel Ríos-Castillo

${ }^{1}$ Gerardo Weisstaub. Profesor Asistente. Instituto de Nutrición y Tecnología de los Alimentos (INTA).Departamento de Pediatría (Campus Centro). Universidad de Chile. gweiss@ inta.uchile.cl.

2 Enrique O. Abeyá-Gilardon. Médico pediatra y sanitarista, consultor independiente en nutrición y salud pública materno infantil. Argentina. enrique.abeya@gmail.com.

${ }^{3}$ Gustavo Cediel. Doctor en Nutrición y Alimentos. Escuela de Nutrición y Dietética, Universidad de Antioquia, Medellín, Colombia. cedielgiraldo@gmail.com.

${ }^{4}$ Ana María Aguilar Liendo. Docente investigadora Instituto de Investigación en Salud y Desarrollo - Facultad de Medicina Universidad Mayor de San Andrés. Bolivia. ana. aguilar@umsalud.edy.bo.

${ }^{5}$ Israel Ríos-Castillo Oficial Regional de Nutrición. Organización de las Naciones Unidas para la Alimentación y la Agricultura (FAO). Oficina Subregional de la FAO para Mesoamérica. Ciudad de Panamá, Panamá. Israel.Rios@fao.org.

Resumen: $\quad$ La doble carga de la malnutrición se caracteriza por la coexistencia de desnutrición junto con sobrepeso, obesidad o enfermedades crónicas transmisibles relacionadas con la alimentación a lo largo del ciclo de vida. Resultado del modelo económico de desarrollo, la urbanización, el cambio demográfico y el aumento del consumo de alimentos altamente procesados se ha producido un cambio significativo en la calidad la alimentación. Este dipo de enfermedades puede manifestarse tanto a nivel individual como poblacional, desde la infancia a la vida adulta. En la actualidad, casi una de cada tres personas en todo el mundo sufre de al menos una forma de malnutrición, especialmente en los países en vías de desarrollo. La distribución de los determinantes sociales, condicionantes de la inequidad, pueden explicar la prevalencia y combinación de 
las patologías que coexisten en un mismo lugar y población. El acceso a dietas saludables parte de un adecuado suministro de alimentos que contemple formas de producción ambientalmente sostenibles, adecuados canales de venta y distribución. A pesar de la responsabilidad de los estados en la regulación del consumo de alimentos, algunos programas de prevención de malnutrición centran la mayor parte de la responsabilidad alimentaria en el individuo, una visión que despolitiza la dificultad que subyace detrás de este tipo de decisiones. Dado que los factores que condicionan este tipo de malnutrición subyacentes en los sistemas de alimentación se dan simultáneamente e interactúan con los que han generado el cambio climático las acciones sinérgicas serán esenciales para lograr la salud planetaria, que definimos como la salud y el bienestar de los seres humanos y los entornos naturales de los que dependemos

Palabras-clave: Desnutrición Proteica; Obesidad Pediátrica; Enfermedad Crónica; Desarrollo Económico; Desigualdad Social; Niño.

\section{Definición y epidemiologia de la Doble Carga de Enfermedad}

¿Qué entendemos como doble carga? La concurrencia de dos o más condiciones, distintas y a menudo contrarias a primera vista, que ocurren simultáneamente ya sea en un territorio, en un hogar o en una misma persona.

La primera publicación sobre doble carga y malnutrición es de 1995 en Brasil aplicada a hogares de niños desnutridos y madres obesas ${ }^{1}$. En estos últimos 10 años ha habido un aumento importante en la bibliografía indexada en PubMed y el concepto se extiende a colectivos más amplios como comunidades y países ${ }^{2,3}$.

Las realidades nutricionales representadas por la doble carga suelen ser situaciones más complejas que en la aparente doble carga y que incluso en la bibliografía se han ampliado a triple y cuádruple carga ${ }^{4}$. En un primer abordaje, la doble carga significó la continuidad de las enfermedades infecciosas que tienen una alta incidencia en las tasas de mortalidad materno infantil (diarrea, malaria, neumonía, sepsis neonatal, entre otras) y la desnutrición de 
macro y micronutrientes junto a enfermedades crónicas asociadas a un estilo de vida occidental y a la excesiva ingesta de calorías, que tradicionalmente existían en países con recursos elevados ${ }^{5}$.

A nivel del hogar, la doble carga de malnutrición se la ha descrito en cuatro variedades i) Individual: niño con retraso de crecimiento y obeso; y en un mismo hogar: ii) madre con sobrepeso u obesidad y menor de 5 años con peso bajo; iii) madre con sobrepeso u obesidad y un menor de 5 años con retraso de crecimiento; iv) madre con peso bajo y menor de cinco años con obesidad. Esta última tiene una frecuencia menor a 1\%; mientras que la tercera variedad es la más frecuente ${ }^{6}$.

El denominador común de esta diversidad de combinaciones es la ausencia de una dieta saludable y la complejidad de interacciones metabólicas que puede tener efecto a lo largo del curso de vida. La mayoría de los países, de manera independiente a sus ingresos, presenta uno o más variedades, a la que se añade la deficiencia de micronutrientes, y constituye lo que se denomina la nueva realidad de nutrición. Lograr una dieta saludable en los países es el logro satisfactorio de los cuatro componentes que la Organización de las Naciones Unidas para la Alimentación y la Agricultura (FAO) reconoce como integrantes de la seguridad alimentaria: disponibilidad, accesibilidad/ consumo, utilización y estabilidad.

En Centroamérica la FAO asimismo reconoce un quinto componente: institucionalidad. Todos estos componentes tienen diferente implicancia y relevancia en la causalidad de la doble carga dependiendo del sistema alimentario de cada país para garantizar una dieta saludable. A esta situación se añade el déficit de micronutrientes de alta prevalencia en países de ingresos medianos y bajos ${ }^{7}$.

La doble carga de enfermedad no se manifiesta de la misma manera en todos lados, por lo que para poder entender las diferentes formas de malnutrición que pueden coexistir de mayor prevalencia es importante conocer la situación epidemiológica. Por ejemplo, si el lugar (países y regiones dentro de países) al que se hace referencia se encuentra en transición nutricional este proceso influye en la forma como la población se alimenta, bebe, transporta se divierte y se mueve al trabajo, en el hogar ha afectado la distribución de la composición corporal y creado problemas nutricionales. La transición ha producido cambios importantes en la actividad física y dietas 
y un rápido incremento de sobrepeso, obesidad y enfermedades crónicas no transmisibles. Para poder entender cómo el contexto epidemiológico influye en la forma en que se manifiesta la doble carga es indispensable analizar el grado de inequidad de la sociedad.

\section{Inequidad en el acceso de alimentos y malnutrición}

La inequidad en la doble carga de enfermedad puede ser explicada en gran parte por la distribución en la población de los determinantes sociales ${ }^{8,9}$ lo cual permite identificar aquellas intervenciones integrales a través del curso de vida y con una mirada epigenética que mejorarían la situación?

La presencia simultánea de la desnutrición y la obesidad, en el mismo individuo o en individuos de la misma familia, ha sido ampliamente documentada en países de bajos y medianos ingresos. Un aumento de 0.1 puntos en el coeficiente de Gini se asocia con un aumento de $8-12 \%$ en las probabilidades que un individuo tenga tanto obesidad como bajo peso ${ }^{10}$.

Así se pueden encontrar madres obesas con niños desnutridos o niños con retraso en el crecimiento infantil y obesidad. Lee $\mathrm{J}$ y $\mathrm{col}^{11}$, en un estudio realizado en Guatemala buscaron identificar de factores socioeconómicos asociados con esta dualidad de la desnutrición en una muestra de casi 2500 hogares. Los resultados revelaron una mayor prevalencia de retraso en el crecimiento infantil, pero una menor prevalencia de sobrepeso materno entre los pobres en comparación con los hogares ricos. La desigualdad económica en el retraso del crecimiento infantil fue mayor que la desigualdad económica en el sobrepeso materno. Además, se encontró que era más probable encontrar una diada madre obesa/niño con retraso de crecimiento en hogares del quintil de consumo medio que en los del primer quintil (mejor NSE). En un estudio realizado en Sri Lanka, en niños de 5 a 10 años, mostró que la menor educación de las madres presentaba se asociaba con una mayor delgadez del niño (OR=2,3 IC 95\% 1,08-5,00) $)^{12}$.

Una de las recomendaciones para prevenir la obesidad es realizar diariamente actividad física, especialmente de intensidad moderada o vigorosa. Para poder llevar a la práctica esta recomendación se requiere de espacios públicos adecuados. Sin embargo, su distribución tampoco es equitativa. En 
Santiago de Chile, las cuatro comunas de más altos ingresos concentran un tercio de la superficie total de áreas verdes, mientras que las cuatro comunas más pobres sólo el $4 \%$. En el mismo estudio se observa que mientras en una comuna de bajos ingresos solo el $20 \%$ de la población tiene acceso a un área verde de al menos $5.000 \mathrm{~m}^{2}$ cerca de su vivienda $(300 \mathrm{~m})$ lo que contrasta con el $74 \%$ encontrado en una comuna de ingresos altos ${ }^{13}$. La práctica de ejercicio tampoco se distribuye uniformemente entre los diferentes niveles socio económicos de la sociedad. En la última Encuesta Nacional de Salud realizada en Chile se observa que la mayor prevalencia de sedentarismo (90\%) se da en las mujeres con menos de 8 años de educación ${ }^{14}$.

En escolares también se puede observar el mismo fenómeno. En el “Estudio Nacional de Educación Física” de Chile realizado en casi diez mil niños y niñas de todo el país se observó que la condición física aeróbica evaluada por la prueba de Navette fue satisfactoria solo en el 31\% de los escolares que asistían a colegios municipales en comparación con el $41 \%$ de los que asistían a colegios particulares pagados (de mejor nivel socio económico) ${ }^{15}$.

Avanzar por un camino de mayor equidad igualdad no es solo un imperativo ético en una región con brechas sociales que se expresan en diversos ámbitos. Es necesario pensar en un nuevo estilo de desarrollo, es decir, en cómo se ordena y organiza una sociedad para la producción, la distribución y el consumo de alimentos y cómo se articula el crecimiento económico con la calidad de vida ${ }^{16}$.

\section{Doble carga de enfermedad y producción de alimentos: sustentabilidad social y medio ambiental}

Una dieta saludable es esencial para reducir, prevenir y controlar las diferentes formas de malnutrición que conviven en la doble carga y las enfermedades crónicas no transmisibles, causantes de alta morbimortalidad y discapacidad a nivel mundial ${ }^{17}$. El acceso a dietas saludables, especialmente a frutas, verduras, legumbres, pescado, nueces y semillas, parte de un adecuado suministro de alimentos que contemple formas de producción ambientalmente sostenibles, adecuados canales de venta y distribución ${ }^{18,19}$. A pesar de los anterior, algunos programas de prevención centran la mayor 
parte de la responsabilidad alimentaria y nutricional en el individuo, una visión neoliberal de las "selecciones" que despolitiza la dificultad que subyace en el fondo de cada una ${ }^{20}$. Muy por el contrario, esta visión puede ser parte de la causa de la realidad epidemiológica actual de las múltiples formas de malnutrición, que afectan profundamente a la población más vulnerable ${ }^{21,22}$. Intentando generar estrategias superadoras de la mirada individual del problema emergen otra iniciativa como la teoría de los ambientes alimentarios con tres elementos claves: el acceso físico y económico a los alimentos (proximidad y asequibilidad); la promoción de alimentos, etiquetado, publicidad e información (ambiente alimentario informativo); y la calidad y seguridad de los alimentos ${ }^{23}$.

En este escenario, actores como los gobiernos provinciales y nacionales y la industria alimentaria son señalados como los dos grupos interesados con la mayor capacidad para modificar los entornos alimentarios y las dietas de la población. Con esta visión, algunos países han trabajado para promover políticas y acciones gubernamentales sobre ambientes alimentarios saludables para reducir la obesidad, las enfermedades crónicas no transmisibles relacionadas con la alimentación y sus inequidades asociadas ${ }^{24}$. Esta alternativa, aunque es novedosa y resulta un avance, todavía presenta influencias del nutricionismo, con regulaciones al acceso físico y económico a los alimentos, basadas en el concepto de alimentación adecuada, que está reducida a la presencia o no de nutrientes y a la seguridad de los alimentos solo en términos de inocuidad 25 .

Es desde este mirada que la FAO, enfatiza que las dietas saludables y sostenibles son patrones alimentarios que deben promoverse de modo de alcanzar todas las dimensiones de la salud y el bienestar de las personas; tienen baja presión ambiental e impacto; son accesibles, asequibles, seguros y equitativos; y son culturalmente aceptables. ${ }^{19}$ Los programas de protección social que incorporan la dimensión alimentación y nutrición, favorecen el acceso a alimentos saludables, especialmente a poblaciones en mayor vulnerabilidad. ${ }^{26}$ Las políticas y programas sociales deben permitir el acceso físico y económico a dietas saludables, por ejemplo, en escuelas y centros de desarrollo infantil temprano ${ }^{26}$. Dichos programas sociales deben coordinar y articular con el sector alimentación, agricultura y salud para promover la producción, suministro y entrega de alimentos 
frescos, mínimamente procesados y naturales, acorde con las directrices nacionales de alimentación saludable como las Guías Alimentarias Basadas en Alimentos y los programas de prevención y control de la obesidad y las enfermedades crónicas no transmisibles ${ }^{27}$.

La dimensión sostenibilidad debe considerar, por lo tanto, las medidas necesarias para incrementar la resiliencia de los sistemas alimentarios para que puedan facilitar la disponibilidad de alimentos saludables, incluso durante períodos de crisis antropogénicas o naturales ${ }^{18}$. Sin embargo, el sistema alimentario actual está caracterizado por una alta disponibilidad y acceso a productos procesados y ultra procesados, baratos, con una alta percepción de convenientes y con grandes presupuestos para su promoción y publicidad ${ }^{28,29}$. Así como, resistencias desde el sector privado a medidas de salud pública que promueven ambientes alimentarios saludables tales como las leyes de etiquetado frontal de advertencia nutricional, impuestos a bebidas azucaradas y a comidas chatarra; y a la regulación de su publicidad, entre otros ${ }^{30,31}$.

En la cadena de suministros de alimentos, la falta de insumos productivos, mano de obra y dificultades con el transporte, almacenamiento y distribución afecta el cultivo y venta de alimentos, especialmente de frutas, verduras y hortalizas ${ }^{32}$. La falta de insumos agrícolas, por distintas razones, incluido el incremento de los precios, ocasiona elevados costos de producción, haciendo que las dietas saludables sean inaccesibles a los segmentos de mayor pobreza. El transporte y distribución de alimentos es especialmente relevante para los alimentos frescos y perecederos, imprescindibles para mantener dietas nutritivas, diversificadas y saludables. Por lo que es necesario contar con soluciones a nivel de políticas y programas de apoyo a la producción agropecuaria. Esta cadena de suministro debe velar además por la calidad e inocuidad de los alimentos ${ }^{33}$. De igual forma, se deben considerar a los demás actores en la cadena de suministro, tales como las operaciones de los bancos de alimentos, las organizaciones no gubernamentales, los grupos comunitarios y las organizaciones benéficas privadas. Además, se requieren intervenciones e iniciativas para reducir las pérdidas y desperdicio de alimentos en los diferentes eslabones de la cadena de suministro de alimentos ${ }^{34}$. El comercio electrónico es otro elemento disruptivo en la cadena de suministro de alimentos, pudiendo facilitar el 
acceso a productos perecederos como frutas, verduras, lácteos y pescado; pero también a dietas no saludables, como la comida chatarra y bebidas azucaradas. Por lo tanto, se requiere ampliar el enfoque de políticas para regular el mobile e-commerce y el social e-commerce, a fin de que las dietas saludables sean accesibles a todos los segmentos sociales de la población ${ }^{35}$.

En algunos países, como por ejemplo Argentina, el sistema alimentario es muy dependiente del agronegocio exportador con alta concentración oligopólica. que sólo le interesa la ganancia por lo que es fundamental regular el acopio, la comercialización y la exportación ${ }^{36,37}$. La agricultura familiar, los pequeños y medianos agricultores son actores clave para incrementar la disponibilidad a dietas saludables ${ }^{38}$. Especialmente las mujeres campesinas e indígenas quienes se encargan de la venta en los mercados locales. Otro de los nudos críticos desde la cadena de suministros para una mayor disponibilidad a dietas saludables es la baja participación de los agricultores familiares, los pequeños y medianos productores a los mercados locales ${ }^{39}$. Lo anterior mejorará las economías locales y facilitará el acceso a dietas más saludables. Otras iniciativas para incrementar la disponibilidad a los alimentos saludables desde la cadena de suministro de alimentos incluyen los huertos domésticos, escolares, comunitarios, urbanos y periurbanos, con la finalidad de aumentar la producción local de alimentos frescos ${ }^{40}$.

Por lo tanto, a nivel del sistema alimentario se deben implementar medidas prácticas, innovadoras y seguras que mantengan activa la cadena de suministro de alimentos, estimular la producción local y asegurar la disponibilidad de alimentos frescos y saludables a la población. ${ }^{32}$ Contar con políticas diferenciadas para el segmento de la agricultura familiar, de los pequeños y medianos productores agrícolas, a través de incentivar la demanda constante de alimentos frescos y saludables. En especial, contar con programas que faciliten las compras públicas de alimentos saludables, social y ambientalmente sustentables para diversos espacios institucionales como escuelas, hospitales, orfanatos, asilos, servicio militar, penitenciarías, entre otros, considerando además los sistemas tradicionales de producción de alimentos ${ }^{41}$. Pero el sistema alimentario no es un elemento aislado en nuestro planeta, su desarrollo y sostenimiento tiene impacto sobre otros sistemas igual o más complejos que este, como el sistema climático. La interacción entre ambos ha generado una "Sindemia Global" 


\section{Doble carga de enfermedad, sistema alimentario y cambio climático}

La desnutrición, el sobrepeso, la obesidad y el "cambio climático" conllevan riesgos serios para el bienestar y la salud de la humanidad en su conjunto. Se dan simultáneamente, interactúan, se potencian y comparten factores comunes y subyacentes en los sistemas de alimentación, transporte, diseño urbano y uso del suelo. La comisión de la revista The Lancet ha calificado esta sinergia de pandemias como una Sindemia Global que pone en peligro los logros alcanzados en salud en el último medio siglo.

Ambas pandemias, malnutrición y cambio climático, están impulsadas por el alto uso de fuentes de energía baratas. En la alimentación consumiendo alimentos altamente procesados y carnes rojas que incrementan la malnutrición por exceso y enfermedades relacionadas y. generan cerca de un tercio de las emisiones de gases de efecto invernadero. El uso de fuentes de energía derivadas de combustibles fósiles para el transporte ${ }^{42}$.

La prevalencia de desnutrición y de la obesidad, sumadas de manera conjunta, ha aumentado en las ultimadas décadas, especialmente en los sectores más pobres de la población en la que ambos tipos de malnutrición coexisten. Desde el punto de vista económico se calcula que la pérdida económica estimada por la obesidad representa el 2,8\% del producto interno bruto mundial. A esto se suma la pérdida económica estimada por el cambio climático que representa el 5 al 10\% del mismo indicador.

En términos ambientales, este tipo de alimentos también tiene un impacto negativo. Por ejemplo, para producir un kg de tomates se usan 65 litros de agua, pero para producir un kilo de chocolate son 25 mil litros de agua, sin considerar huella de carbono, el uso de agrotóxicos, deforestación y cambio de uso de suelos. No sólo sus largos procesos, que incluyen muchas veces importación-procesamiento-exportación, consideran una gran huella, sino también los desechos que generamos con el paquete especialmente los productos ultra procesados, que siempre lo requieren.

A nivel mundial, la pandemia de COVID-19 ya ha dado lugar a importantes aumentos en el desempleo y se espera que conduzca a aumentos sin precedentes en la pobreza y la inseguridad alimentaria, así como a malos resultados de salud y nutrición ${ }^{43}$. El confinamiento y la crisis económica está 
afectando al sector de la alimentación y la agricultura, poniendo en riesgo la continuidad de las cadenas de suministro de alimentos. Además, los mismos factores, afectan nuestros ambientes y hábitos alimentarios, especialmente en los grupos más vulnerables. En algunos países, existen datos que muestran cómo, durante la pandemia, ha aumentado la inseguridad alimentaria. En el área metropolitana de Buenos Aires el porcentaje de hogares con niñas, niños y adolescentes en los que se redujo la cantidad de alimentos aumento del 26 al 30\%. En el mismo grupo, el incremento de la inseguridad alimentaria severa fue aún mayor, ya que las situaciones de "hambre" por falta de alimentos, aumento del $6,5 \%$ al $15 \%^{44}$. El contexto actual se vislumbra adverso y probablemente también aumente la obesidad, por el aumento del sedentarismo y el consumo de alimentos altamente procesados de bajo costo, condición que además se ha descrito como de mayor riesgo para la severidad de la enfermedad por coronavirus ${ }^{45}$.

\section{Conclusiones}

La doble carga de malnutrición aparece como la más clara expresión de una transición epidemiológica nutricional entre una etapa con franca predominancia de enfermedades agudas infectocontagiosas a otra de predominancia de enfermedades crónicas no transmisibles. Durante esa transición hay concomitancia de ambas situaciones expresadas en las dos morbilidades paradigmáticas, una de desnutrición por deficiencia energético-proteica y la otra de sobrepeso por exceso calórico y desbalance dietarios, esto último como consecuencia de la mayor accesibilidad a alimentos procesados y bebidas azucarados baratos y poco saludables (altos en calorías, grasas saturadas y sodio). Este proceso de doble carga de la malnutrición ha sido más pronunciado en países de ingresos medios y bajos, aumentando la inequidad en salud según niveles socioeconómicos.

Muchas recomendaciones actuales para reducir la obesidad y la malnutrición también son beneficiosas para la mitigación y adaptación al cambio climático, y viceversa. Es de esperar, para que el impacto en ambas pandemias sea posible, que las intervenciones que se realicen tengan en cuenta el bienestar y la salud humana, la equidad social, el respeto al medio ambiente 
y el desarrollo económico. Tan complejos son los cambios se requieren que estos deben incluir modificaciones profundas en el andamiaje jurídico, político y económico que define los modelos de desarrollo de nuestra sociedad. En el área de la alimentación algunos ejemplos son redirigir los subsidios gubernamentales existentes para la carne de res, los productos lácteos, el azúcar, hacia la agricultura sustentable (ej: agricultura campesina y familiar) de alimentos saludables. Agregar a los etiquetados de advertencia sanitaria y nutricional de los alimentos la huella de carbono y el consumo de agua por kilo para producirlo y de ese modo estimular una reformulación de productos dentro de la industria.

Lamentablemente la gran mayoría de los gobiernos, hasta ahora, han tenido una respuesta lenta e insuficiente frente a estos problemas y los han tratado de manera independiente. La inercia política para implementar políticas públicas efectivas, capaces de prevenir y mitigar los efectos de la "Sindemia", es en gran parte consecuencia de los intereses comerciales en juego. Se necesita de un movimiento social transformador, a través de los niveles local, nacional y global, para superar la inercia descrita anteriormente. Las acciones sinérgicas serán esenciales para lograr la salud planetaria, que definimos como la salud y el bienestar de los seres humanos y los entornos naturales de los que dependemos. Es responsabilidad de todos los sectores de la sociedad realizar su aporte para superar la crisis que ha generado nuestro modelo de desarrollo.

\section{Referências}

1. SAWAYA AL, Gerald D, Solymos G et al. Obesity and Malnutrition in a Shantytown Population in the City of Sao Paulo, Brazil. Obes Res 1995; 3 Suppl 2: 107s-115s.

2. KHOR GL, Sharif ZM. Dual Forms of Malnutrition in the Same Households in Malaysia-a Case Study Among Malay Rural Households. Asia Pac J Clin Nutr 2003;12(4):427- 37.

3. GILLESPIE, SR; Haddad, $\amalg$. The double burden of malnutrition in Asia. Causes, consequences, and solutions. Sage Publication. New Delhi, 2003.

4. HICKEY GM, Unwin N. Addressing the triple burden of malnutrition in the time of COVID-19 and climate change in Small Island Developing States: what role for improved local food production? Food Secur. 2020 Jul 9:1-5. 
5. WELLSJC, Sawaya AL, Wibaek Ret al. The double burden of malnutrition: aetiological pathways and consequences for health. The Lancet 2020;395(10217):75-88.

6. Black RE, Victora CG, Walker SP, et al. Maternal and child undernutrition and overweight in low-income and middle-income countries.Lancet. 2013;382(9890):427- 451

7. Batis C, Mazariegos M, Martorell R, Gil A, Rivera JA. Malnutrition in all its forms by wealth, education and ethnicity in Latin America: who are more affected? Public Health Nutr. 2020;23(S1):s1-s12.

8. Gubert MB, Spaniol AM, Segall-Corrêa AM, Pérez-Escamilla R. Understanding the double burden of malnutrition in food insecure households in Brazil. Matern Child Nutr 2017;13.e12347

9. World Health Organization. The double burden of malnutrition.. Policy brief: World Health Organization, 2017

10. Hanandita W, Tampubolon G. The double burden of malnutrition in Indonesia: Social determinants and geographical variations. SSM Popul Health. 2015;1:16-25. Published 2015 Nov 18.

11. Lee J, Houser RF, Must A, de Fulladolsa PP, Bermudez OI. Socioeconomic disparities and the familial coexistence of child stunting and maternal overweight in Guatemala. Econ Hum Biol. 2012;10(3):232-241

12. Shinsugi C, Gunasekara D, Gunawardena NK, et al. Double burden of maternal and child malnutrition and socioeconomic status in urban Sri Lanka [published correction appears in PLoS One. 2020 Mar 19;15(3):e0230785]. PLoS One. 2019;14(10):e0224222

13. Reyes Päcke S, Figueroa Aldunce M. Distribución, superficie y accesibilidad de las áreas verdes en Santiago de Chile. EURE 2010, 36: 89-110

14. Encuesta Nacional de Salud. Ministerio de Salud. Chile. 2017. (Acceso en julio 2020. https://www.minsal.cl/wp-content/uploads/2017/11/ENS-2016-17_PRIMEROS- RESULTADOS.pdf)

15. Informe de Resultados Estudio Nacional de Educación Física 2013 Agencia de Calidad de la Educación. Ministerio de Educación de Chile. (Acceso en Julio 2020 http://archivos.agenciaeducacion.cl/biblioteca_digital_historica/resultados/2013/result8b_edfisica_2013.pdf)

16. Comisión Económica para América Latina y el Caribe (CEPAL), La inefciencia de la desigualdad, 2018 (LC/SES.37/3-P), Santiago, 2018

17. Branca F, Lartey A, Oenema S, Aguayo V, Stordalen GA, Richardson R, et al. Transforming the food system to fight non-communicable diseases. BMJ. 2019; 364:1296.

18. FAO. Nutrition-sensitive agriculture and food systems in practice. Options for intervention. Nutrition-sensitive agriculture and food systems in practice. Options for intervention. Roma: United Nations Food and Agriculture Organization (FAO); 2017. 102 p. 
19. FAO, WHO. Sustainable healthy diets: Guiding principles. Sustainable healthy diets. Rome; 2019. 44 p.

20. Bedoya Hernández M. La gestión de sí mismo. Editorial Universidad de Antioquia, editor. 2018. 353 p.

21. Popkin BM, Corvalan C, Grummer-Strawn LM. Dynamics of the double burden of malnutrition and the changing nutrition reality. Lancet [Internet]. 2020 Jan 4 [cited 2020 Apr 10];395(10217):65-74. Available from: http://www.ncbi.nlm.nih. gov/ pubmed/31852602

22. Cediel G, Perez E, Gaitán D, Sarmiento OL, Gonzalez L. Association of all forms of malnutrition and socioeconomic status, educational level and ethnicity in Colombian children and non-pregnant women. Public Health Nutr [Internet]. 2020 Mar 5 [cited 2020 Apr 12];1-8. Available from: http://www.ncbi.nlm.nih.gov/ pubmed/32131920

23. High Level Panel of Experts on Food Security and Nutrition. HLPE Report on Nutrition and food systems [Internet]. [cited 2020 Apr 14]. Available from: http:// www. fao.org/fileadmin/user_upload/hlpe/hlpe_documents/HLPE_S_and_R/ HLPE_2017_Nutrition-and-food-systems_S_R-EN.pdf

24. Sandevijvere S, Dominick C, Devi A, Swinburn B. The healthy food environment policy index: findings of an expert panel in New Zealand. Bull World Health Organ [Internet]. 2015 May 1 [cited 2020 Apr 15];93(5):294-302. Available from: http:// www. who.int/entity/bulletin/volumes/93/5/14-145540.pdf

25. Scrinis G. Nutritionism: the science and politics of dietary advice [Internet]. First. Columbia Univers. Press (18 de junio de 2013), editor. Columbia University Press; 2013 [cited 2020 Apr 8]. 352 p. Available from: https://www.amazon.es/Nutritionism- Politics-Traditions-Perspectives-Culinary/dp/0231156561

26. FAO, OPS/OMS, PMA, UNICEF. Panorama de la Seguridad Alimentaria y Nutricional de América Latina y el Caribe. Santiago; 2019.

27. Wijesinha-Bettoni R, Khosravi A, Sherman J, Hernandez-Garbanzo Y, Vargas M, Ramos A. Implementing food-based dietary guidelines for policies, programmes and nutrition education. UNSCN News. 2017; 42:77-89.

28. Popkin BM, Reardon T. Obesity and the food system transformation in Latin America. Obes Rev. 2018;1-37.

29. Monteiro C, Moubarac J, Cannon G, Ng SW, Popkin B. Ultra-processed products are becoming dominant in the global food system. Obes Rev. 2013;14(S2):21-8.

30. Hawkes C, Smith TG, Jewell J, Wardle J, Hammond RA, Friel S, et al. Smart food policies for obesity prevention. Lancet. 2015;385(9985):2410-21.

31. Mialon M, Gaitan Charry DA, Cediel G, Crosbie E, Scagliusi FB, Perez Tamayo EM. 'I had never seen so many lobbyists': food industry political practices during the development of a new nutrition front-of-pack labelling system in Colombia [published online ahead of print, 2020 Aug 21]. Public Health Nutr. 2020;1-9

32. HLPE. Nutrition and food systems: A report by The High Level Panel of Experts on Food Security and Nutrition. Rome; 2017. 
33. Grace D. Food safety in low- and middle-income countries. Int J Environ Res Public Health. 2015; 12:10490-507.

34. Corrado S, Caldeira C, Eriksson M, Hanssen OJ, Hauser HE, van Holsteijn F, et al. Food waste accounting methodologies: Challenges, opportunities, and further advancements. Glob Food Sec. 2019; 20:93-100.

35. Beurskens F. The Economics of Dot.coms and E-commerce in the Agrifood Sector. Rev Agric Econ. 2003;25(1):22-8.

36. Mayet M, Greenberg S. Las tres megafusiones de agronegocios: macabros verdugos de la soberanía de las y los agricultores. Observatorio del Derecho a la Alimentación y a la Nutrición 2017;(7):76-85. (accesible en: https://www.righttofoodandnutrition.org/files/rtfanw-2017_spa.pdf)

37. Batis C, Mazariegos M, Martorell R, Gil A, Rivera JA. Malnutrition in all its forms by wealth, education and ethnicity in Latin America: who are more affected? Public Health Nutr. 2020;23(S1): s1-s12. doi:10.1017/S136898001900466X

38. FAO. Smallholders and Family Farmers. Sustainability Pathways. Rome: United Nations Food and Agriculture Organization (FAO); 2012. p. 4.

39. Pinstrup-Andersen P. Nutrition-sensitive food systems: From rhetoric to action. Lancet. 2013;382(9890):375-6.

40. Galhena DH, Freed R, Maredia KM. Home gardens: A promising approach to enhance household food security and wellbeing. Agric Food Secur. 2013; 2:8.

41. Kanter R, Boza S. Strengthening Local Food Systems in Times of Concomitant Global Crises: Reflections from Chile. Am J Public Health. 2020; 110:971_973.

42. Swinburn BA, Kraak VI, Allender S, et al. The Global Syndemic of Obesity, Undernutrition, and Climate Change: The Lancet Commission Lancet. 2019;393(10173):791846

43. Pérez-Escamilla R, Cunningham K, Moran VH. COVID-19, food and nutrition insecurity and the wellbeing of children, pregnant and lactating women: A complex syndemic [published online ahead of print, 2020 May 26]. Matern Child Nutr. 2020; e13036

44. Tuñón I, Sánchez ME. Las infancias en tiempos de cuarentena. Observatorio de la Deuda Social Argentina Universidad Católica Argentina. Mayo 2020. http:// wadmin. uca.edu.ar/public/ckeditor/Observatorio\%20Deuda\%20Social/Presentaciones /2020/2020_OBSERVATORIO_EDSA\%20COVID19_INFANCIA-V.pdf

45. Qingxian C, Fengjuan C, Fang L, Xiaohui L, Tao W, Qikai W, et al. Obesity and COVID-19 Severity in a Designated Hospital in Shenzhen, China. Lancet Infect Dis. 2020; (202002073000001 


\section{Capítulo 2}

\section{DESAFÍO E INNOVACIÓN EN POLÍTICAS PÚBLICAS PARA LA NIÑEZ EN SITUACIONES DE VIOLENCIA EN BRASIL: VIOLACIÓN DE DERECHOS}

\section{Adelma Alves de Figueirêdoํㅜ, Blenda Avelino Garcia², \\ Priscila Campos de Matos Lacerda ${ }^{3}$, Denise Abreu Cavalcanti ${ }^{4}$}

${ }^{1}$ Gastroenteróloga pediátrica; Maestría en Pediatría. Universidad Federal de Minas Gerais, Brasil; Profesor de Medicina en la Universidad Federal de Roraima, Brasil; Presidenta de la Sociedad Roraimense de Pediatría.

2 Pediatra. Catedrático de Medicina de la Universidad Federal de Roraima, Brasil; vicepresidenta de Consejo Regional de Medicina, Roraima, Brasil.

3 Pediatra. Máster en Ciencias de la Salud por la UFRR. Paciente de la Facultad de Medicina, Universidad Federal de Roraima, Brasil

${ }^{4}$ Abogada. Presidenta de la Comisión de Derechos de la Niñez y la Adolescencia de la OBA/RR y del Instituto Brasileño de Derecho de Familia en Roraima. Estudiante de Maestría en Derecho Migratorio Internacional en UNIVALI y la Universidad de Perguia/Italia.

Los niños, cuando están bien cuidados, son una semilla de paz y esperanza

Zilda Arns Neumann

Resumen: $\quad$ Este capítulo utiliza la conceptualización de los diferentes tipos de violencia infantil definidos por la Organización Mundial de la Salud en Brasil, país reconocido por tener un alto nivel de violencia en el mundo, un gran número de niños son víctimas de algún tipo de violencia. Sin embargo, a pesar de esto, existe una gran movilización nacional para garantizar los derechos de este grupo vulnerable. Existen políticas públicas efectivas para enfrentar el problema, pero el reflejo de prácticas autoritarias y de subyugación infantil, muchas veces implementadas por quienes deben proteger, contribuyen al subregistro 
de casos, lo que convierte a este en un grave problema de salud pública y violación de la salud. derechos humanos, asociados con tasas crecientes de abuso sexual doméstico y homicidios de adolescentes. En este sentido, buscamos reflexionar sobre las causas sociales de la violencia y su asociación con la violación de los derechos de la niñez y la adolescencia, mostrando la evolución de las políticas públicas y de todo el aparato legal para enfrentar el problema, exponiendo el escenario de desafíos e innovaciones.

Palabras clave: Abuso infantil; negligencia infantil; violencia infantil.

\section{Introducción}

Con respecto a los niños y adolescentes, la Organización Mundial de la Salud (OMS) define la violencia como cualquier forma de abuso emocional y/o físico, abuso sexual, negligencia, exploración comercial o de otro tipo, con la posibilidad de que resulte en un daño potencial o real a la salud, la supervivencia, el desarrollo o la dignidad de los niños en el contexto de una relación de responsabilidad, confianza o poder ${ }^{1}$.

En nivel mundial, mil millones de niños, que corresponden a más del $50 \%$ de ellas, entre 2 y 17 años, sufrieron violencia psicológica, física o sexual en $2016^{2}$. En Brasil, un escenario desolador impregna esta realidad, siendo que el número de notificaciones de casos de violencia contra niños, niñas y adolescentes ha crecido exponencialmente a lo largo de los años. Solo en 2017, el SINAN ${ }^{3}$ (Sistema de Información de Enfermedades Notificables) registró 126.230 casos de violencia contra niños menores de 19 años.

Por lo tanto, la violencia contra la niñez y la adolescencia se trata actualmente como un grave problema de salud pública y derechos humanos. Sin embargo, se cree que tales registros representan solo el principio del problema de la violencia cotidiana, ya que un número significativo de hechos no alcanzan la visibilidad social y la debida notificación $n^{4}$.

Esta realidad vivida en Brasil puede explicarse por el comportamiento de la sociedad brasileña desde su formación histórica. La no ciudadanía de los niños brasileños data del período colonial y continuó hasta la instalación de la República. 
Hace algunas décadas, la población infantil y juvenil era vista desde una perspectiva egocéntrica, marcada, sobre todo, por la devaluación y el desconocimiento de su propia existencia. Muchas prácticas autoritarias, coercitivas e incluso castigos físicos se llevaron a cabo y se justificaron por el ejercicio del poder de la patria, bajo el cual los menores fueron completamente subyugados ${ }^{5}$.

Estas prácticas no fueron revisadas en Brasil hasta fines de la década de 1980, luego de la promulgación de la Constitución de la República en 1988 y, poco después, del Estatuto de la Niñez y la Adolescencia (Ley No. $8.069 / 90)^{6}$. El país comenzó a adoptar el principio de protección integral, por el cual los niños, niñas y adolescentes se convirtieron efectivamente en sujetos de derechos.

Así, la doctrina de la protección integral surgió como un intento de articular una política de salvaguarda, basada en la acción conjunta entre gobierno y sociedad. Como resultado, la familia, la sociedad, la Unión, los Estados y los Municipios, de manera solidaria, se han visto obligados a garantizar y asegurar un acceso amplio a los derechos fundamentales: Salud, Convivencia Familiar y Comunitaria, Educación, Deporte y Ocio, Dignidad, Respeto, Libertad, Preparación y Protección en el Trabajo. En consecuencia, cualquier violación de estos derechos pasó a ser considerada una práctica de violencia?.

Lentamente, Brasil ha ido avanzando en lo que respecta a la protección de la niñez y la adolescencia. La reducción de la mortalidad infantil fue uno de los principales hitos alcanzados de acuerdo con los Objetivos de Desarrollo del Milenio, propuestos por la ONU, en 2015. Sin embargo, las crecientes tasas de homicidios en la adolescencia son evidentes ${ }^{8}$.

El homicidio es la forma más extrema de violencia y violación de derechos. Las estadísticas apuntan a un aumento significativo de las tasas de homicidio de adolescentes desde 2012, cuyo trágico desenlace es proporcionalmente mayor en este grupo de edad que en otros segmentos de la población. Además, el género masculino y la raza negra destacan en medio de notificaciones?.

No es casualidad que Brasil aparezca como el quinto país más violento del mundo, con una tasa de homicidios más alta que la de los países en guerra. Para combatir y enfrentar este fenómeno de la "juventud perdida" 
es necesario analizar en profundidad las causas sociales de la violencia, el fortalecimiento de las medidas orientadas a la educación, la oferta de empleo para los adolescentes más vulnerables y el firme compromiso de extinguir la impunidad. de cada caso de homicidio contra ese grupo social ${ }^{10}$.

El propósito de este capítulo es situar al lector en el tema, contextualizándolo como un importante tema de salud pública y derechos humanos. Además, se pretendía realizar una breve revisión de las políticas públicas orientadas a abordar el tema, exponiendo el escenario de desafíos e innovaciones.

\section{Formas de violencia contra niños y adolescentes}

Al retomar la amplitud del concepto de violencia contra la niñez y la adolescencia, se hace necesario distinguirlo en sus diferentes formas. Se asume que la violencia practicada traspasa los límites de la agresión física, haciendo más integral la caracterización; clasificadas en estructurales, psicológicas, físicas y sexuales, incluidas las subdivisiones, pero a menudo una forma se agrega a otras ${ }^{11}$.

\section{Violencia estructural}

Quizás sea la violencia menos percibida o la más disfrazada. Este tipo se refiere a las injusticias sociales que históricamente han sufrido los niños, incluso antes de nacer, como la falta de políticas públicas dirigidas a protegerlos. Ciertas situaciones ilustran la trayectoria histórica de vulnerabilidad social asociada a este tipo de violencia, como el nacimiento en hogares mal estructurados, donde el niño es el resultado de un embarazo no planeado, los lazos familiares son frágiles, existen desigualdades sociales y analfabetismo de los padres. Según Minayo (2001)12, esta forma de violencia parece naturalizada en Brasil, ya sea por la continuidad de su carácter o porque el binomio autor-acción no se percibe rápidamente. En otras palabras, los autores políticos de las acciones socioeconómicas que generaron tal violencia.

\section{Violencia psicológica}

Humillar, abandonar emocionalmente, criticar en exceso, controlar, avergonzar o hacer que las personas se sientan culpables son formas de violencia 
psicológica contra los niños y adolescentes. Cuantos más traumas sufre el individuo en la infancia, menor es su capacidad de adaptación emocional y mayores son los impactos en la personalidad, además de un riesgo 17 veces mayor de suicidio en la edad adulta ${ }^{13}$.

\section{Violencia física}

Se refiere a la violencia causada por el uso de la fuerza física, que puede provocar dolor sin lesiones, lesiones de leves a graves o incluso la muerte. Lamentablemente, si bien las calles y las instituciones son lugares de gran vulnerabilidad a este tipo de violencia, los hogares de niños, niñas y adolescentes también son vulnerables. Un estudio realizado por UNICEF (2014) ${ }^{14}$, demostró que la violencia física está presente en la vida cotidiana de los niños de entre 2 y 14 años en todo el mundo. Los resultados muestran que alrededor de 6 de cada 10 menores son sometidos a castigos físicos con regularidad como forma de instituir la disciplina.

En Brasil, datos del SINAN (2017) ${ }^{15}$ demuestran un aumento en el número de notificaciones cada año por violencia física en menores de 19 años. Los resultados que se muestran en la Tabla 1 corresponden a una serie histórica entre los años 2009 a 2017.

Además del aumento progresivo del número de notificaciones, a lo largo de los años, se destaca como el grupo de edad más afectado por problemas físicos, en Brasil, el de los adolescentes entre 15 y 19 años. Sin embargo, los autores infirieron que los casos de violencia física contra niños más pequeños son menos denunciados, debido al propio miedo del niño a denunciar lo sucedido, así como al miedo a otros castigos. Además, las dificultades de notificación pueden deberse tanto a fallos de diagnóstico como a la falta de dispositivos estandarizados y eficaces, durante la conducción de los casos, por parte del sistema de salud. 
Tabla 1 - Número de notificaciones por violencia física registradas por grupo de edad entre los años 2009 a 2017 en Brasil

\begin{tabular}{|r|r|r|r|r|r|}
\hline \multirow{2}{*}{ ANO } & \multicolumn{5}{|c|}{ IDADE (ANO) } \\
\cline { 2 - 6 } & $<\mathbf{1}$ & $\mathbf{1}$ a $\mathbf{4}$ & $\mathbf{5}$ a 9 & $\mathbf{1 0}$ a $\mathbf{1 4}$ & $\mathbf{1 5}$ a $\mathbf{1 9}$ \\
\hline $\mathbf{2 0 0 9}$ & 472 & 884 & 1291 & $\mathbf{2 2 7 9}$ & 4164 \\
\hline $\mathbf{2 0 1 0}$ & 837 & 1450 & 2016 & 4117 & 7437 \\
\hline $\mathbf{2 0 1 1}$ & 1339 & 1917 & 2709 & 6136 & 12668 \\
\hline $\mathbf{2 0 1 2}$ & 1774 & 3028 & 3975 & 8575 & 18992 \\
\hline $\mathbf{2 0 1 3}$ & 1705 & 2885 & 3922 & 9669 & 22368 \\
\hline $\mathbf{2 0 1 4}$ & 1511 & 3329 & 4182 & 10215 & 24426 \\
\hline $\mathbf{2 0 1 5}$ & 1742 & 3442 & 4522 & 10140 & 25577 \\
\hline $\mathbf{2 0 1 6}$ & 1643 & 3699 & 4696 & 10741 & 27307 \\
\hline $\mathbf{2 0 1 7}$ & $\mathbf{2 8 8 6}$ & 4247 & 5235 & 13372 & 33553 \\
\hline TOTAL & $\mathbf{1 3 . 9 0 9}$ & $\mathbf{2 4 . 8 8 1}$ & $\mathbf{3 2 . 5 4 8}$ & $\mathbf{7 5 . 2 4 4}$ & $\mathbf{1 7 6 . 9 4 2}$ \\
\hline
\end{tabular}

Fuente: Ministerio de Salud, Brasil - Sistema de Información de Enfermedades Notificables - SINAN $\mathrm{Net}^{15}$

Algunos autores como Gawryszewski et al (2009)16, Mascarenhas et al. $(2010)^{17}$ y Garbin et al. (2011) ${ }^{18}$ encontraron en sus estudios el maltrato, por problemas físicos, en los niños como la forma más frecuente de violencia. Dichos registros pueden estar asociados a la existencia de lesiones corporales fácilmente identificables, favoreciendo la ocurrencia de quejas.

\section{Violencia sexual}

La violencia sexual contra niños, niñas y adolescentes se define como todo acto o juego sexual con la intención de estimular sexualmente al niño, niña o adolescente, cuyo objetivo es someterse a una práctica para obtener satisfacción sexual, en la que los autores de la violencia se encuentran en la etapa de desarrollo psicosexual, antes que las víctimas ${ }^{19}$.

La Ley N N 12.015/200920 modificó el Código Penal brasileño, creando la figura de violación vulnerable. Así, se considera que las personas menores de 14 años se encuentran en absoluta vulnerabilidad, y que el acto sexual - por sí mismo - ya constituye un delito, independientemente de si hubo consentimiento del menor y/o de los responsables, complexión física y, aun así, si la víctima ha tenido experiencia sexual previa. 
Como niños y adolescentes son seres en desarrollo, la violencia que sufren tendrá un impacto mucho mayor que en los adultos, pues además de afectar al ser humano en el momento de la lesión, influye negativamente en el desarrollo biopsicosocial de ese ciudadano. Cuanto más joven, mayor y más prolongada sea la violencia, más problemas actuales y futuros ocurrirán. Recientemente, esta idea comenzó a aclararse mejor y demostrarse como "estrés tóxico"21.

En esta ocasión, el neurodesarrollo se entiende como un proceso complejo en el que el cerebro, para alcanzar su potencial genético, necesita una buena nutrición, seguridad afectiva y estimulación psicomotora. Es decir, para un buen desarrollo, es necesaria la integración cualitativa entre las condiciones neurobiológicas y ambientales. Los bebés criados con cariño, estimulación, educación y nutrición adecuada y que no experimentan experiencias traumáticas, tendrán un mejor desempeño cognitivo y habilidades emocionales en la edad adulta. El trauma cerebral en la niñez puede resultar en cambios en el desarrollo con repercusiones en la vida adulta.

Así, todo niño que experimente estrés, como enfermedad, nacimiento de un hermano, adversidades familiares, entre otros, pero que reciba un buen apoyo familiar y / o institucional, podrá resolver este estrés, evitando que se vuelva tóxico. Si esto no sucede, se producirán cambios estructurales cerebrales y una pérdida irreparable de habilidades emocionales y cognitivas ${ }^{21}$.

\section{Los derechos de los niños y adolescentes asegurados por ley}

De acuerdo con la Constitución Federal de Brasil (1988)22, los derechos del niño están así garantizados:

Art. 227: Es deber de la familia, la sociedad y el Estado velar por el derecho a la vida, la salud, la alimentación, la educación, el esparcimiento, la profesionalidad, la cultura, de la niñez, adolescencia y juventud, con absoluta prioridad, dignidad, respeto, libertad y convivencia familiar y comunitaria, además de ponerlos a salvo de toda forma de negligencia, discriminación, explotación, violencia, crueldad y opresión.

Art. 228: Los menores de 18 años están sujetos a responsabilidad penal, con sujeción a las normas de la legislación especial. 
En este sentido, la Ley No. 8.0696, de 13 de julio de 1990, creó el Estatuto de la Niñez y la Adolescencia (ECA), en oposición al antiguo Código de Menores y en consonancia con la Convención sobre los Derechos del Niño, adoptado por la Asamblea General de las Naciones Unidas. Así, la familia, la sociedad, la Unión, los Estados y los Municipios, solidariamente, deben garantizar y asegurar un acceso amplio a los derechos fundamentales recogidos en la Constitución y el TCE.

En 1991, se instituyó mediante la Ley n. 8.242/199123 del Consejo Nacional de los Derechos de la Niñez y la Adolescencia - CONANDA, con el objetivo, entre otros, de la elaboración de normas generales para atender los derechos de la niñez y adolescencia, para supervisar las acciones de ejecución, observando el Estatuto.

La Ley $13.431 / 2017^{24}$ creó el sistema para garantizar los derechos de los menores víctimas o testigos de violencia y modificó la Ley $8.069 / 1990^{6}$ que regulaba el ECA.

\section{Políticas públicas}

Ley no. $13.257 / 2016^{25}$, modificó el artículo ocho del ECA, asegurando que todas las mujeres y gestantes tengan acceso a las políticas públicas en el ámbito del Sistema Único de Salud (SUS), sin embargo, cuestiona cuáles pueden ser estas medidas y cómo se aplican. En forma de Ley, "Son acciones y programas desarrollados por el Estado para garantizar y poner en práctica los derechos previstos en la Constitución Federal y otras leyes. Se trata de medidas y programas creados por gobiernos dedicados a garantizar el bienestar de la población. Definiciones recientes consideran que la política pública va más allá de una decisión gubernamental, ya que puede resultar de decisiones y acciones de otros actores, como la sociedad civil ${ }^{26}$.

En el caso analizado, los sujetos de los errores (niños, niñas y adolescentes), de acuerdo con la legislación nacional, han sido sujetos a políticas públicas diseñadas e implementadas por el Estado, de acuerdo con sus especificidades y que, por su naturaleza, son sólidas. políticas públicas sociales.

Hofling (2001)27, afirma que "las políticas sociales se refieren a acciones que determinan el estándar de protección social implementado por el Estado, orientadas, en principio, a la redistribución de los beneficios sociales 
con miras a la reducción de las desigualdades estructurales producidas por el desarrollo socioeconómico".

En este sentido, la Ley no. 13.257/2016 25 trajo una importante innovación, instituyendo el Estatuto de la Primera Infancia y estableciendo políticas públicas para atender a los niños de cero a seis años.

Cada estado desarrolla sus propias políticas públicas, de acuerdo con las normas y especificidades legales vigentes. Sin embargo, se sabe que existe una gran discrepancia entre las políticas públicas sociales y la implementación efectiva.

Para apoyar este estudio, se utilizaron políticas de seguridad alimentaria en las escuelas ${ }^{28}$, en el estado de Roraima y en sus municipios. El PNAE - Programa Nacional de Alimentación Escolar (2013) ${ }^{29}$ - establece, entre otros, que el menú de las escuelas "debe respetar las referencias nutricionales, los hábitos alimentarios, la cultura alimentaria local”. También, destaca que debe "cumplir con las especificidades culturales de las comunidades indígenas y/o quilombolas". Quilombolas son descendientes y remanentes de comunidades formadas por fugitivos, africanos negros, esclavizados (los quilombos), entre el siglo XVI y el año 1888 (cuando se abolió la esclavitud) en Brasil.

Otro ejemplo legal que se utilizó se refiere a la Ley $13.431 / 2017^{24}$, que instituyó la obligación de la escucha calificada de niños, niñas y adolescentes, en un ambiente adecuado y con profesionales calificados. Sin embargo, no todos los estados han creado tal estructura, que debe contar con comisarías especializadas para investigar delitos en los que niños, niñas y adolescentes son víctimas o testigos, evitando, como ya se dijo en otro lugar, la revictimización y sus consiguientes abusos.

Aunque la ley ha avanzado, muchas familias, la sociedad y el gobierno aún muestran dificultades para seguir las nuevas pautas. Los descubrimientos de la ciencia que estudian los efectos de la violencia en los niños deben generar cambios profundos en el trato a los niños y jóvenes, que también se reflejan en el propio sistema de justicia penal brasileño. A pesar de estos hallazgos, la lucha por la niñez es muy importante, y debe ser exhaustiva para que se establezcan los derechos, se reproduzcan los logros alcanzados para que sean reconocidos y valorados. 


\section{i. Desafíos}

¿Cómo proteger a una población dependiente física y emocionalmente? ¿Cómo identificar la violencia, dado que a menudo es sutil, culturalmente aceptada y ocurre en el entorno del hogar? ¿Cómo hacer que los niños pequeños hablen de ser violados o incluso adolescentes, ya que el agresor a menudo tiene antepasados familiares sobre la víctima? Y, sin embargo, ¿cómo podemos crear una cultura de no violencia en Brasil, un país tan amplio, diverso y cruelmente desigual? Son preguntas retóricas que convergen en desafíos constantes, que deben ser ininterrumpidos en todos los esfuerzos por afrontarlos.

Al respecto, actualmente, en Brasil, hay algunos proyectos, planes y estrategias. Algunos incipientes y otros bien sedimentados, sin embargo, no llegan a toda la población objetivo. La falta de plena coordinación de acciones se atribuye a la falta de coordinación de acciones, a través de una política pública de Estado que transpone a los gobiernos de manera longitudinal. Por tanto, los esfuerzos son ineficaces.

Quizás, más que crear nuevos proyectos, es necesario relevar los que existen, los que han dado mejores resultados a corto y largo plazo para que funcionen. Por ello, es fundamental que exista una coordinación central, con la integración de varios portafolios relacionados - salud, educación, seguridad, seguridad social, entre otros -, ya que la violencia tiene una interfaz en los más variados segmentos de la sociedad.

\section{ii. Innovaciones}

En 2018, Brasil se convirtió en miembro de la Alianza Global para el Fin de la Violencia contra la Niñez y la Adolescencia, liderada por la ONU, cuyo objetivo es contribuir al logro de los Objetivos de Desarrollo Sostenible (ODS), especialmente aquellos que están destinados a acabar con todos. las formas de violencia y tortura contra los niños. Al ingresar a esta Alianza Global, Brasil se comprometió a desarrollar una Hoja de Ruta Nacional (hoja de ruta integrada) de acciones integradas y se comprometió a desarrollar un sistema de indicadores de violaciones de los derechos de la niñez y la adolescencia.

El país creó la Secretaría Nacional de los Derechos de la Niñez y la Adolescencia (SNDCA), vinculada al Ministerio de Derechos Humanos, organismo encargado de coordinar las políticas públicas para combatir las 
manifestaciones de violencia contra la niñez y la adolescencia ${ }^{30}$. Para ello, creó Dial 100, que recibe denuncias de violaciones de derechos humanos; en alianza con Unicef, desde 2013, se ha ampliado con la aplicación “Proteger Brasil”, que facilita y fortalece las denuncias de violencia. En 2016 se lanzó una nueva versión ampliando su funcionalidad e integrándola en Dial $100^{31}$.

Además, firmó una alianza con la Sociedad Brasileña de Pediatría (SBP), el Consejo Federal de Medicina (CFM) y el Ministerio de Derechos Humanos para buscar soluciones contra las agresiones contra la niñez y la adolescencia. Un ejemplo de este logro fue la elaboración del Manual de Atención a Niños, Niñas y Adolescentes Víctimas de Violencia, dirigido a profesionales de la salud32.

\section{iii. Inspirar}

Se refiere al proyecto de medidas elaborado por la OPS / OMS y varias otras entidades, como el Centro para el Control y Prevención de Enfermedades de Estados Unidos, el Fondo de las Naciones Unidas para la Infancia (UNICEF), el Banco Mundial, entre otros. INSPIRE está compuesto por siete estrategias y orienta actividades transversales que, en su núcleo, contribuyen a conectar y fortalecer las siete estrategias, así como a evaluar su avance ${ }^{33}$. No se trata de un programa nuevo, sino de estrategias bien definidas que deben adaptarse a cada realidad para que funcionen. Estas estrategias se describen en la Tabla 2.

Tabla 2 - Estrategias INSPIRE para prevenir y abordar la violencia infantil

\begin{tabular}{|l|l|}
\hline Estratégia & Medidas \\
\hline $\begin{array}{l}\text { Implementación } \\
\text { y cumplimiento } \\
\text { de leyes }\end{array}$ & $\begin{array}{l}\text { - Leyes que prohíben a los padres, madres, maestros u } \\
\text { otros cuidadores aplicar castigos violentos a los niños. } \\
\text { - Leyes que penalizan el abuso sexual y la explotación } \\
\text { infantil } \\
\text { - Leyes que previenen el abuso de alcohol } \\
\text { - Leyes que limitan el acceso de los jóvenes a armas de } \\
\text { fuego y otras armas }\end{array}$ \\
\hline Normas y valores & $\begin{array}{l}\text { Cambio en la adherencia a las normas sociales y de } \\
\text { género que son restrictivas. }\end{array}$ \\
& $\begin{array}{l}\text { - Programas de movilización comunitaria } \\
\text { - Intervenciones con testigos }\end{array}$ \\
\hline
\end{tabular}




\begin{tabular}{|c|c|}
\hline Estratégia & Medidas \\
\hline $\begin{array}{l}\text { La seguridad } \\
\text { ambiental }\end{array}$ & $\begin{array}{l}\text { - Reducir la violencia actuando en "áreas críticas" } \\
\text { - Detener la propagación de la violencia } \\
\text { - Mejora del espacio urbano }\end{array}$ \\
\hline $\begin{array}{l}\text { Padres, madres } \\
\text { y cuidadores } \\
\text { reciben apoyo }\end{array}$ & - A través de visitas domiciliarias \\
\hline $\begin{array}{l}\text { Aumento de } \\
\text { ingresos y } \\
\text { fortalecimiento } \\
\text { económico }\end{array}$ & - A través de grupos en comunidades \\
\hline $\begin{array}{l}\text { Respuesta de } \\
\text { los servicios de } \\
\text { atención y apoyo }\end{array}$ & $\begin{array}{l}\text { - Asesoramiento y apoyo terapéutico } \\
\text { - Seguimiento de casos combinado con intervenciones } \\
\text { - Programas de tratamiento para jóvenes en conflicto } \\
\text { con la ley en el sistema de justicia penal } \\
\text { - Intervenciones de atención familiar, con participación } \\
\text { de los servicios de bienestar social }\end{array}$ \\
\hline $\begin{array}{l}\text { Educación y } \\
\text { habilidades para } \\
\text { la vida }\end{array}$ & $\begin{array}{l}\text { - Aumento de las tasas de matriculación en preescolar, } \\
\text { primaria y secundaria. } \\
\text { - Crear un entorno escolar seguro y estimulante } \\
\text { - Mejorar el conocimiento de los niños sobre el abuso } \\
\text { sexual y las formas de protegerse. } \\
\text { - Formación de habilidades sociales y para la vida } \\
\text { - Programas dirigidos a adolescentes para prevenir la } \\
\text { violencia infligida por una pareja íntima }\end{array}$ \\
\hline
\end{tabular}

Fuente: OPAS, $2017^{33}$

\section{iv. Primer Proyecto Infatil Mejor - Porto Alegre/RS}

Política pública infantil, socioeducativa, preventiva, pionera en Brasil, que promueve el desarrollo integral, que aumenta los lazos afectivos y fortalece la identidad familiar, desde el embarazo hasta los seis años. Involucra a tres departamentos Municipal, Educación, Salud y Cultura para asistir a familias en situación de vulnerabilidad social ${ }^{34}$. 


\section{v. Programa Crece con tu Niño - Fortaleza/CE}

Este programa se lleva a cabo en conjunto con la Estrategia Salud de la Familia en la ciudad de Fortaleza/CE. Su principal objetivo es apoyar a las familias en situaciones de vulnerabilidad social, promoviendo el desarrollo integral de los niños, desde el embarazo hasta los tres años. Durante las visitas semanales a las familias inscritas, el agente comunitario de salud realiza actividades según el grupo de edad del niño, con el fin de fortalecer los dominios del desarrollo cognitivo, afectivo, motor y del lenguaje, incentivando y capacitando a los cuidadores en su participación. actividades recreativas ${ }^{35}$.

\section{vi. Programa de Bienvenida Familiar - Boa Vista/RR}

Es una política pública integral dirigida a la primera infancia, que busca garantizar el pleno desarrollo del niño, fortaleciendo lazos de afecto y estabilidad entre las familias. Involucra a varios departamentos, desde la creación de espacios físicos planificados para los niños y sus familias hasta la integración de todos los servicios ofrecidos con un enfoque en la Primera Infancia. La gestante ingresa al programa hasta la semana 20 de gestación, contará con atención prenatal, consejería para el cuidado después del nacimiento del bebé, recibirá el ajuar y tendrá seguimiento médico y psicosocial, además de una guardería garantizada, tiempo completo. a partir de los dos años (Figuras 1 y 2 ) $^{36}$.

Figura 1 - Universidad del bebé. Grupos temáticos familiares

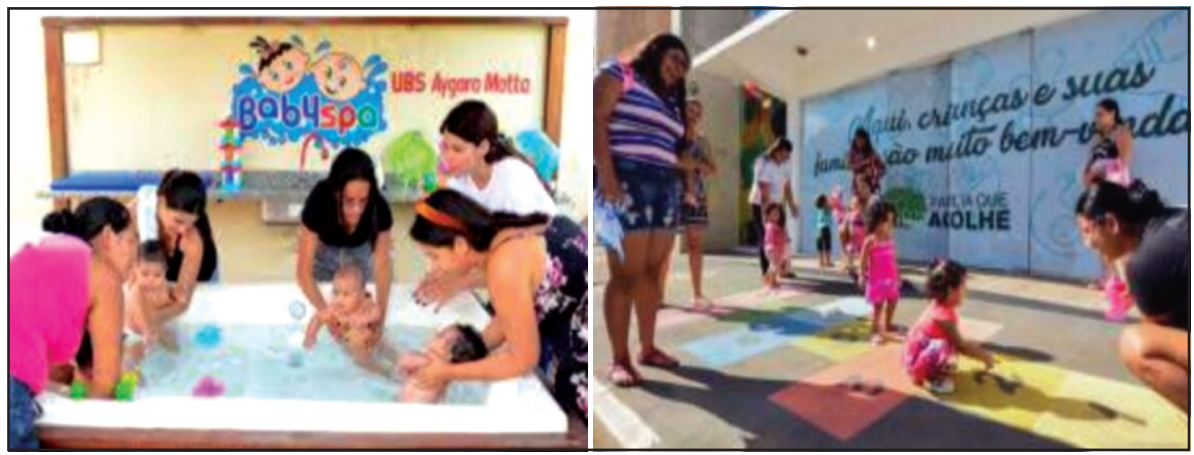

Fuente: Ayuntamiento de Boa Vista/RR 
Figura 2 - Caminos de la Primera Infancia - Adecuación de rutas que componen la Unidad Básica de Salud, el Centro de Asistencia Social, escuelas, guarderías, la Casa Madre y una plaza; para que los niños se diviertan con sus familias y fortalezcan los lazos.

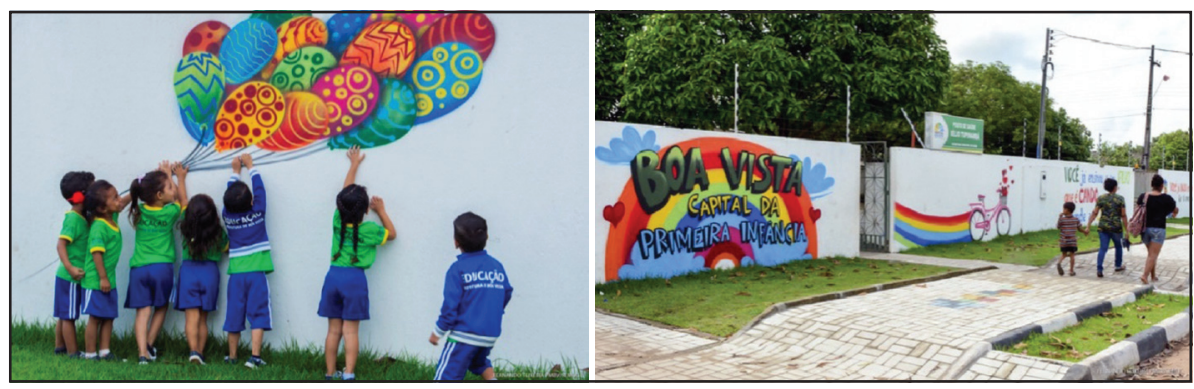

Fuente: Ayuntamiento de Boa Vista/RR

\section{Consideraciones finales}

Las autoras evalúan los programas como importantes iniciativas asistenciales y, en consecuencia, para el enfrentamiento y combate a la violencia, en el entendido de que, con la planificación familiar, se generan hijos deseados y esperados. Esta conciencia evita la violencia del embarazo adolescente para los padres, la violencia física y psicológica del aborto clandestino y el descuido del cuidado de un bebé no deseado. También garantiza la calidad de los primeros mil días de vida y evita la poda neuronal excesiva, que impide no solo un adecuado crecimiento cognitivo, sino también la adquisición de habilidades psicoafectivas, como la empatía, tan importante para la no perpetración de la violencia.

Además, se registra que, al realizar la revisión bibliográfica para la elaboración de este capítulo, los autores se enfrentaron a un importante acervo de clasificaciones, estrategias, programas y proyectos destinados a prevenir y resolver las desgracias provocadas por la violencia contra la población infantil. juvenil. Se destacan propuestas importantes y complejas, como INSPIRE, de la Organización Mundial de la Salud, y las otras existentes en Brasil y mencionadas en este trabajo. Sin embargo, debido a la persistencia de tal crueldad hacia los niños, deducimos que las buenas ideas no se implementan del todo, o son para la parte más pequeña de la 
población objetivo, dejando a la mayoría al margen de esta protección vital, que debería ser la regla. Contradictoriamente, mientras la humanidad en el siglo XXI ya se ha desarrollado hasta el punto de crear soluciones, utilizando la inteligencia artificial, los derechos de la niñez y la adolescencia siguen siendo violados y dependen de políticas atrasadas. Es necesario, por tanto, exigir tal modernización.

\section{Referências}

1. KRUG E.G.; DAHLBERG L.L.; MERCY J.A.; ZWI A.B.; LOZANO R. World report on violence and health. Geneva: World Health Organization; 2002

2. HILLIS S, MERCY J, AMOBI A, et al. Global prevalence of past-year violence against children: a systematic review and minimum estimates. Pediatrics. 2016;137(3):e20154079.

3. SINAN. Sistema de Informação de Agravos de Notificação. 2017 Disponível em http://tabnet.datasus.gov.br/cgi/tabcgi.exe?sinannet/cnv/violebr.def. Acesso 04 MAI 2020.

4. UNICEF. Hidden in plain sight: a statistical analysis of violence against children New York: UNICEF; 2014.

5. RIZZINI I., PILOTTI F et al. A arte de governar crianças. Rio de Janeiro: Amais, Santa Úrsula; 1996.

6. BRASIL. Lei 8.069 de 13 de julho de 1990. Dispõe sobre o Estatuto da Criança e Adolescente e dá outras providências. Diário Oficial da União, Brasília, DF, 13 jul. 1990. Disponível em: http://www.planalto.gov.br/ccivil_03/leis/l8069.htm. Acesso 05 ABR 2020.

7. CONTINI, M. L. (2002). Prefácio - a adolescência e psicologia: práticas e reflexões críticas. In M. L. J. Contini, S. H. Koller \& M. N. S. Barros (Orgs.). Adolescência e psicologia: concepções, práticas e reflexões críticas (pp.11-14). Brasília, DF: Conselho Federal de Psicologia

8. ATLAS DA VIOLÊNCIA 2018. IPEA - Instituto de Pesquisa Econômica Aplicada. Brasília, DF, 5. jun. 2018. Disponível em: http://www.ipea.gov.br/portal/images/ stories/PDFs/relatorio_institucional/180604_atlas_da_violencia_2018.pdf. Acesso em 06 mai. 2020.

9. BRASIL. Ministério da Saúde. Departamento de Informática do SUS. Informações de Saúde, Epidemiológicas e Morbidade: banco de dados. Disponível em: http:// www2.datasus.gov.br/DATASUS/index.php?area=02. Acesso em 08 mai. 2020

10. UNICEF. Mais que promessas: compromissos reais com a infância e a adolescência no Brasil, 2018. Disponível em: https://www.unicef.org/brazil/ media/3051/file/ Mais_que_promessas.pdf. Acesso em 08 mai. 2020. 
11. KOIFMAN, L., MENEZES, R. M., BOHRER, K. R. (2012). Abordagem do tema "Violência contra a criança" no curso de Medicina da Universidade Federal Fluminense. Revista Brasileira de Educação Médica, 36(2), 172-179. Disponível em: http://www. scielo.br/pdf/rbem/v36n2/04.pdf. Acesso em 06 mai. 2020.

12. MINAYO, Maria Cecília de Souza. Violência contra crianças e adolescentes: questão social, questão de saúde. Rev. Bras. Saude Mater. Infant., Recife, v. 1, n. 2, p. 91-102, Aug. 2001.

13. ARAÚJO, R. M. F. et al. Mais do que palavras: a associação do abuso emocional na infância com o comportamento suicida. 2015. Dissertação de Mestrado em Medicina e Ciências da Saúde. Faculdade de Medicina. Pontifícia Universidade Católica do Rio Grande do Sul, RS.

14. UNICEF. Hidden in plain sight: a statistical analysis of violence against children New York: UNICEF; 2014.

15. SINAN. Sistema de Informação de Agravos de Notificação. 2017 Disponível em http://tabnet.datasus.gov.br/cgi/tabcgi.exe?sinannet/cnv/violebr.def. Acesso em 04 mai. 2020.

16. GAWRYSZEWSKI, Vilma Pinheiro et al. Maus-tratos contra a criança e o adolescente no Estado de São Paulo, 2009. Rev. Assoc. Med. Bras., São Paulo, v. 58, n. 6, p. 659-665, Dez. 2012.

17. MASCARENHAS, M. D. M. et al . Violência contra a criança: revelando o perfil dos atendimentos em serviços de emergência, Brasil, 2006 e 2007. Cad. Saúde Pública, Rio de Janeiro, v. 26, n. 2, p. 347-357, Feb. 2010.

18. GARBIN, Cléa Adas Saliba et al. Violência denunciada: ocorrências de maus- tratos contra crianças e adolescentes registradas em uma unidade policial. Rev. bras. enferm., Brasília, v. 64, n. 4, p. 665-670, Aug. 2011.

19. BRASIL. Linha de cuidado para a atenção integral à saúde de crianças, adolescentes e suas famílias em situação de violências: orientação para gestores e profissionais de saúde. (2010). Brasília:MS; 2010.

20. Lei $\mathrm{n}^{\circ} 12.015$ de 7 de agosto de 2009. Altera o Título VI da Parte Especial do Decreto-Lei no 2.848, de 7 de dezembro de 1940 - Código Penal, e o art. 10 da Lei no 8.072, de 25 de julho de 1990, que dispõe sobre os crimes hediondos, nos termos do inciso XLIII do art. $5^{\circ}$ da Constituição Federal e revoga a Lei $n^{\circ} 2.252$, de 10 de julho de 1954, que trata de corrupção de menores. Diário Oficial da União 2009, Brasília, DF 10 ago.2009, Disponível em: http://www.planalto.gov. br/ ccivil_03/_ato2007-2010/2009/lei/L12015.htm. Acesso em 09 mai. 2020.

21. SBP. Departamento Científico de Pediatria do Desenvolvimento e Comportamento. Manual de Orientação. O papel do pediatra na prevenção do estresse tóxico na infância. Rio de Janeiro: SBP, n 3; 2017.

22. BRASIL. Constituição da República Federativa do Brasil. Diário Oficial da União, 5 de outubro de 1988 
23. BRASIL, 1991. Lei $n^{\circ} 8.242$ de 12 de Outubro de 1991. Cria o Conselho Nacional dos Direitos da Criança e do Adolescente (Conanda) e dá outras providências. Diário Oficial da União . Brasília, DF, 16 de outubro de 1991. Disponível em: http:// www.planalto.gov.br/ccivil_03/leis/l8242.htm. Acesso em 10 mai. 2020.

24. BRASIL, 2017. Lei $n^{\circ} 13.431$ de 4 de Abril de 2017. Estabelece o sistema de garantia de direitos da criança e do adolescente vítima ou testemunha de violência e altera a Lei n 8.069, de 13 de julho de 1990 (Estatuto da Criança e do Adolescente). Diário Oficial da União, Brasília, DF, 05 abr 2017. Disponível em http:// www.planalto.gov.br/ccivil_03/_ato2015-2018/2017/lei/l13431.htm. Acesso em 06 mai. 2020.

25. BRASIL, 2016. Lei $n^{\circ} 13.257$ de 8 De Março de 2016. Dispõe sobre as políticas públicas para a primeira infância e altera a Lei nº 8.069, de 13 de julho de 1990 (Estatuto da Criança e do Adolescente), o Decreto-Lei n 3.689, de 3 de outubro de 1941 (Código de Processo Penal), a Consolidação das Leis do Trabalho (CLT), aprovada pelo Decreto-Lei $n^{\circ} 5.452$, de $1^{\circ}$ de maio de 1943 , a Lei $n^{\circ} 11.770$, de 9 de setembro de 2008, e a Lei $n^{\circ} 12.662$, de 5 de junho de 2012. Diário Oficial da União 2009, Brasília, DF 09 mar.2016, Disponível em: http://www.planalto.gov.br/ ccivil_03/_ato2015-2018/2016/lei/l13257.htm. Acesso em 07 mai. 2020.

26. HOWLETT, M.; RAMESH, M.; PERL, A. Política pública: seus ciclos e subsistemas uma abordagem integral. Rio de Janeiro: Elsevier, 2013.

27. HOFLING, E. M. Estado e políticas (públicas) sociais. Cad. CEDES, Campinas, v. 21, n. 55, p. 30-41, Nov. 2001.

28. Lei $n^{\circ} 11.947$, de 16 de junho de 2009. Dispõe sobre o atendimento da alimentação escolar e do Programa Dinheiro Direto na Escola aos alunos da educação básica; altera as Leis nos 10.880, de 9 de junho de 2004, 11.273, de 6 de fevereiro de 2006, 11.507, de 20 de julho de 2007; revoga dispositivos da Medida Provisória no 2.178-36, de 24 de agosto de 2001, e a Lei 8913, de 12 de julho de 1994; e dá outras providências. Diário Oficial da União. Brasília, DF, 17 de junho de 2009.

29. BRASIL. RESOLUÇÃO N 26 DE 17 DE JUNHO DE 2013. Dispõe sobre o atendimento da alimentação escolar aos alunos da educação básica no âmbito do Programa Nacional de Alimentação Escolar - PNAE.

30. BRASIL. Secretaria Especial de Direitos Humanos (2009). Programa Nacional de Enfrentamento da Violência Sexual Contra Crianças e Adolescentes: Disque Denúncia Nacional DDN 100. Brasília: SEDH.

31. PROTEJA BRASIL. UNICEF. 2016. Disponível em http://www.protejabrasil.com.br/ br/. Acesso em 07 mai. 2020.

32. WAKSMAN, R. D.; HIRSCHHEIMER, M.R. Manual de atendimento às crianças e adolescentes vítimas de violência. Núcleo de Estudos da Violência Doméstica contra a Criança e o Adolescente. Brasília, DF, 2011. Disponível em: https://portal. cfm.org.br/images/stories/biblioteca/manual\%20atendimento\%20crianca\%20 adolescente.pdf. Acesso em 06 mai. 2020. 
33. OPAS. INSPIRE. Sete estratégias para por fim à violência contra crianças. Washington, D.C.: OPAS, 2017.

34. SECRETARIA DE SAÚDE - RS. Programa Primeira Infância Melhor. https://saude. rs.gov.br/programa-primeira-infancia-melhor-pim).

35. PREFEIRURA DE FORTALEZA. Cresça com seu filho. https://www.fortaleza. ce.gov. $\mathrm{br} /$ noticias/tag/cres\%C3\%A7a\%20com\%20seu\%20filho.

36. PREFEITURA DE BOA VISTA/RR. PROGRAMA FAMÍLIA QUE ACOLHE. https:// www. boavista.rr.gov.br/canal-do-cidadao-projetos/familia-que-acolhe-fqa. 


\section{Capítulo 3}

\section{DESAFÍOS DE LAS POLÍTICAS PÚBLICAS PARA EL CONTROL DE LA OBESIDAD INFANTIL EN AMÉRICA LATINA Y EL CARIBE}

\section{Asha V. Badaloo ${ }^{1}$, Shelley McFarlane ${ }^{2}$, Carolyn Taylor-Bryan ${ }^{3}$, Daniel Thomas ${ }^{4}$}

${ }^{1}$ B.Sc. (Química y Bioquímica), M.Sc. Y Doctorado (Nutrición Humana). Profesor de Metabolismo Nutricional, Unidad de Investigación del Metabolismo Tropical, Instituto del Caribe para la Investigación en Salud, Universidad de las Indias Occidentales.

2 M. Phil. (Bioquímica y Diabetología), PhD (Epidemiología). Profesor de Epidemiología, Unidad de Investigación del Metabolismo Tropical, Instituto del Caribe para la Investigación en Salud, Universidad de las Indias Occidentales.

${ }^{3}$ B.Sc. (Química y Bioquímica), MBBS, DM (Pediatría), PhD (Nutrición). Profesor de Nutrición, Unidad de Investigación del Metabolismo Tropical, Instituto del Caribe para la Investigación en Salud, Universidad de las Indias Occidentales.

${ }^{4}$ B.Sc. (Hon) (Ciencias Médicas Básicas), MBBS. Becario de Investigación Clínica.

Resumen:

La obesidad es una epidemia mundial caracterizada por una alta morbilidad y mortalidad, asociada a Enfermedades no Transmisibles que comienzan a manifestarse en la infancia y persisten durante todo el ciclo de vida hasta la edad adulta. Este capítulo analiza los desafíos de las políticas públicas en el control de la obesidad en la niñez y la adolescencia en América Latina y el Caribe. Se dan antecedentes sobre el contexto de la obesidad infantil en la región, destacando la importancia del tema a nivel regional e internacional, y dando una perspectiva histórica sobre los avances que se han dado hasta el momento para abordar la obesidad infantil. Se presenta un análisis de las principales políticas y acciones que se han implementado en la región, incluidas las políticas de alimentación y nutrición, así como las orientadas a promover prácticas de estilo de vida saludable, incluida la actividad física. Los autores han presentado una discusión sobre los desafíos multifacéticos que enfrenta no solo la creación sino 
también la implementación de estas políticas de salud y el enfoque multisectorial que es importante para combatir adecuadamente esta creciente amenaza para la salud de nuestra población.

Palabras-clave: Control de la obesidad; Sistemas de manejo de la obesidad; Obesidad pediátrica; Inequidad social.

\section{Introducción}

En las últimas décadas, la prevalencia de la obesidad en los niños ha aumentado de forma espectacular. Esta epidemia mundial tiene consecuencias importantes, que incluyen trastornos psiquiátricos, psicológicos y psicosociales en la infancia y un mayor riesgo de desarrollar enfermedades no transmisibles (ENT) más adelante en la vida ${ }^{1}$. El tratamiento de la obesidad es difícil y es probable que los niños con exceso de peso se conviertan en adultos con obesidad². Desde 2016, la Organización Mundial de la Salud (OMS) ha calificado a la obesidad infantil como "uno de los desafíos de salud pública más graves del siglo XXI”3. El aumento global del exceso de peso en la población ha venido exigiendo acciones gubernamentales encaminadas a prevenir los impactos en la salud que genera la obesidad. Estas tendencias han llevado a los estados miembros de la OMS ${ }^{4}$ a respaldar el objetivo de "No aumentar la obesidad en la infancia para 2025".

Generalmente, la obesidad infantil es impulsada por la interacción de la nutrición y la actividad física influenciada por factores socio-ecológicos. Esta interacción presenta diferentes desafíos y oportunidades para actuar a lo largo del curso de la vida. Los factores bien reconocidos relacionados con la inactividad física y la reducción del gasto de energía que han contribuido a la epidemia mundial de obesidad incluyen una reducción de las caminatas debido a un mayor uso del transporte motorizado, una disminución de las actividades físicas ocupacionales como consecuencia del aumento de la automatización y el uso de la tecnología. y un aumento del tiempo libre dedicado a la realización de conductas sedentarias. El estilo de vida sedentario es alto en América Latina y el Caribe (ALC). Un estudio de cohorte de nacimiento en Pelotas, Brasil, mostró un 58\% de estilos de vida 
sedentarios entre los jóvenes, caracterizados por ver televisión en exceso y falta de actividad física ${ }^{5,6,7}$. Gaskin et al ${ }^{8}$ observaron resultados similares en un estudio escolar de niños de 9 a 11 años en Barbados. De manera alarmante, el $43 \%$ de los adultos y adolescentes de América Latina fueron clasificados como inactivos, lo que indica que la región es la más inactiva del mundo 9,10.

Los cambios en la dieta se han producido de forma paralela a los cambios en el sistema alimentario en general y en dos sentidos: el conjunto de cadenas de suministro desde las granjas, pasando por los segmentos intermedios de procesamiento, venta al por mayor y logística, hasta los segmentos posteriores del servicio minorista y de alimentos (restaurantes y cadenas de comida rápida) ${ }^{11}$. Esto se refleja en una mayor cantidad y variedad de alimentos densos en energía disponibles; niveles crecientes de promoción y comercialización de alimentos densos en energía; oportunidades de compra de alimentos más frecuentes y generalizadas; mayor uso de restaurantes y tiendas de comida rápida; Porciones más grandes de comida que ofrecen una mejor "relación calidad-precio"; Mayor frecuencia de ocasiones para comer; aumento del uso de refrescos para reemplazar el agua, p. ej. en las escuelas ${ }^{7,8}$.

\section{Contexto de la obesidad infantil en América Latina y el Caribe}

Actualmente, la región de ALC, con la mayor prevalencia de sobrepeso y obesidad en el mundo, enfrenta una combinación de importantes problemas de salud relacionados con la dieta y relacionados con la inactividad acompañados de enormes costos económicos y sociales. Los cambios en la dieta son profundos con notables cambios rápidos hacia niveles muy altos de sobrepeso y obesidad entre todas las edades, junto con, en algunos países, altas cargas de retraso en el crecimiento. Si bien los países de América Latina han avanzado en la reducción de la desnutrición y las carencias de micronutrientes, faltan políticas integrales e intersectoriales para abordar la ${ }^{12}$.

La prevalencia estimada de obesidad en 2014 fue de $21,7 \%$ en niños latinoamericanos menores de 20 años $^{13,14,15}$. La OMS ${ }^{15}$ notificó niveles más bajos de sobrepeso en niños menores de 5 años en 2013 en las regiones de América Latina y el Caribe, con pocos cambios en los 13 años anteriores; pero países con grandes poblaciones, como Argentina, Brasil, Chile, Perú y 
el Estado de Bolivia observaron niveles de aumento del $7 \%$ y superiores ${ }^{16}$. A fines de 2010, la prevalencia reportada del $14 \%$ en niños caribeños en el grupo de edad menor de 5 años es incluso mayor que en AL; y llegó al 27\% en las niñas y al 33\% en los niños en los niños de 11 a 13 años ${ }^{17}$.

Para prevenir y controlar específicamente la obesidad en los niños menores de 5 años, la Asamblea Mundial de la Salud en 2012 aprobó un plan de implementación integral para la nutrición materna, del lactante y del niño pequeño, que comprende 6 metas nutricionales para 2025; el cuarto objetivo es "no aumentar el sobrepeso infantil para 2025"18. En este contexto, el grupo de trabajo proporcionó varias recomendaciones e información clara para el consumidor, tales como:

a) etiquetado de alimentos;

b) alentar a las empresas de alimentos a que ofrezcan alimentos más nutritivos y con menor energía comercializados para niños y a desarrollar criterios de publicidad que promuevan una alimentación más saludable.

c) mejorar la nutrición materna y fomentar la lactancia materna de los bebés.

d) diseñar instalaciones de juego seguras y vecindarios locales seguro;

e) alentar a las escuelas a promulgar políticas coherentes de alimentación, nutrición y actividad física;

f) alentar a los profesionales médicos y de la salud a participar en el desarrollo de programas de salud pública.

De acuerdo con estas recomendaciones de la guía, ALC ha estado trabajando en conjunto para implementar y promulgar estas políticas de salud pública. Fue en la década siguiente que la Organización Panamericana de la Salud (OPS) (2014) publicó un Plan de Acción para la prevención de la obesidad en niños y adolescentes en las Américas. También en 2014, la Agencia de Salud Pública del Caribe (CARPHA) publicó un plan de acción complementario. Estos dos documentos siguieron las recomendaciones del Grupo de Trabajo de Obesidad Interna de 2004. ¿Pero por qué tomó una década para que estas políticas fueran adoptadas por las regiones? ¿Cuáles fueron los desafíos encontrados para llegar a ese punto? ¿Dónde nos encontramos ahora? Este capítulo intentará abordar estas preguntas. 


\section{A. Políticas públicas para abordar la obesidad infantil en la región de América Latina}

Los altos niveles de obesidad infantil en América Latina (LA) son impulsados por altos niveles de urbanización, alrededor del 80\% (19), la limitación del espacio y el tiempo para la actividad física y la transición nutricional que se caracteriza por una mayor ingesta de alimentos ricos en energía y azúcar. Bebidas azucaradas (SSB) desde la década de 1900. Esto va acompañado de un acceso fácil y conveniente a alimentos altamente procesados y ricos en grasas y azúcares. Se ha demostrado que la inseguridad alimentaria, que es un sustituto de las disparidades económicas, está asociada con la prevalencia de la obesidad en Los Ángeles, y los países de AL tienen algunas de las mayores disparidades de ingresos del mundo a pesar de un desarrollo económico significativo ${ }^{19,20,21}$. Sin embargo, América Latina ha sido líder en la implementación de programas para reducir la obesidad infantil14,19,22,23. Estos programas pueden agruparse en dos categorías: dieta y nutrición y programas de actividad física.

\section{Políticas relacionadas con la dieta y la nutrición en América Latina}

Las siguientes son algunas de las políticas fiscales y no fiscales destacadas en América Latina que han demostrado reducir la ingesta de alimentos ricos en energía y pobres en nutrientes ${ }^{12,23}$.

1. El impuesto especial sobre las bebidas azucaradas (SSB) en México.

2. Requisitos para el empaque frontal en Chile, Ecuador y México.

3. Políticas que restringen la comercialización de bebidas azucaradas sin alcohol con alimentos altos en calorías y bajos en nutrientes para niños en Bolivia, Brasil, Chile, Colombia, Ecuador, México, Perú y Uruguay.

4. Incentivos económicos para el consumo de alimentos saludables en Chile, Colombia, Costa Rica, Ecuador, Perú y Uruguay.

5. Eliminación de ácidos grasos trans de los alimentos procesados en Argentina, Brasil, Chile, Costa Rica, México.

El impuesto especial sobre las bebidas azucaradas se basó en investigaciones clave que muestran que la alta densidad energética de la dieta de los niños y las bebidas azucaradas son las principales fuentes de azúcar 
añadido ${ }^{24}$. Los estudios de investigación también crearon apoyo basado en evidencia para la imposición de impuestos a las bebidas azucaradas, específicamente que un aumento del $10 \%$ en el precio se asoció con una reducción del $11,6 \%$ en la demanda, donde los principales sustitutos eran el agua y la leche. Estos resultados se difundieron en conferencias, publicaciones y se presentaron a agencias como el Congreso y el Ministerio de Hacienda y actualmente se encuentran en proceso de seguimiento y evaluación ${ }^{23}$.

Si bien varios países han creado políticas con respecto al etiquetado de los alimentos, muchos otros aún no han desarrollado ninguna forma de política o regulación. Incluso entre aquellos en los que existe algún tipo de pautas regulatorias, no todos tienen estándares obligatorios de etiquetado nutricional. En Chile y Ecuador, las políticas para el etiquetado frontal del empaque han demostrado ser efectivas y el $95 \%$ de las madres de niños y adolescentes en edad preescolar entrevistadas coincidieron en que el Ministerio de Salud está ayudando a los consumidores a identificar los alimentos no saludables. Se ha demostrado que otras pautas de etiquetado del frente del paquete, como en el caso de México, carecen de claridad y transparencia?.

Aunque la OMS ha identificado la eliminación de los ácidos grasos trans (AGT) del suministro de alimentos como una intervención de salud pública de 'mejor compra' para los países de ingresos bajos y medianos ${ }^{23}$, muchos países de América Latina aún no lo han hecho. incluyó la eliminación de los AGT como objetivo de seguimiento mundial debido a las preocupaciones sobre la viabilidad, la viabilidad y el efecto en la salud pública de eliminarlos del suministro de alimentos. Argentina es uno de los pocos países de AL que ha creado normativas políticas efectivas para restringir los AGT en la dieta. El gobierno inició regulaciones obligatorias que especifican que los AGT en los alimentos no deben exceder el $2 \%$ de las grasas totales en los aceites vegetales y las margarinas para consumo directo y el $5 \%$ de las grasas totales en otros alimentos. Argentina también ha estado inspeccionando y haciendo cumplir eficazmente el cumplimiento de estas regulaciones por parte de la industria. La política fue evaluada adicionalmente mediante un estudio de modelado que predijo los beneficios para la salud traducibles de esta intervención, creando evidencia científica adicional para respaldar esta política ${ }^{23}$. 


\section{Programas de actividad física en América Latina}

En la escuela de Los Ángeles, las intervenciones de Actividad Física (AF) y las Ciclovías (calles abiertas) han sido las principales estrategias para combatir la inactividad física y aumentar el gasto energético. Desde 2005 se inició una Guía de Intervención Útil para la Actividad en AL (GUIA) para examinar y promover estrategias basadas en la evidencia con el objetivo de aumentar la $A F$ en $A^{6}{ }^{6,25}$. La AF en la escuela se identificó como una intervención con un cuerpo de evidencia lo suficientemente fuerte como para hacer una recomendación práctica.

En 2010 se llevó a cabo una revisión sistemática de 5 intervenciones escolares 6 . Se realizó un estudio en Brasil, dos estudios en Chile y dos en la frontera entre Estados Unidos y México. Tres estudios utilizaron un diseño de grupo aleatorio y dos utilizaron un diseño no aleatorio con un grupo de comparación. La revisión demostró aumentos positivos consistentes en AF en los tres estudios aleatorizados. Los autores concluyeron que los resultados impulsan la implementación de intervenciones de AF escolares de alta calidad en la región; y que mejorar la calidad de la AF en las escuelas depende del desarrollo de capacidades y la capacitación de los maestros e instructores de Educación Física (EF), cambios apropiados en el plan de estudios de EF, infraestructura adecuada, incluidos equipos y materiales, y ajustes a diversas características políticas, culturales y socioeconómicas. Casi ocho años después del inicio de la GUIA, las revisiones adicionales ${ }^{25,26}$ todavía estaban en la etapa de hacer recomendaciones de que las intervenciones basadas en la escuela deberían promoverse como un componente importante para los programas integrados, las políticas y los marcos de monitoreo diseñados para revertir la infancia. obesidad en la región.

La estrategia de las Ciclovías (calles abiertas) ha sido la política de AP dominante en la región de Los Ángeles. Se trata de cerrar las calles temporalmente al tráfico motorizado para transformarlas en un espacio seguro para actividades como andar en bicicleta, caminar, trotar y participar en eventos sociales, de promoción de la salud y culturales. Basado en el éxito de Ciclovías en Bogotá, este programa se ha extendido a 461 ciudades en Los Ángeles como se muestra en la Figura $1^{23}$. 
Figura 1 - Crecimiento exponencial de las ciclovías a lo largo del tiempo en ciudades de América Latina.

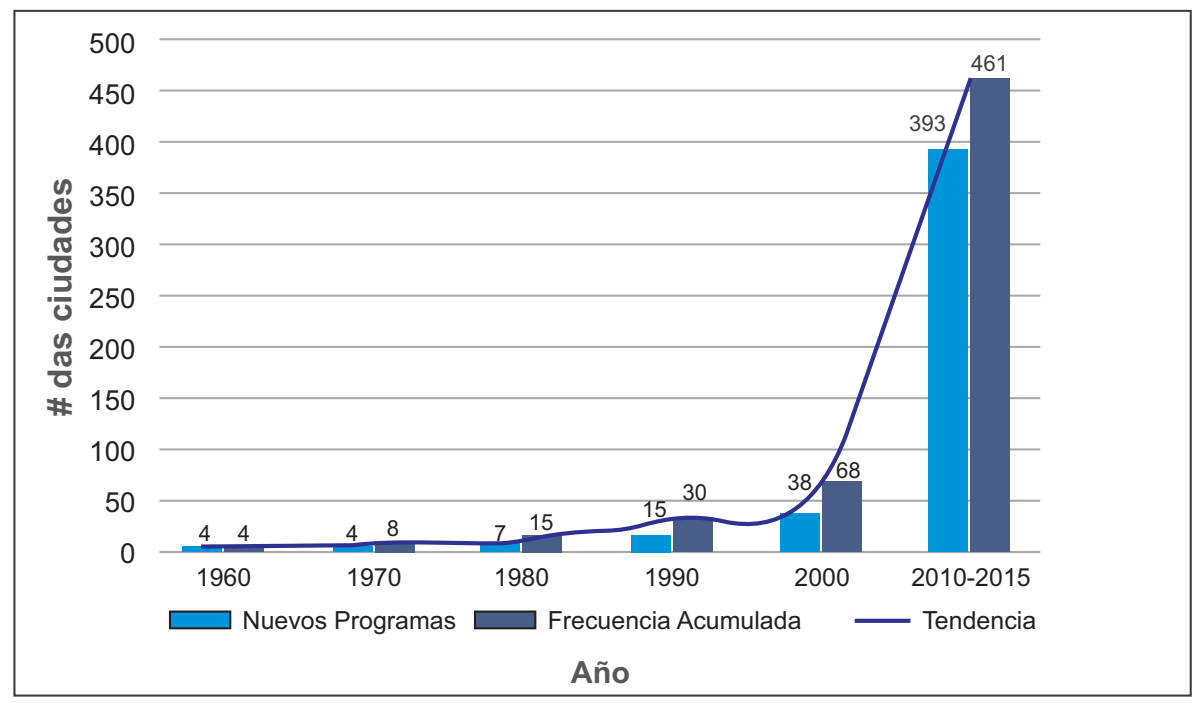

Fonte: Adaptado de Pérez-Escamilla et $\mathrm{al}^{23}$.

\section{B. Políticas públicas para abordar la obesidad infantil en la región del Caribe}

En una reunión de CARICOM en 2013, la región del Caribe estableció un plan de acción en línea con el Plan de acción mundial para la prevención y el control de enfermedades no transmisibles 2013-2020 y un Plan de implementación integral anterior sobre nutrición materna, infantil y del niño pequeño de 2012. Ambos consideraron el uso de impuestos y subsidios como políticas claves basadas en la población para permitir elecciones dietéticas saludables y abordar la obesidad y la diabetes ${ }^{27,28}$. A partir de esta reunión de líderes de CARICOM, se desarrolló un Plan de Acción de 6 puntos. Este Plan de acción para promover pesos saludables en el Caribe: prevención y control de la obesidad infantil (2014-2019) estableció metas para la región del Caribe y desarrolló tarjetas de puntuación para monitorear y evaluar a cada isla caribeña en el logro de las metas ${ }^{29,30}$.

La mayoría de las políticas implementadas en la región del Caribe se basaron en la nutrición. La aplicación de estrategias fiscales es mucho menor en el Caribe en comparación con Los Ángeles. Algunos de los principales 
programas de políticas de los países del Caribe en respuesta a la epidemia de obesidad infantil son:

i El Estándar Regional de CARICOM: Especificación para el etiquetado de alimentos preenvasados: No hay información disponible sobre si la política se ha implementado en algún país del Caribe ${ }^{27}$.

ii Plan Estratégico Nacional de Prevención y Control de las Enfermedades No Transmisibles (ENT): Uno de los objetivos de esta política es reducir la prevalencia de obesidad en niños y adolescentes. Las áreas de acción incluyen la promoción de la nutrición materno infantil, que incluye la promoción de la lactancia materna exclusiva durante seis meses, programas de salud y nutrición en las escuelas y la inclusión de la nutrición en el currículo escolar. Esta política fue adoptada en Jamaica. Aunque se dispone de una política similar en Trinidad y Tobago, Bahamas, Guyana, Barbados, Granada, San Vicente, las Granadinas, San Kitts y Nevis, no hay información disponible sobre si estos programas se han implementado con éxito ${ }^{27}$.

iii Plan de Acción Nacional para la Prevención y Control de la Obesidad Infantil: Esta política fue desarrollada para operativizar las actividades de prevención de la obesidad del Plan Estratégico y Acción Nacional para la Prevención y Control de las ENT. Fue adoptado en Barbados. Jamaica también tiene esta política, pero no hay información disponible sobre su implementación. El objetivo de esta política es revertir la tendencia de aumento de la obesidad promoviendo la lactancia materna exclusiva durante 6 meses, reduciendo la prevalencia de baja actividad física en adolescentes e implementando programas de salud y nutrición en las escuelas y también incluyendo la nutrición en el currículo escolar ${ }^{27}$.

iv Política nacional de alimentación del lactante y del niño pequeño: esta política se adoptó en Jamaica. Sirve para aumentar el acceso al apoyo a la lactancia materna en las comunidades y en el lugar de trabajo y para lograr el estatus de Hospital Amigo del Niño en todas las instituciones que ofrecen servicios de salud materno infantil. Otros cinco países también han implementado la Iniciativa de Hospitales Amigos del Niño (BFHI) y tienen políticas de nutrición escolar, y varios estaban en proceso de implementar legislación sobre la comercialización de sucedáneos de la leche materna ${ }^{27}$. San Vicente y las granadinas tiene 
un Plan de Acción Nacional para Bebés y Niños Pequeños y una Política Nacional de Lactancia Materna, y Dominica también tiene una política de lactancia materna (Política Comunitaria de Lactancia Materna de Dominica), que fue adoptada desde 1993 y posteriormente revisada en 1999. Granada tiene una Política de Nutrición Escolar con metas similares a las enumeradas anteriormente ${ }^{27}$.

$v$ Defensa de la sociedad civil-Plan de acción 2017-2021 de la Coalición del Caribe Saludable (HCC): Prevención de la obesidad infantil en el Caribe (CSAP): La HCC es una organización no gubernamental integrada por miembros de todas las asociaciones y sociedades que defienden prevención de la obesidad en los niños. La coalición ha actuado como enlace entre la sociedad civil, el sector privado y el gobierno en un esfuerzo por adoptar un enfoque multisectorial coherente de la epidemia de obesidad infantil. Este tipo de ciudadanía en el Caribe ejemplifica el papel de las alianzas público-privadas en la lucha contra la obesidad infantil ${ }^{29}$.

vi. Intervenciones fiscales: En 2015, Barbados fue el primer país del Caribe y el décimo país del mundo en implementar un impuesto especial sobre las bebidas azucaradas. Introdujeron un impuesto especial del $10 \%$ sobre todas las bebidas azucaradas ${ }^{30}$. Unos meses después, Dominica aplicó un impuesto especial del 10\% a las bebidas azucaradas y los alimentos con alto contenido de azúcar, como la goma de mascar y las barras de chocolate ${ }^{31}$. Varios países también han implementado subsidios para frutas y verduras locales ${ }^{27}$. Sin embargo, hasta la fecha, no existen países del Caribe con regulaciones vigentes que prohíban la comercialización de alimentos no saludables a los niños ${ }^{27}$.

\section{Desafíos de las políticas públicas en América Latina y el Caribe}

Todas las políticas de nutrición están disponibles para cada país por la OMS: Base de datos mundial sobre la implementación de acciones de nutrición (GINA)27. Un vistazo a este sitio web muestra que muchas de las políticas, incluidas las destinadas a reducir la obesidad infantil en LAC, no se han adoptado o no hay información disponible. Esto apunta a una debilidad en la implementación, el seguimiento y la evaluación, como se destacó en un taller reciente celebrado en 2014 con el apoyo del Instituto Nacional de 
Salud de EE.UU. En el taller, se examinó una agenda para la investigación regional y la asociación estratégica para prevenir la obesidad infantil en Los Ángeles. Se han revelado muchas lagunas y oportunidades en cuatro publicaciones ${ }^{14,19,22,23}$ de las actas del taller. Esto es casi 12 años después de la GUIA y 5 años después de establecer la meta de la OMS de "No aumentar la obesidad infantil para $2025^{\prime 18}$. No es sorprendente que los miembros del taller resumieran el progreso para abordar la creciente epidemia de obesidad infantil como lento e inconsistente.

\section{Brechas de investigación}

A pesar de la implementación exitosa de algunos programas de políticas para prevenir y reducir la obesidad infantil en América Latina, la evidencia científica limitada impide el desarrollo y la implementación de intervenciones efectivas más innovadoras en la región ${ }^{19}$. Es necesaria evidencia local, culturalmente apropiada que tenga en cuenta las particularidades del entorno de alimentación y actividad física de la región para determinar las acciones más efectivas para prevenir la obesidad ${ }^{32}$. Muchos países tienen una disponibilidad limitada de datos debido a la falta de sistemas de información nutricional sistemáticos. En muchos países de la región, la información sobre los indicadores del estado nutricional, como los indicadores antropométricos y bioquímicos, así como los biomarcadores del estado de los micronutrientes, está desactualizada o falta ${ }^{12}$. Esto inhibe el proceso de toma de decisiones informada y oportuna y la formulación de intervenciones nutricionales específicas entre poblaciones vulnerables. Las encuestas de salud y nutrición disponibles son representativas a nivel nacional, utilizando metodologías estandarizadas y muestras probabilísticas. Sin embargo, debido a que no se llevan a cabo de forma sistemática y a menudo en intervalos de tiempo diferente, es difícil hacer comparaciones y sacar conclusiones de los datos ${ }^{12}$.

La capacidad de investigación para prevenir la obesidad infantil en AL fue revisada por Parra et $a^{14}$. Los autores señalaron que el número muy bajo de estudios de intervención en publicaciones y casi ninguna investigación de políticas sugiere una falta de capacidad de investigación relevante. Asimismo, en los países del Caribe, la escasez de literatura publicada sobre algunas intervenciones dificulta la traducción de estos hallazgos en políticas. Dado que la investigación es fundamental para comprender, monitorear e implementar estrategias, políticas y programas para enfrentar la epidemia de obesidad, 
se recomienda que exista una demanda para incrementar la capacidad investigadora e incluir más investigación e implementación traslacional en los portafolios del país ${ }^{13}$. Por ejemplo, si bien existe evidencia sólida para apoyar la intervención de AF en las escuelas para prevenir la obesidad infantil en Los Ángeles desde 2005, esto no se ha convertido en una política. Los desafíos para lograr esta acción pueden estar relacionados con la necesidad de futuras investigaciones para identificar otros elementos prácticos clave, como legislación, política, barreras y facilitadores para la promoción de la EF en las escuelas ${ }^{6}$. Además, las publicaciones de investigación muestran pocas colaboraciones aparentes entre países en $\mathrm{AL}^{14}$, que también vemos en el Caribe. Otra área sobre la que hay muy poca información para la región es el efecto de la nutrición materna y el bajo crecimiento intrauterino que predisponen al desarrollo de obesidad en la descendencia ${ }^{33}$. La intervención antes y durante el embarazo tiene el potencial de reducir la prevalencia de obesidad en los niños ${ }^{34}$.

\section{Tablas de composición de alimentos}

En América Latina y el Caribe, existe una necesidad específica de medir detalladamente los alimentos y el gasto energético/composición de alimentos o energía, subyacente de estos rubros para informar los programas y la planificación de políticas para la prevención de la obesidad infantil. Las bases de datos actuales proporcionan datos limitados y en algunos casos cuestionables sobre la calidad de los macronutrientes, nutrientes e ingredientes, especialmente para muchos alimentos y bebidas producidos localmente. Para crear medidas precisas de composición de alimentos, se requieren encuestas dietéticas nacionales y tablas de composición de alimentos actualizadas. El proyecto INFORMAS22 está documentando y creando bases de datos limitadas de alimentos y bebidas con códigos de barras en Brasil, Chile, México y otros países de América Latina y en países seleccionados como México, Brasil, Colombia y Chile, y se están recopilando esfuerzos de evaluación bases de datos completas de todos los alimentos procesados envasados. Si bien todos los países de la región recopilan datos sobre ingresos y gastos, solo hay unos pocos países donde los académicos utilizan estos datos para el análisis nutricional, lo que se debe en parte a los datos limitados que proporcionan. El análisis químico de los alimentos es necesario para validar algunos de estos datos ${ }^{22}$. 
Una vigilancia mejorada a través de investigaciones representativas a nivel nacional o subnacional, en combinación con tablas de composición de alimentos mejoradas, permitiría a los investigadores comprender mejor las dietas en América Latina a lo largo del ciclo de vida y en diferentes subgrupos demográficos. Como resultado, el análisis podría determinar qué alimentos en las dietas locales son los más responsables de la ingesta energética excesiva y los impactos de varios alimentos y otros factores, incluido el contexto y el momento de la ingesta de alimentos y bebidas, sobre el apetito y la saciedad. Se necesitan con urgencia tecnologías para reducir el tiempo y los gastos necesarios para recopilar datos dietéticos; además de los datos sobre actividad física, las medidas agregadas son inadecuadas para desarrollar políticas y programas de prevención de la obesidad infantil22.

\section{Seguimiento y evaluación de las políticas implementadas}

Los programas implementados deben ser monitoreados y evaluados continuamente. Este ha sido un punto débil en la mayoría de ALC. Esta falta de monitoreo impide la identificación temprana de las barreras relacionadas con la implementación, el acceso y la utilización de los servicios de salud, así como con el cumplimiento y la cobertura. La información sobre recursos humanos y financieros para la implementación de acciones de nutrición es escasa en la región y hay una flagrante falta de informes completos y artículos revisados por pares sobre la evaluación de estas políticas. En la mayoría de los países de ALC, el monitoreo de programas o la vigilancia del estado nutricional como parte de los esfuerzos para evaluar la implementación de acciones nutricionales es una parte débil o faltante de los sistemas de información en salud ${ }^{12}$. También hay una falta general de información publicada sobre la implementación y evaluación de políticas y programas y sobre los recursos humanos y financieros para las metas de nutrición. Recientemente, Ribeiro et $a^{6}{ }^{6}$ señalaron que se están llevando a cabo muchas intervenciones de AP prometedoras en AL, pero su efectividad en general no ha sido evaluada. En el Caribe, el desarrollo de la tarjeta de puntuación del Caribe sobre obesidad infantil (COPS, por sus siglas en inglés) buscó brindar monitoreo y vigilancia de los numerosos programas escolares y de obesidad infantil que se han iniciado. Sin embargo, tampoco se ha evaluado la eficacia de los programas ${ }^{30}$. 


\section{Gobierno y partes interesadas}

Las políticas y acciones de nutrición están respaldadas por marcos regulatorios, pero los países carecen de la capacidad para monitorear y hacer cumplir su implementación. Esto se debe en gran parte a la falta de conciencia o la falta de "aceptación" de los sucesivos gobiernos de la región. Esta falta general de conciencia en los gobiernos y las agencias de cooperación sobre la importancia y la necesidad de identificar y asignar fondos adecuados para la implementación de sistemas de información sostenibles da como resultado entornos con escasos recursos para la ampliación de intervenciones comprobadas y una aceptación y promoción limitadas de iniciativas de políticas. En consecuencia, esto ha dado lugar a largas demoras en la transferencia de programas e iniciativas a documentos de políticas. La falta de voluntad política es un factor de disuasión importante en la implementación y el seguimiento de las políticas. Además, existe la percepción por parte del gobierno de una alta carga regulatoria para la implementación de políticas, lo que resulta en la falta de financiamiento para las actividades de seguimiento y evaluación de políticas. Esto es particularmente desafiante para AL y la región del Caribe que comprende países de ingresos bajos y medianos. Es de destacar que los países de AL tienen algunas de las disparidades de ingresos más grandes del mundo a pesar de un desarrollo económico significativo ${ }^{19,20,21}$. Por lo tanto, no es sorprendente que la inseguridad alimentaria se haya asociado con la obesidad en algunos países de América Latina. La inseguridad alimentaria puede conducir a la obesidad no solo a través del consumo de energía en exceso de alimentos de alto contenido energético baratos y fácilmente disponibles, sino también en relación con la desnutrición previa ${ }^{16}$.

Si bien la mayoría de los países de AL y el Caribe han establecido políticas nacionales de seguridad alimentaria y nutricional, se deben fortalecer los mecanismos de coordinación entre los niveles nacional, regional y local. Los objetivos y acciones de nutrición no se han incorporado plenamente en las políticas nacionales de desarrollo o reducción de la pobreza ${ }^{12}$.

\section{Challenges from Private Sector}

El cabildeo de entidades opuestas a los cambios de políticas, como la industria alimentaria, ha planteado uno de los mayores desafíos para la creación de políticas públicas a nivel mundial y ALC no es una excepción. Los grupos de intereses especiales han aprovechado los temores del público, 
en particular el miedo a la pérdida de oportunidades económicas, como munición contra la institución de muchas políticas. En particular, la industria de las bebidas es un socio vital en la reducción del contenido de azúcar de las bebidas que se venden en el mercado. A nivel mundial, la industria de bebidas se ha resistido a los esfuerzos para implementar impuestos al azúcar y esto ha influido enormemente en los mercados de América Latina y el Caribe. Por experiencia, Barbados recomienda que los formuladores de políticas busquen involucrar a las partes interesadas, como los sectores agrícola y manufacturero, antes de la implementación de la política, para abordar las preocupaciones y disipar los temores en los sectores que se oponen a la introducción de impuestos sobre las bebidas azucaradas ${ }^{29}$.

De manera similar, la introducción de las ciclovías se ha encontrado con cierta resistencia por parte de las empresas y otros sectores, incluidas las empresas de transporte, que se vieron afectados por los cierres de carreteras ${ }^{23}$. En la mayoría de los casos, estos desafíos se han superado proporcionando prácticas recomendadas basadas en evidencia para implementar Ciclovías, junto con una fuerte participación de la sociedad civil, destacando nuevas oportunidades de desarrollo económico para los propietarios de pequeñas empresas ${ }^{23}$.

\section{Civil Society Advocacy}

También existe el desafío de crear a nivel comunitario, una actitud consciente de la salud y cambios de comportamiento. Mientras que en el Caribe la HCC actúa como un vibrante defensor civil y perro guardián, en América Latina ha habido dificultades para obtener el apoyo de defensores informados y partidarios de la divulgación pública a nivel regional que puedan influir en la percepción pública a través de la difusión de información clara. y mensajes concisos $^{23}$. Los gobiernos y las partes interesadas deben promover la participación de la sociedad civil para fortalecer la responsabilidad social ${ }^{12}$.

\section{Resumen y conclusión}

En este documento, se han discutido muchos intentos para abordar la obesidad infantil en ALC que muestran un éxito variable, mientras que la prevalencia sigue siendo alta. Los desafíos para abordar este importante problema de salud incluyen la falta de evidencia sólida para informar los 
programas de implementación e incluso cuando se implementan, a menudo hay un monitoreo y una evaluación inadecuados que son barreras para la traducción de los programas en políticas. La investigación de políticas prospectivas puede ser útil para promover la traducción del conocimiento ${ }^{23}$. En general, en cada paso del proceso se requieren más publicaciones de investigación no solo para informar la implementación, sino para proporcionar conocimiento de los programas implementados, ampliados a la política y sus éxitos.

Además, es importante la influencia de factores socio ecológicos que indican que se requiere un enfoque multisectorial. En 2018, en la 39a Cumbre, los jefes de Gobierno y de Estado de CARICOM, el coordinador residente de la ONU indicó que para un enfoque multisectorial exitoso para combatir la obesidad, deben existir las 3P: "Voluntad política, la política pública correcta y socios". Este principio también se enfatiza en AL, como lo destacan Mariachiara et al ${ }^{4}$, que el trabajo de los gobiernos, la sociedad civil, las corporaciones privadas y otras partes interesadas clave debe estar bien coordinado para enfrentar la epidemia. Si este enfoque se aplica a todos los niveles, habrá menos barreras para abordar con éxito la obesidad infantil en la región. La colaboración entre países de las distintas regiones también podría ser una ventaja.

\section{Referências}

1. Gupta N, Goel K, Shah P, Misra A. Childhood obesity in developing countries: epidemiology, determinants, and prevention. Endocr Rev. 2012;33(1):48-70).

2. Guo SS, Wu W, Chumlea WC, Roche AF. Predicting overweight and obesity in adulthood from body mass index values in childhood and adolescence. Am J Clin Nutr. 2002;76(3):653-8.

3. Organization WH. Childhood overweight and obesity. 2016.

4. Di Cesare M, Sori, M, Bovet P, Miranda JJ, Bhutta Z, Stevens GA, et al. The epidemiological burden of obesity in childhood: a worldwide epidemic requiring urgent action. BMC Med. 2019 Dec;17(1):212.

5. Hallal PC,Wells JCK, Reichert FF, Anselmi L, Victora C. Early determinants of physical activity in adolescence prospective birth cohort study. BMJ;: doi:10.1136/ bmj.38776.434560.7C.) 
6. Ribeiro IC, Parra DC, Hoehner CM, Soares J, Torres A, Pratt M, et al. School- based physical education programs: evidence-based physical activity interventions for youth in Latin America. Glob Health Promot. 2010 Jun;17(2):05-15.

7. Lobstein et al The International Association for the Study of Obesity. Obesity reviews 5 (Suppl. 1), 4-85.

8. Gaskin PS, Lai P, Guy D, Knight J, Jackson M, Nielsen AL. Diet, Physical Activity, Weight Status, and Culture in a Sample of Children from the Developing World. Journal of Nutrition and Metabolism. 2012;2012:1-8.

9. Cominato L, Di Biagio GF, Lellis D, Franco RR, Mancini MC, de Melo ME. Obesity Prevention: Strategies and Challenges in Latin America. Curr Obes Rep. 2018 Jun;7(2):97-104.

10. Ng SW, Popkin BM. Time use and physical activity: a shift away from movement across the globe. Obes Rev. 2012;13(8):659-80

11. Popkin BM, Reardon T. Obesity and the food system transformation in Latin America: Obesity and food system transformation. Obesity Reviews. 2018 Aug;19(8):1028-64.

12. Galicia L, Grajeda R, de Romaña DL. Nutrition situation in Latin America and the Caribbean: current scenario, past trends, and data gaps. Rev Panam Salud Publica. 2016 Aug;40(2):104- 13. Galicia L, de DL, Harding KB, De-Regil M, Grajeda R. Tackling malnutrition in Latin America and the Caribbean: challenges and opportunities. Rev Panam Salud Publica. 2016;9.

13. Rivera JA, González de Cossío T, Pedraza LS, Aburto TC, Sánchez TG, and Martorell R. Childhood and adolescent overweight and obesity in Latin America: a systematic review. The Lancet Diabetes-Endocrinology 2014; 2: 321-332. http:// www.thelancet.com/pdfs/journals/landia/PIIS2213-8587(13)70173-6.pdf.)

14. Parra DC, Vorkoper S, Kohl HW, Caballero B, Batis C, Jauregui A, et al. Research capacity for childhood obesity prevention in Latin America: an area for growth: Childhood obesity prevention. Obesity Reviews. 2017 Jul;18:39-46.

15. Ng M, Fleming $T$, Robinson $M$ et al. Global, regional, and national prevalence of overweight and obesity in children and adults during 1980-2013: a systematic analysis for the Global Burden of Disease Study 2013. Lancet 2014; 384: 766-781.

16. Published by the Food and Agriculture Organization of the United Nation and the Pan American Health Organization, Santiago de Chile, 2017.

17. Henry F. Obesity prevention: The key to noncommunicable disease prevention and control. http://caribbean.scielo.org/scielo.php?pid=S0043-31442011000400014\&script=sci_arttext\&tlng=en. West Indian Medical Journal, 2011; 60 (4): 446-451.

18. WHO. Global nutrition targets 2025: childhood overweight policy brief (WHO/ NMH/ NHD/14.6). Geneva: World Health Organization; 2014.

19. Caballero B, Vorkoper S, Anand N, Rivera JA. Preventing childhood obesity in Latin America: an agenda for regional research and strategic partnerships: Childhood obesity in Latin America. Obesity Reviews. 2017 Jul;18:3-6. 
20. Su D, Esqueda OA, Li L, Pagan JA. Income inequality and obesity prevalence among OECD countries. J Biosoc Sci. 2012; 44(4):417-32. [PubMed: 22214551]

21. Schlussel MM, Silva AA, Perez-Escamilla R, Kac G. Household food insecurity and excess weight/obesity among Brazilian women and children: a life-course approach. Cad Saude Publica. 2013; 29(2):219-26. [PubMed: 23459802]

22. Kline L, Jones-Smith J, Jaime Miranda J, Pratt M, Reis RS, Rivera JA, et al. A research agenda to guide progress on childhood obesity prevention in Latin America: Child obesity research guide Latin Am. Obesity Reviews. 2017 Jul;18:19-27.

23. Pérez-Escamilla R, Lutter CK, Rabadan-Diehl C, Rubinstein A, Calvillo A, Corvalán $\mathrm{C}$, et al. Prevention of childhood obesity and food policies in Latin America: from research to practice: Obesity research to practice in Latin America. Obesity Reviews. 2017 Jul;18:28-38.

24. Sánchez-Pimienta TG, Batis C, Lutter CK, Rivera JA. Sugar-Sweetened Beverages Are the Main Sources of Added Sugar Intake in the Mexican Population. The Journal of Nutrition. 2016; 146(9): 1888S-1896S. [PubMed: 27511931]

25. Hoehner CM, Ribeiro IC, Parra DC, Reis RS, Azevedo MR, Hino AA, et al. Physical Activity Interventions in Latin America. American Journal of Preventive Medicine. 2013 Mar;44(3):e31-40.

26. Holub CK, Elder JP, Arredondo EM, Barquera S, Eisenberg CM, Sánchez Romero LM, et al. Obesity Control in Latin American and U.S. Latinos. American Journal of Preventive Medicine. 2013 May;44(5):529-37.

27. World Health Organization, Global Database on the Implementation of Nutrition Action (GINA). [Accessed on 15 July 2020]. Available at https://extranet.who.int/ nutrition/gina/en/policies/summary.

28. WHO | Fiscal policies for diet and the prevention of noncommunicable diseases [Internet]. WHO. [cited 2020 July 2020]. Available from: http://www.who. int/ dietphysicalactivity/publications/fiscal-policies-diet-prevention/en/)

29. HCC Brief: A Closer Look, The Implementation of Taxation on Sugar-Sweetened Beverages by the Government of Barbados [Internet]. Healthy Caribbean Coalition. 2016 [cited 12 July 20202]. Available from: http://www.healthycaribbean. org/hcc-brief-taxation-sugar-sweetened-beverages-barbados/)

30. www.healthycaribbean.org > cop > cop-scorecard

31. Commonwealth of Dominica. Excise Tax (Amendment) Order, 2015. [Accessed 12 July 2020]. Available from: https://untobaccocontrol.org/impldb/wp-content/ uploads/reports/dominica_2016_annex6_excise_tax_2015.pdf.

32. Banna J. Obesity Prevention in Children in Latin America Through Interventions Using Technology. American Journal of Lifestyle Medicine. 2019 Mar;13(2):138-41.

33. Schroeder DG, Martorell R, Flores R. Infant and child growth and fatness and fat distribution in Guatemalan adults. Am J Epidemiol. 1999;149(2):177-185.

34. James WP. The epidemiology of obesity: the size of the problem. J Intern Med. 2008;263(4):336-352. 


\section{Capítulo 4}

\section{POLÍTICA DE SEGURIDAD ALIMENTARIA Y NUTRICIONAL EN BRASIL: ENFOQUE EN LA LUCHA CONTRA LA DEFICIENCIA DE MICRONUTRIENTES}

\section{Wendell Costa Bila ${ }^{1}$, Joel Alves Lamounier ${ }^{2}$, Inocencia Palmira Peralta López ${ }^{3}$,}

Ana María Lozano Alemán', Camilo Adauton Mariano da Silva ${ }^{5}$.

${ }^{1}$ Educador Físico. Doctor en Ciencias de la Salud. Profesor de la Facultad PitágorasUnidade Divinópolis, Minas Gerais, Brasil. Profesor de la Universidad UNIFENAS, Brasil.

2 Pediatra. Nutrólogo. Máster en Bioquímica e Inmunología y Doctorado en Salud Pública y Nutrición. Jefe del Departamento de Medicina. Universidad Federal de São João Del Rei, Minas Gerais, Brasil.

${ }^{3}$ Bioquímica. Profesora / Investigadora. Centro Multidisciplinario de Investigaciones Tecnológicas - CEMIT-UMA. Facultad de Ciencias Químicas, Universidad Nacional de Asunción - FCQ, UMA.

${ }^{4}$ Profesora/Investigadora de la Universidad Nacional Autónoma de Honduras, Máster en Salud Publica, Coordinadora Nacional IBFAN Honduras.

${ }^{5}$ Nutricionista. Máster en Demografía y Doctor en Ciencias. Profesor asociado de la Universidad Federal de Ouro Preto, Minas Gerais, Brasil. Ex Coordinador de Investigación, Evaluación y Seguimiento del Centro Colaborador de Alimentación y Nutrición Escolar (CECANE/UFOP/FNDE).

Resumen: $\quad$ En este capítulo se abordan los principales temas relacionados con las deficiencias de micronutrientes, en el contexto de las políticas públicas para combatir el hambre y sus consecuencias para la salud de las poblaciones de América Latina y el Caribe (ALC). Describe las necesidades nutricionales y las consecuencias de la falta o exceso de macro y micronutrientes sobre la salud, especialmente para el crecimiento y desarrollo infantil. Se discute el tema social vinculado a estas deficiencias y su asociación con las desigualdades sociales y la pobreza en América Latina y el Caribe, cuyos países enfrentan importantes violaciones de derechos. Aborda las principales políticas de seguridad alimentaria y nutricional y alimentación saludable de la 
región, además de los programas gubernamentales que trabajan para combatir el hambre.

Palabras clave: Seguridad Alimentaria y Nutricional, Derechos Nutricionales, Acción Integral de Salud.

\section{Introducción}

\section{Macro y Micronutrientes}

Los Macronutrientes son nutrientes que ayudan a proporcionar al organismo la energía necesaria en grandes cantidades. El agua, los carbohidratos, las grasas y las proteínas se clasifican como macronutrientes. Las proteínas son necesarias para el crecimiento, la construcción y la reparación de los tejidos y también están presentes en la constitución de las células. Los carbohidratos evitan que las proteínas de los tejidos se utilicen para el suministro de energía. Las grasas protegen los órganos de lesiones, ayudan a mantener la temperatura corporal, permite la absorción de algunas vitaminas y genera sensación de saciedad ${ }^{1-3}$.

Los micronutrientes son minerales y vitaminas. El organismo necesita menos micronutrientes en comparación con los macronutrientes. Son nutrientes necesarios para la regulación metabólica del organismo, aunque se requieren en pequeñas cantidades, desde miligramos hasta microgramos. Por ser nutrientes esenciales, deben estar presentes en la dieta diaria. Su déficit puede provocar enfermedades o disfunciones y, el exceso, intoxicaciones. Por lo tanto, la dieta debe ser siempre equilibrada y variada ${ }^{1,2}$.

La función principal es facilitar las reacciones químicas que tienen lugar en el organismo. Las vitaminas, por ejemplo, son esenciales para el funcionamiento del metabolismo y la regulación de la función celular. En cuanto a las vitaminas, la vitamina B está presente en las verduras de hoja verde. La vitamina $C$ se encuentra principalmente en los cítricos. Las vitaminas A, D, E y K se encuentran en la leche, los productos lácteos, los aceites vegetales y las verduras de hoja verde. En la categoría de minerales se encuentran el calcio, potasio, hierro, sodio, magnesio, cobre, zinc, cobalto, cromo y flúor. Los micronutrientes son necesarios en todas las etapas y ciclos de vida ${ }^{1,2}$. 
En este capítulo se abordan los principales temas relacionados con las carencias de micronutrientes en la población brasileña, en el contexto de las políticas públicas de lucha contra el hambre y sus consecuencias para la salud de las personas.

\section{Micronutrientes y necesidades nutricionales}

Los minerales más importantes para el hombre, además del hierro, son calcio, fósforo, magnesio, sodio, cloro, potasio, azufre, zinc, yodo, selenio, cobre, manganeso, flúor, cromo, molibdeno y cobalto.

Las deficiencias en estos nutrientes tienen consecuencias para el organismo y pueden, entre otras repercusiones, comprometer el crecimiento y el desarrollo normal ${ }^{2}$. Además, la deficiencia de micronutrientes también causa problemas de déficit de crecimiento en los niños, siendo la más relevantes las deficiencias de vitamina A, C, D, E y minerales como calcio, hierro, magnesio y zinc ${ }^{4}$.

\section{Aspectos epidemiológicos}

Según la FAO, la desnutrición en la población mundial, bajo el aspecto de insuficiencia alimentaria, disminuyó entre 2005 y 2015 y, a partir de entonces, mostró un aumento, volviendo a los valores de 2013. Como consecuencia de esta insuficiencia, la desnutrición proteico-energética (DEP), especialmente en los niños, se ha considerado un importante problema de salud pública en varios países del mundo ${ }^{2-7}$. En Brasil, desde el Estudio Nacional de Gasto Familiar - Endef ${ }^{8}$ hasta la Encuesta de Presupuesto Familiar (POF) 20082009, la desnutrición entre los niños de 5 a 9 años (altura/edad) disminuyó del $29,3 \%$ en $7,2 \%$. En este camino, otro dato importante se refiere a la prevalencia de la deficiencia de micronutrientes en América Latina y el Caribe. Los resultados mostraron que la deficiencia de vitamina A pareció reducirse en varios países, la deficiencia de folato es actualmente casi inexistente y el estado de B12 es deficiente en la mayoría de las regiones. La anemia ferropénica sigue siendo un problema de salud pública para los niños menores de 6 años y las mujeres en edad férti².

Datos recientes publicados por la Encuesta Nacional por Muestra de Hogares (Pnad Continua) del Instituto Brasileño de Geografía y Estadística (IBGE) 5 indican un aumento de la pobreza extrema en el país en alrededor del 11\%, de 2016 a 2017 (13,3 para 14,8 millones de personas). Ese aumento 
de la pobreza extrema puede, sí, reflejarse en el aumento del número de personas que pasan hambre en el país. En Brasil, las cifras indican que, en 2017, más de 5,2 millones de personas pasaron un día o más sin consumir alimentos, lo que corresponde al 2,5\% de la población. Esto nos pone en alerta sobre la posibilidad de que el hambre vuelva a afectar a las familias brasileñas más vulnerables ${ }^{6}$.

En cuanto a las enfermedades asociadas a las deficiencias de micronutrientes, la Encuesta Nacional de Demografía y Salud de Niños y Mujeres, realizada en 20067, reafirmó que las deficiencias de hierro y vitamina $\mathrm{A}$ aún persisten como problemas de salud pública en Brasil, es decir, 17 el $4 \%$ de los niños y el $12,3 \%$ de las mujeres en edad fértil tenían hipovitaminosis A, mientras que el $20,9 \%$ y el $29,4 \%$ de estos grupos de población, respectivamente, tenían anemia ferropénica ${ }^{8}$. Estos hallazgos clasificaron al país según los criterios de la Organización Mundial de la Salud (OMS) de 1996 como un problema de salud pública moderado.

\section{Seguridad y inseguridad alimentaria y nutricional}

La política SAN se entiende como un conjunto de acciones planificadas para garantizar la oferta y el acceso a los alimentos a toda la población, promoviendo la nutrición y la salud. Debe ser una estrategia sustentable, es decir, debe desarrollarse articulando condiciones que permitan su mantenimiento a largo plazo. Requiere la participación tanto del gobierno como de la sociedad civil organizada, en sus diferentes sectores o áreas de acción - salud, educación, trabajo, agricultura, desarrollo social, medio ambiente, entre otros y en diferentes ámbitos (producción, comercialización, control de calidad), acceso y consumo) $)^{9,10}$.

El derecho humano a una alimentación adecuada (DHAA) ha sido reconocido internacionalmente como una prerrogativa fundamental de la persona humana desde 1947. DHAA es el principio fundamental de SAN². Este derecho se viola cuando las personas, grupos o comunidades no tienen acceso a alimentos en cantidad y calidad adecuadas para satisfacer sus necesidades nutricionales, lo que afecta directamente el estado nutricional del individuo ${ }^{11}$.

Para el Consejo Nacional de Seguridad Alimentaria y Nutricional (CONSEA) se pueden detectar situaciones de inseguridad alimentaria y nutricional a partir de diferentes tipos de problemas, como el hambre, la 
obesidad, las enfermedades asociadas a la mala alimentación y el consumo de alimentos de dudosa calidad o nocivo para la salud. La producción de alimentos depredadora en relación con el medio ambiente, los precios abusivos y la imposición de normas alimentarias que no respetan la diversidad cultural son, también causas de inseguridad alimentaria?.

La inseguridad alimentaria está generalmente relacionada con la vulnerabilidad social, y también es el resultado de una combinación de situaciones que influyen negativamente en la calidad de vida, como el desempleo, los ingresos familiares insuficientes, la producción y distribución inadecuada de alimentos, entre otros aspectos ${ }^{10}$.

Inicialmente, en la década del 2000, la situación motivó no solo la construcción de políticas públicas de transferencia de ingresos para combatir el hambre, sino también políticas enfocadas en el fortalecimiento de la soberanía alimentaria, incluyendo el desarrollo de la producción agrícola familiar y su inclusión en el Sistema brasileño de abastecimiento agroalimentario. A pesar de algunos avances, la situación actual aún revela problemas de Seguridad y inseguridad alimentaria y nutricional (SAN) con desafíos relacionados con la elaboración de programas, proyectos y acciones innovadore ${ }^{11}$.

Para promover la SAN por parte de los gobiernos, existen aparatos y estructuras legales materializados en un Sistema Nacional de Seguridad Alimentaria y Nutricional denominado SISAN. A través de este sistema, instituido por la Ley Nacional $N^{\circ}$.11.346/2006, la política de RAS está diseñada para ser operativa en todos los ámbitos de gobierno (Federal, Estatal y Municipal) ${ }^{11}$.

La Comisión Intersectorial de Alimentación y Nutrición es una de las comisiones del Consejo Nacional de Salud (CNS) previstas en la Ley $N^{\circ}$ 8.080/90 y tiene como objetivo monitorear, proponer y evaluar la operacionalización de los lineamientos y prioridades de la Política Nacional de Alimentación y Nutrición (PNAN) y promover la articulación y complementariedad de políticas, programas y acciones de interés para la salud, cuya ejecución involucra áreas no comprendidas en el ámbito específico del Sistema Único de Salud (SUS). La planificación de acciones que garanticen la seguridad y calidad nutricional de los alimentos, controlando y previniendo los riesgos para la salud, está presente en la agenda de promoción de una alimentación adecuada y saludable y la protección de la salud ${ }^{12}$. 
Implementar y utilizar buenas prácticas agrícolas, buenas prácticas de manufactura, buenas prácticas nutricionales y el Sistema de Análisis de Peligros y Puntos Críticos de Control (HACCP), en la cadena de producción de alimentos, potencia y asegura las acciones de protección de la salud del consumidor. El etiquetado nutricional de los alimentos es un instrumento fundamental para mejorar el derecho a la información ${ }^{12}$.

El enfoque de la seguridad alimentaria y nutricional contemporánea permite ampliar el estrecho marco de los programas sociales tradicionales, reconociendo que la población en riesgo puede ser más numerosa que la normalmente identificada. Además, las políticas de seguridad alimentaria y nutricional deben abordar la necesidad de brindar acceso a los alimentos a los grupos inseguros, dadas las dimensiones de cantidad, calidad y regularidad en el consumo de alimentos ${ }^{10}$.

El estudio de Rocha, en 2017, evaluó la anemia e inseguridad alimentaria y nutricional en familias de niños en edad preescolar, así como buscó identificar patrones dietéticos y su relación con la seguridad alimentaria y el estado nutricional, investigando la relación entre inseguridad alimentaria y concentración de hemoglobina en preescolares. Las familias tenían un mayor riesgo de un consumo inadecuado de alimentos, lo que provocaba problemas nutricionales a largo plazo ${ }^{13}$.

La SAN pasó a formar parte de la agenda pública de Brasil, ocupando cada vez más un lugar destacado en los debates y en los programas y acciones intersectoriales. Sin embargo, esto ocurre en un proceso en el que conviven diferentes entendimientos sobre el tema, cada uno con implicaciones específicas para los diseños de investigación, en la definición de indicadores de seguimiento y evaluación y en la construcción de políticas públicas ${ }^{10}$. Así, la institucionalización de la RAS como política nacional, regional y local ha sido uno de los focos de las acciones gubernamentales en los diferentes niveles articulados con la sociedad civil, en la formulación, ejecución, seguimiento y control de sus acciones ${ }^{13}$.

\section{Vigilancia alimentaria y nutricional}

En el sector salud, la Vigilancia Alimentaria y Nutricional (VAN) debe entenderse como el producto de un conjunto de acciones que buscan, en última instancia, el diagnóstico, la promoción de la salud, la prevención y 
rehabilitación de las morbilidades que tienen, directa o indirectamente, relación con la comida, ya sea individual o colectivamente. Así, dentro de este ámbito se incluyen las acciones recomendadas por la OMS, como la Atención Integrada a las Enfermedades de la Infancia (AIEPI) ${ }^{14}$, acciones de seguimiento del crecimiento y desarrollo infanti ${ }^{15,16,17}$, acciones relacionadas con la atención materna ${ }^{12}$ y enfermedades agudas o crónico-degenerativas recomendadas por el Ministerio de Salud para todos los grupos de edad.

La vigilancia alimentaria y nutricional consiste en la descripción y predicción continua de las tendencias en las condiciones alimentarias y nutricionales de la población y sus determinantes ${ }^{12}$. Así, se entiende por actitud de vigilancia el abordaje y posterior intervención en el individuo o comunidad, derivado de la percepción que ha desarrollado el equipo de salud sobre los determinantes y factores involucrados en el estado de salud o nutricional de su población o individuo objetivo. Además de la capacidad de transformar los datos en acciones, anhelos de información que apoyen el diagnóstico y la propia intervención. VAN, por lo tanto, permite brindar datos desagregados para diferentes áreas geográficas, categorías de género, edad, raza/etnia, poblaciones específicas (como pueblos y comunidades indígenas y tradicionales) y otras de interés para una comprensión amplia de la diversidad y dinámica nutricional y de la población brasileña ${ }^{12}$. La actitud de vigilancia presupone la identificación y el reconocimiento de realidades individuales o colectivas.

Subsidiar la planificación de cuidados nutricionales y acciones relacionadas con la promoción de la salud y la alimentación adecuada y saludable y la calidad y regulación de la alimentación, en los ámbitos de gestión del SUS, SISVAN (Sistema de Vigilancia Alimentaria y Nutricional), operado desde VAN, tiene como objetivo principal monitorear el patrón dietético y el estado nutricional de los individuos asistidos por el SUS, en todas las fases del curso de vida ${ }^{12}$, siendo un proceso permanente y regular de recolección, análisis y distribución de la información necesaria para mantener el conocimiento actualizado de la producción, calidad y consumo de alimentos y el estado nutricional de la población, capaz de identificar sus causas y tendencias, predecir sus posibles variaciones y decidir, en su momento, las acciones preventivas o correctivas que el caso requiera. 
También es importante destacar que no le corresponde al sector salud, de manera aislada, resolver problemas alimentarios en los que el origen se ubica en otra esfera de determinación. Generalmente, la prescripción de medicamentos para el tratamiento de las deficiencias de micronutrientes no considera una serie de factores, como la biodisponibilidad, las interacciones entre medicamentos y suplementos vitamínicos, especialmente el acceso a los alimentos y, por tanto, el costo-beneficio de esta práctica. Así, se cuestiona la necesidad real de tales prácticas y, al mismo tiempo, la sustitución de los alimentos como vehículo natural para satisfacer las necesidades nutricionales y alimentarias.

\section{Políticas públicas y programas institucionales}

La alimentación y la nutrición están presentes en la legislación del Estado brasileño, con énfasis en la Ley 8.080, de 19/09/1990, que entiende la alimentación como factor condicionante y determinante de la salud y que deben realizarse las acciones de alimentación y nutrición, de forma transversal a las acciones de salud, de forma complementaria y con formulación, ejecución y evaluación dentro de las actividades y responsabilidades del sistema de salud ${ }^{12}$.

Los nuevos desafíos alimentarios en América Latina y el Caribe tienen en cuenta los nuevos Objetivos de Desarrollo Sostenible (ODS) son, en gran medida, un reflejo de los cambios sociales y económicos vividos en el mundo en los últimos años. En particular, el objetivo de la Agenda 2030 de lograr la seguridad alimentaria y nutricional es exactamente el ODS, en el sentido de acabar con el hambre, lograr la seguridad alimentaria y mejorar la nutrición y promover la agricultura sostenible. Entre las 8 metas y los 15 indicadores, hay 2 metas que hacen referencia directa a la erradicación del hambre y la desnutrición ${ }^{12}$.

Si bien la composición de una dieta saludable depende de las particularidades culturales de cada país o región, existe consenso en que debe contener una combinación equilibrada de macronutrientes, como carbohidratos, proteínas y grasas, y micronutrientes esenciales, como vitaminas y minerales. Esto se reflejó en el establecimiento de guías alimentarias basadas en alimentos (GABA) en la mayoría de los países del 
mundo, que recomiendan el consumo de alimentos frescos como base para una dieta adecuada, incluyendo variedades de cereales, especialmente cereales integrales, hortalizas, frutas y hortalizas. así como alimentos de origen animal ${ }^{18,19}$.

Todas las iniciativas encaminadas a cambiar la dieta, desde el punto de vista del consumo, pasan por aspectos vinculados a políticas que tienen como objetivo incentivar la adopción de dietas saludables, como las acciones proposicionales relacionadas con las pautas dietéticas, educación nutricional, también a través de acciones regulatorias, tales como la definición de estándares para la publicidad de alimentos, el etiquetado de productos alimenticios o la implementación de instrumentos fiscales (impuestos o subsidios) para incentivar la compra de alimentos saludables, o incluso desalentar la compra de productos con alto contenido calórico, azúcar, sal o grasa, según el caso ${ }^{19}$.

Entre estos instrumentos se encuentran las guías alimentarias, basadas en alimentos, que son una de las políticas más utilizadas para promover la alimentación saludable en la región, y que actualmente están presentes en 28 de los 33 países de América Latina y el Caribe, siendo la base para la implementación de políticas que, en este momento, se han concentrado principalmente en los sectores de salud y educación, ante una menor presencia en las políticas de desarrollo agrícola y social. Cabe señalar que, en todo caso, se han considerado guías alimentarias en la elaboración de políticas de seguridad alimentaria y nutricional en Costa Rica, Brasil, Argentina, El Salvador, Belice y Guyana ${ }^{19}$.

Para abordar los efectos negativos de la publicidad de alimentos, algunos países de la región han comenzado a generar leyes y/o normativas para regular la generación de publicidad de alimentos y bebidas no alcohólicas dirigida a los niños. En particular, seis países de la región han establecido, a través de leyes nacionales, la regulación de la publicidad de alimentos, incluido Brasilin.

Con respecto a la política de enriquecimiento de alimentos, sus costos son extraordinariamente bajos, en comparación con los costos sociales de la discapacidad generada por la deficiencia. La estrategia de educación nutricional, que apunta al adecuado consumo cuantitativo y cualitativo de alimentos, fuentes de diversos nutrientes, es una alternativa que tiene bajo 
costo y no produce efectos indeseables.

En Brasil, en 2001, el Ministerio de Salud determinó que la adición de hierro y ácido fólico a la harina de maíz y trigo era obligatoria. La fortificación dejó de ser opcional y pasó a ser obligatoria. Para combatir la deficiencia nutricional se han utilizado diversos tipos de alimentos y también diferentes sales de hierro, como se muestra en el cuadro 1 . También es importante la estrategia de fortificar la alimentación infantil con micronutrientes en polvo y consiste en agregar una mezcla de vitaminas y minerales, envasados en sobre, que se distribuyen en las guarderías participantes del Programa Salud en la Escuela (PSE), cubriendo a todos los niños matriculados, con especial atención al grupo de edad entre los 6 y los 48 meses.

La Ley $N^{\circ} 11.346$, de 15 de septiembre de 2006, conocida como Ley Orgánica de Seguridad Alimentaria y Nutricional (LOSAN), creó el Sistema Nacional de Seguridad Alimentaria y Nutricional (SISAN) y estableció definiciones, principios, lineamientos y objetivos del Sistema. A través del SISAN, los poderes públicos (órganos y entidades de la Unión, los Estados, el Distrito Federal y los Municipios), con la participación de la sociedad civil organizada, deben formular e implementar políticas, planes, programas y acciones con miras a asegurar derecho humano a una alimentación adecuada $^{15}$.

Si bien el ejercicio de DHAA requiere acciones inmediatas en salud y en alimentación y nutrición, estas acciones demuestran la dificultad, durante décadas, de nuestra sociedad para eliminar el hambre oculta. Para un país caracterizado como uno de los principales productores y exportadores de alimentos, la cronificación de las deficiencias nutricionales muestra que el principal problema sigue siendo el acceso físico/financiero al consumo de alimentos. 
Tabla 1 - Fortificación de alimentos con hierro en el Brasil

\begin{tabular}{|c|c|c|c|c|}
\hline Autor / Año & $\begin{array}{l}\text { Vehículo } \\
\text { alimenticio }\end{array}$ & Sal de hierro & $\begin{array}{l}\text { Reducción de } \\
\text { la anemia }\end{array}$ & $\begin{array}{l}\text { Duración } \\
\text { del estudo }\end{array}$ \\
\hline $\begin{array}{l}\text { Nogueira et } \\
\text { al. (1992) }\end{array}$ & Galletas & $\begin{array}{l}\text { Hemoglobina } \\
\text { bovina }\end{array}$ & $75 \%$ para $0 \%$ & 3 meses \\
\hline $\begin{array}{l}\text { Dutra de } \\
\text { Oliveira et al. } \\
(1994)\end{array}$ & Agua & Sulfato ferroso & $58 \%$ para $3 \%$ & 8 meses \\
\hline $\begin{array}{l}\text { Torres et al. } \\
\text { (1995) }\end{array}$ & $\begin{array}{l}\text { Leche en } \\
\text { polvo }\end{array}$ & $\begin{array}{l}\text { Sulfato ferroso } \\
+ \text { vitamina C }\end{array}$ & $\begin{array}{l}66,4 \% \text { para } 20,6 \% \\
72,8 \% \text { para } 18,0 \%\end{array}$ & 6 meses \\
\hline $\begin{array}{l}\text { Torres et al. } \\
\text { (1996) }\end{array}$ & Leche & $\begin{array}{l}\text { aminoácido } \\
\text { quelato de } \\
\text { hierro }\end{array}$ & $62,3 \%$, para $26,4 \%$ & 12 meses \\
\hline $\begin{array}{l}\text { Fisberg ET al. } \\
\text { (1998b) }\end{array}$ & $\begin{array}{l}\text { Galletas y } \\
\text { panes }\end{array}$ & $\begin{array}{l}\text { Aminocolato } \\
\text { de hierro }\end{array}$ & $32 \%$ para $11 \%$ & 2 meses \\
\hline $\begin{array}{l}\text { Ferreira } \\
(2000)\end{array}$ & Leche & $\begin{array}{l}\text { Sulfato ferroso } \\
+ \text { vitamina C }\end{array}$ & $\begin{array}{l}63,24 \% \text { para } \\
33,82 \%\end{array}$ & 6 meses \\
\hline $\begin{array}{l}\text { Giorgini et al. } \\
(2001)\end{array}$ & Panes & $\begin{array}{l}\text { Hierro } \\
\text { quelado }\end{array}$ & $62 \%$ para $22 \%$ & 6 meses \\
\hline $\begin{array}{l}\text { De Paula } \\
\text { e Fisberg } \\
\text { (2001) }\end{array}$ & Azúcar & $\begin{array}{l}\text { Triglicinato de } \\
\text { quelato }\end{array}$ & $\begin{array}{l}38,1 \% \text { para } 19,7 \% \\
29,4 \% \text { para } 19,6 \%\end{array}$ & 6 meses \\
\hline $\begin{array}{l}\text { Tuma et al. } \\
(2003)\end{array}$ & $\begin{array}{l}\text { Harina de } \\
\text { yuca }\end{array}$ & $\begin{array}{l}\text { Aminocolato } \\
\text { de hierro }\end{array}$ & $22,7 \%$ para $8,0 \%$ & 4 meses \\
\hline $\begin{array}{l}\text { Fisberg ET al. } \\
(2003)\end{array}$ & $\begin{array}{l}\text { Frijoles en } \\
\text { polvo }\end{array}$ & $\begin{array}{l}\text { Pirofosfato } \\
\text { férrico }\end{array}$ & $13 \%$ para $0 \%$ & 4 meses \\
\hline $\begin{array}{l}\text { Almeida et } \\
\text { al. (2003) }\end{array}$ & $\begin{array}{l}\text { Jugo de } \\
\text { naranja }\end{array}$ & Sulfato ferroso & $60 \%$ para $20 \%$ & 4 meses \\
\hline $\begin{array}{l}\text { Beinner ET al. } \\
\text { (2005) }\end{array}$ & Agua & Sulfato ferroso & $43,2 \%$ para $21 \%$ & 8 meses \\
\hline $\begin{array}{l}\text { de Almeida } \\
\text { et al. (2005) }\end{array}$ & Agua & $\begin{array}{l}\text { Sulfato ferroso } \\
+ \text { vitamina C }\end{array}$ & $45,9 \%$ para $31,1 \%$ & 6 meses \\
\hline
\end{tabular}

Fuente: Lamounier et al., $2010^{23}$. 
Cabe destacar que, en Brasil, existen acciones integradas como la Estrategia Amamanta e Alimenta Brasil (promoción de la alimentación saludable), el Programa Nacional de Suplementación de Hierro para poblaciones en riesgo, el enriquecimiento de harinas de trigo y maíz y la reciente Estrategia de Fortificación. de Alimentación Infantil con Micronutrientes en Polvo (NutriSUS) para niños en un entorno escolar².

En la última década, se observa que el principal avance fue la incorporación de la alimentación como derecho social. En este sentido, el Estado brasileño, ocupado con la construcción de un nuevo enfoque para actuar en la lucha contra el hambre, la pobreza y en la promoción de una alimentación adecuada y saludable, publicó la Ley 11.346/2006 - Ley Orgánica de Seguridad Alimentaria y Nutricional y el Decreto 7.272/2010 Política Nacional de Seguridad Alimentaria y Nutricional. Tanto la Ley como el Decreto presentan, entre sus bases directivas, el fortalecimiento de las acciones de alimentación y nutrición en el sistema de salud.

Brasil también adopta recomendaciones internacionales, orientando la lactancia materna exclusiva hasta el sexto mes y continuada hasta el segundo año de vida. Según la Encuesta Nacional de Demografía y Salud (PNDS), realizada en 2006, el 95\% de los niños brasileños fueron amamantados alguna vez, pero esta cifra desciende drásticamente durante los dos primeros años de vida ${ }^{12}$.

El alineamiento del gobierno brasileño con las recomendaciones internacionales se intensificó a través de la propuesta, en mayo de 1999, del "Compromiso Social para Reducir la Anemia por Deficiencia de Hierro, culminando posteriormente con el desarrollo de la fortificación de harinas de trigo y maíz. Esta estrategia fue aprobada por el gobierno federal y requería la fortificación con hierro utilizando sulfato ferroso deshidratado, fumarato ferroso, hierro reducido y hierro electrolítico, etilendiaminotetraacético (EDTA) de hierro y sodio y bisglicina quelatada en harinas de maíz y trigo fabricadas o importadas ${ }^{16}$. En este sentido, las acciones de suplementación se vienen realizando desde 1983, pero sufrieron discontinuidad y disrupción entre 1998 y 2000 , debido a la extinción del organismo nacional de gestión. A partir del año 2000, el programa de suplementación se hizo más regular, ampliando su cobertura y perfeccionando los procesos ${ }^{13}$.

En este punto, es importante destacar algunas políticas y programas importantes en el escenario brasileño. 


\section{PNAE}

El Programa Nacional de Alimentación Escolar (PNAE) es el programa social más antiguo del país en el área de Seguridad Alimentaria y Nutricional, caracterizándose, desde sus inicios, por grandes números en cuanto a cobertura poblacional.

El objetivo del PNAE es satisfacer las necesidades nutricionales de los estudiantes durante su estancia en el entorno escolar, contribuyendo a su desarrollo biopsicosocial, aprendizaje y desempeño escolar y promoviendo la construcción de hábitos alimentarios correctos.

\section{PNAN}

La Política Nacional de Alimentación y Nutrición (PNAN), aprobada en 1999, como parte integral de la política nacional de salud, integra los esfuerzos del Estado brasileño que, a través de un conjunto de políticas públicas, se propone respetar, proteger, promover y proporcionar derechos humanos a la salud y la alimentación ${ }^{12}$.

El propósito del PNAN es precisamente garantizar la calidad de los alimentos que se ofrecen para el consumo en el país, la promoción de prácticas de alimentación saludable y la prevención y control de los trastornos nutricionales, así como el impulso de acciones intersectoriales que brinden acceso universal a los alimentos.

En este sentido, la PNAN rescata la vigilancia nutricional como una "actitud" de seguimiento nutricional y alimentario, es decir, nos impone un abordaje epidemiológico proactivo, identificando tanto los factores causales de las enfermedades, como sus tendencias temporales y, así, brindando la propuesta. indicadores de planificación, ejecución y autoevaluación de políticas del sector.

\section{PNSAN}

El Decreto $N^{\circ} 7.272$, de 25 de agosto de 2010, definió los lineamientos y objetivos de la Política Nacional de Seguridad Alimentaria y Nutricional (PNSAN), dispuso sus mecanismos de gestión, financiamiento, seguimiento y evaluación, en el ámbito del SISAN, y estableció los parámetros para la elaboración del Plan Nacional de Seguridad Alimentaria y Nutricional $\left(\right.$ PLANSAN) ${ }^{15}$. Así, la PNAN debe interactuar con la PNSAN y otras políticas 
de desarrollo económico y social, desempeñando un papel importante en la estrategia de desarrollo de las políticas SAN, principalmente en aspectos relacionados con el diagnóstico y vigilancia de la situación alimentaria y nutricional y la promoción de una alimentación adecuada y saludable $e^{12}$.

\section{PNSF}

Hay programas que podemos llamar "medicados" como el Programa Nacional de Suplementación de Hierro (PNSF), el Programa Nacional de Suplementación de Vitamina A (VITA A MAIS), y más recientemente implementado, la Estrategia para fortificar la alimentación infantil con micronutrientes en polvo (NutriSUS) ${ }^{7}$ para combatir las deficiencias de micronutrientes.

De acuerdo con la gravedad del problema y el compromiso que tiene la PNAN de mejorar las condiciones de alimentación, nutrición y salud de la población brasileña, se han establecido acciones de prevención y control de la anemia ferropénica en el ámbito del SUS, como el PNSF, donde se utilizan suplementos de hierro y alimentos como la harina rica en hierro. En este programa, la suplementación profiláctica con sulfato ferroso se ha desarrollado desde 2005, ya que es una medida rentable y eficaz. Está disponible para todos los niños de 6 a 24 meses $^{20}$.

A pesar de todos los esfuerzos, según los datos del PNDS, la anemia todavía tiene una alta prevalencia en la población; lo que indica el bajo impacto logrado por las intervenciones nacionales para el control de la deficiencia de hierro, incluso con mejoras aisladas (BRASIL, 20096).

En Brasil, las políticas públicas innovadoras en el campo de la seguridad alimentaria y nutricional demuestran que, en conjunto con otras políticas, fue posible reducir el hambre y la desnutrición y al mismo tiempo estimular la producción y el consumo de alimentos saludables. Sin embargo, el hambre sigue afectando a muchas personas, y la desnutrición, especialmente la carencia de micronutrientes, y el aumento del sobrepeso y la obesidad, que son cada vez más presentes ${ }^{11}$. Situación paradójica de la transición epidemiológica y nutricional caracterizada en las últimas décadas. Por lo tanto, podemos estar en un país en el que los dos extremos de la desnutrición, desnutrición por carencia y obesidad por exceso, comparten el mismo escenario. Situación denominada paradoja nutricional, típica de la transición nutricional21-23. 
La lucha contra el hambre está justificada, ya que aún existen focos de pobreza con desnutrición. Por otro lado, las familias tienden a incluir en su dieta alimentos ricos en calorías, que generalmente son menos costosos. El problema se puede ver desde el ángulo de la falta de información nutricional, lo que requiere un enfoque en la promoción de la educación y no en la distribución de alimentos. Otro problema es también la cruel distribución de la renta, concentrada mayoritariamente en manos de una pequeña parte de la población. Estos son factores que deben ser considerados en un análisis más profundo del tema nutricional y sus implicaciones para la salud de la población brasileña. Hambre Cero y Obesidad Cero deben ser parte de una misma política que, incluya un programa de educación nutricional y una mejor distribución del ingreso, para que las familias puedan tener un mejor conocimiento y más acceso a alimentos de calidad nutricional adecuada

\section{Referencias}

1. SILVA LSV, THIAPÓ AP, SOUZA GG, et al. Micronutrientes na gestação e lactação. Rev Bras Saúde Matern Infant. 2007; 3:237-44.

2. OMS. Diretriz: Uso de formulações em pó de múltiplos micronutrientes para fortificação caseira de alimentos consumidos por gestantes. Genebra: Organização Mundial da Saúde; 2013.

3. LEME A, ALMEIDA A, RODRIGUES A, et al. Micronutrientes nos primeiros 6 anos de vida. ILSI Brasil. 2019;9.

4. DE SOUZA M, DAS FLORES R, SOARES $P$, et al. Avaliação nutricional e dietética de pré-escolares de Montes Claros, Minas Gerais.

5. IBGE. PNAD. Pesquisa Nacional por Amostra de Domicílios (Pnad Contínua). Instituro Brasileiro de Geografia e Estatística.

6. Plano estadual de Segurança Alimentar e Nutricional Sustentável de Minas Gerais 2018/2019. Belo Horizonte/MG: Câmara Governamental Intersetorial de Minas Gerais - CAISANS; 2018. p. 118.

7. BRASIL. Pesquisa Nacional de Demografia e Saúde da Criança e da Mulher - PNDS 2006: dimensões do processo reprodutivo e da saúde da criança/ Ministério da Saúde, Centro Brasileiro de Análise e Planejamento. Brasília: Ministério da Saúde; 2009. p. 300 p.: il. - (Série G. Estatística e Informação em Saúde).

8. BRASIL. Política Nacional de Alimentação e Nutrição- PNAN. Brasília/DF: Ministério da Saúde. Secretaria de Atenção à Saúde. Departamento de Atenção Básica.Básica; 2013. 
9. TEIXEIRA R. Deficiência de Vitamina A e fatores associados em crianças e adolescentes em dois municípios do semiárido de Minas Gerais [Tese de Doutorado]: Universidade Federal de Minas Gerais; 2010.

10. BONOMO E. Segurança alimentar e perfil de consumo alimentar e antropométrico de escolares e seus fatores associados em dois municípios do semiárido de Minas Gerais: contribuição à política local de segurança alimentar e nutricional [Tese de Doutorado]. Belo Horizonte/MG: Universidade Federal de Minas Gerais; 2010.

11. PIMENTA F. Perfil antropométrico e avaliação da insegurança alimentar de adolescentes de Itinga, Vale do Jequitinhonha, MG. [Dissertação de Mestrado]: Universidade Federal de Ouro Preto. Escola de Nutrição. Programa de Pós Graduação em Saúde e Nutrição; 2018.

12. PEIXOTO M. Segurança Alimentar e Nutricional. Brasília/DF: Senado Federal. Núleo de Estudos e Pesquisas- Consultoria Legislativa- Senado Federal; 2012.

13. ROCHA E. Anemia e Segurança Alimentarem Crianças em Idade Escolar [Tesed de Doutorado]. São Paulo/SP: Universidade de são Paulo; 2017.

14. BENGUIGUI Y. Investigaciones operativas sobre Atención Integrada a las Enfermedades Prevalentes de la Infancia (Aiepi). Washington DC: OPS (Serie HCT/ AIEPI-27.E); 2001.

15. BRASIL. Atendimento à saúde e desenvolvimento da criança: cartão da criança. In: Saúde Md, editor. Brasília: Ministério da Saúde; 1993.

16. BRASIL. Aleitamento materno e orientação alimentar para o desmame. Brasília: Ministério da Saúde; 1994.

17. BRASIL. Saúde da criança: acompanhamento do crescimento e desenvolvimento infantil. Brasília/DF: Ministério da Saúde. Caderno de Atenção Básica; 2002.

18. BRASIL. Assistência pré-natal: manual técnico. Brasília/DF: Ministério da Saúde; 2000.

19. FAO. Panorama da segurança alimentar e Nutricional . sistemas Alimentares sustentáveis para acabar com a fome e a má nutrição. Santiago do Chile: Organização das Nações Unidas para a Alimentação e a Agricultura (FAO) e Organização Pan- Americana da Saúde (OPAS); 2017.

20. BRASIL. Manual de Condutas Gerais. Programa Nacional de Suplementação de Ferro. Brasília/DF: Ministério da Saúde; 2013.

21. LAMOUNIER JA. Transição epidemiológica nutricional em crianças e adolescentes argentinos de áreas carentes. Editorial. Rev Paul Pediatr. 2009;27(2):124-6.

22. BATISTA FILHO M, SOUZA AI, MIGLIOLI TC, et al. Anemia e obesidade: um paradoxo da transição nutricional Brasileira. Cad Saúde Pública. 2008;24 (Sup 2):S247-S57.

23. LAMOUNIER JA, VIEIRA EC, LEAO E. Desnutriçao versus obesidade: o paradoxo nutricional. Rev Med MG. 2004;14(4):215-90. 


\section{Capítulo 5}

\section{POLÍTICAS PARA COMBATIR LA POBREZA INFANTIL EN AMÉRICA LATINA Y EL CARIBE}

\section{Matilde Peguero' ${ }^{1}$, Amarilis Then-Paulino²}

${ }^{1}$ Bioanálista. Maestra y Doctora en Salud, Pública. Docente de la Escuela de Salud Pública de la Universidad Autónoma de Santo Domingo. República Dominicana.

2 Médica. Maestra en Salud Pública. Docente de la Facultad de Ciencias de la Salud; Escuela de Salud Pública, Universidad Autónoma de Santo Domingo. República Dominicana.

Resumen: $\quad$ Los países comprometidos con la mejora de la salud infantil, incluso como un punto fundamental de la reducción de la pobreza, han establecido políticas públicas que, de implementarse, contribuirían en gran medida al bienestar de la niñez y la adolescencia en los países de América Latina y el Caribe. Sin embargo, a pesar de los esfuerzos realizados, muchas de estas políticas solo sirven como tarjeta de presentación en las páginas de gobierno de muchos países, que por diversas razones prefirieron adherirse a la política dictatorial neoliberal de países y gobiernos externos. Este capítulo presenta las principales políticas relacionadas con el marco legal de protección de los derechos de la niñez y la adolescencia. Debido a la limitada disponibilidad de estudios en algunos países de la región, la información para el presente capítulo, casi en su totalidad, fue tomada de documentos disponibles en sitios web relacionados con "Política de salud de Primera Infancia" de los países de América Latina. Los documentos consutados incluyen: descripción de las políticas, inicio de creación, proceso de implementación, así como definición de objetivos y marcos políticos. En general, Guatemala y Haití aparecen como países de alta vulnerabilidad social para la niñez, mientras que Chile es el país con mayor bienestar para la niñez y la adolescencia.

Palabras clave: Pobreza, Políticas públicas; Igualdad de oportunidades; Marginación social. 


\section{Introducción}

La Convención sobre los Derechos del Niño consagra el derecho de toda la niñez al pleno desarrollo de sus potencialidades ${ }^{1}$, por lo que es necesario avanzar en las políticas de desarrollo infantil. De esta forma, existe el compromiso y grandes esfuerzos de todos los países para cumplir con estas políticas. La infancia es un período en el que las personas necesitan especial cuidado y contención, porque es la etapa donde se sientan las bases para el desarrollo de sus capacidades, habilidades y potencialidades. Por lo tanto, el niño/a durante su desarrollo y crecimiento debe contar con un sistema público de protección social adecuado².

Las políticas y los programas equitativos para la primera infancia son cruciales para lograr los Objetivos de Desarrollo Sostenible (ODS). Además, su implementación favorece a que los niños desarrollen habilidades intelectuales, creatividad y el bienestar necesario para convertirse en adultos saludables y productivos ${ }^{3}$. Los niños/as menores de 5 años residentes en países de ingresos bajos están expuestos a múltiples riesgos: pobreza, desnutrición, entornos domésticos inseguros y estimulantes que afectan negativamente su desarrollo cognitivo, motor y socioemocional²; así como su impacto en el desarrollo social y económico en general ${ }^{4}$. Además, existe evidencia neurocientífica que vincula situaciones adversas en la infancia con las deficiencias nutricionales, y con el mal desarrollo de las funciones cerebrales que repercuten a lo largo de la vida5; siendo la aplicación de políticas dirigidas a la primera infancia insuficientes para revertir la situación en gran mayoría de los países de ingresos bajos ${ }^{3}$.

Eliminar los riesgos para el desarrollo integral en la primera infancia, es un desafío que requiere conocer la situación del estado de desarrollo de los niños y niñas en la primera infancia. Es así que el ODS número 1, expresa el compromiso de "Erradicar la pobreza en todas sus formas en todo el mundo"; y su meta 1.1, enfatiza la erradicación de la pobreza extrema para todas las personas en el mundo para 2030; en tanto que la meta 1.2, propone para 2030 reducir a menos de la mitad la proporción de hombres, mujeres y niños de todas las edades en situación de pobreza en todas sus dimensiones. La pobreza extrema es medida por quienes reciben US \$1,25 por día 6 . 
EL ODS 1, hace referencia a un concepto multidimensional de pobreza y menciona explícitamente a los niños como parte fundamental de la población objetivo. Para lograr este objetivo, los gobiernos y la sociedad civil deben considerar la posibilidad de ampliar los programas de desarrollo de la primera infancia, haciendo que estos además sean rentables y de alta calidad ${ }^{7}$. La población infantil es más vulnerable a la pobreza, debido a la alta dependencia de los cuidados por parte de los adultos y por sufrir las mayores consecuencias biopsicosociales derivadas de ella.

El número de niños y adolescentes obesos se ha multiplicado por diez en las últimas cuatro décadas. Las líneas estratégicas de acción, propuestas para ayudar a los países de la región a enfrentar la creciente epidemia de sobrepeso y obesidad son: a) atención primaria de salud; b) promoción de la lactancia materna y la alimentación saludable; c) mejora de los entornos nutricionales y de salud; d) actividad física escolar; e) políticas fiscales; f) regulación de la comercialización y etiquetado de alimentos, entre otras acciones multisectoriales ${ }^{8}$.

\section{Principales políticas para combatir la pobreza infantil en América Latina y el Caribe}

En América Latina, los países comprometidos con la mejora de la salud infantil, incluso como punto fundamental de la reducción de la pobreza, han desarrollado varias iniciativas que, a pesar de establecer metas comunes, varían en alcance y metodología de desarrollo.

Las principales políticas públicas sobre desarrollo infantil fueron compiladas por Aulicino y Langou (2016) y y son las siguientes: Brasil Cariñoso (Brasil); Estancias Infantiles (México), Estrategia Integral de Atención a la Primera Infancia de Cero para Siempre (Colombia), Plan Integral de Atención a la Primera Infancia - PAIPI (Panamá), Plan Nacional de Acción por los Derechos de la Niñez y la Adolescencia (Argentina), Plan Nacional de Desarrollo Integral de la Primera Infancia (Paraguay), Política de Desarrollo Integral de la Niñez (Ecuador), Política Nacional de Educación y Desarrollo Integral de la Primera Infancia (El Salvador), Política Nacional de la Primera Infancia "Amor por los Pequeños” (Nicaragua), Política Pública para el Desarrollo Integral de la Primera Infancia (Guatemala), Política Pública para el Desarrollo Integral 
de la Primera Infancia (Honduras), Quisqueya Empieza Contigo (República Dominicana), Red Nacional de Cuidado y Desarrollo Infantil (Costa Rica), Sistema de Atención Integral a la Niñez y la Adolescencia (Perú), Subsistema de Protección Integral a la Niñez Chile Crece Contigo (Chile) y Uruguay crece contigo (Uruguay).

La implementación de políticas, como estrategia para reducir las inequidades en el desarrollo de la primera infancia, orientadas a atender al niño de manera integrada e intersectorial en esta etapa, aun cuando son implementadas de forma parcial, tienen potencial para reducir las inequidades.

Esta práctica de implementación debe incluir los siguientes mecanismos: a) la coordinación intersectorial en el cumplimiento de las políticas previamente delineadas para la niñez, a través de la red intersectorial de servicios, tales como salud, educación y desarrollo social; b) creación de espacios para la discusión de viabilidad local, la formación de líderes, y para continuar los programas; c) la formación sistemática de los recursos humanos que trabajan en la primera infancia, utilizando metodologías de educación en salud; d) monitorear las acciones políticas con indicadores específicos, indicándose las barreras relacionadas con la organización de sistemas y servicios, además de las ubicadas en el campo de la cultura y las representaciones sociales a nivel de pacientes/individuos tomadores de decisiones, trabajadores de salud, organización de servicios y sistemas de salud. En este contexto serán listadas las políticas que han sido implementadas en los países de América Latina y el Caribe.

\section{Plan Nacional de Acción por los Derechos de los Niños, Niñas y Adolescentes (Argentina)}

El plan en Argentina fue creado en 2012, con el objetivo de generar condiciones para el efectivo cumplimiento de los derechos de la niñez y la adolescencia, en su calidad de ciudadanos a través del desarrollo de políticas públicas integrales, de implementación interinstitucional e intersectorial y con enfoque territorial. El plan buscaba: 1) garantizar los derechos de la niñez y la adolescencia como política de Estado prioritaria; 2) incrementar los grados de igualdad, particularmente territorial y de género; 3) asegurar el acceso a bienes y servicios de igual calidad? 
Argentina ha experimentado algunos avances en la protección de la primera infancia, entre ellos el Salario Familiar Universal por Niño y Embarazo, el Plan SUMAR (cobertura universal de salud), educación preescolar obligatoria a los cuatro años, pasando de 57,3\% (2003) a 86,2 (2013); pero los avances en estas políticas fueron incompletos, debido a la desarticulación entre sectores y niveles de gobierno y las dificultades en la gestión del federalismo argentino, incluyendo las relaciones entre niveles de gobierno con diferentes capacidades técnicas y fiscales ${ }^{10}$. Asimismo, el Centro de Implementación de Políticas Públicas para la Equidad y el Crecimiento (CIPPEC), propuso la construcción institucional para la primera infancia, que incluyó:

a) definición de un organismo vinculado a la presidencia del país, para el seguimiento presupuestario de los organismos ejecutores sectoriales de políticas estratégicas para la primera infancia;

b) elaboración de un pacto federal de políticas e inversiones de primera infancia en los distintos niveles de gobierno;

c) invertir en 2019 el 1,82\% del PIB en salud y nutrición, educación inicial y atención infantil;

d) garantizar mecanismos de gestión en todos los niveles de gestión gubernamental;

e) capacitación continua de los funcionarios públicos sobre el tema ${ }^{11}$.

\section{El Programa Brasil Cariñoso (Brasil)}

El programa Brasil cariñoso, creado en 2011, es un proyecto desarrollado por el Gobierno Federal de Brasil, que compone la Ley $N^{\circ}$ 570, del 14 de mayo de 2012. Está vinculado al Ministerio de Desarrollo Social y representa la transferencia de ingresos para financiar el desarrollo de la educación. Contribuir a las acciones de atención integral, seguridad alimentaria y nutricional, además de asegurar el acceso y permanencia del niño en la educación infantil, para estudiantes de cero a 18 meses, matriculados en guarderías públicas o en alianza con el gobierno, cuyas familias son beneficiarios del Programa Bolsa Familia (BRASIL) ${ }^{12}$. 


\section{Chile Crece Contigo (Chile)}

Es un sistema integral de protección a la niñez, creado desde 2006 y sigue evolucionando. Consiste en el seguimiento y protección integral de todos los niños y niñas más vulnerables de la población y sus familias, a través de acciones y servicios universales, además de un apoyo especial a los más vulnerables. El seguimiento del crecimiento y desarrollo se realiza en el sistema público de salud, de manera personalizada, desde el período prenatal hasta ingresar al sistema escolar en el primer nivel de transición o pre-kindergarten; a partir del año 2016 hubo una expansión gradual hasta los 8 o 9 años, o el final del primer ciclo básico ${ }^{13}$ la política tiene tres líneas de acción:

1. Programa educativo masivo: dirigido a toda la población nacional con el objetivo de generar un entorno social con ambientes familiares y comunitarios favorables a la primera infancia, a través de acciones de sensibilización, promoción y educación.

2. Programa de apoyo al desarrollo del recién nacido: mediante la entrega de elementos prácticos y educativos a las familias atendidas en un establecimiento perteneciente a la Red Asistencial de Servicios de Salud.

3. Beneficios diferenciados para familias en situación de vulnerabilidad. Se continúa implementando la política integral de protección a la niñez y se actualizan los indicadores ${ }^{16}$.

\section{De Cero a Siempre (Colombia)}

Creado en 2012, con la misión de promover y garantizar el desarrollo infantil de la niñez en la primera infancia, a través del trabajo unificado e intersectorial, desde la perspectiva de los derechos. Está dirigido a todos los niños de 0 a 5 años y sus familias. Busca garantizar el cumplimiento de sus derechos, definir una política de calidad a largo plazo, técnica y financieramente sostenible, sensibilizar a la sociedad colombiana y fortalecer el papel de la familia como actor fundamental. Se entiende que el desarrollo integral se centra en las necesidades del niño a partir de cinco elementos estructurales: el cuidado y la crianza; salud, alimentación y nutrición; educa- 
ción inicial; recreación; ejercicio de ciudadanía y participación. Estos cinco ejes estructuradores deben trabajarse en cuatro entornos: hogar, salud, educación y espacios públicos ${ }^{14}$.

\section{Red Nacional de Asistencia y Desarrollo Infantil (RNADI) (Costa Rica)}

Establece el sistema de atención infantil y desarrollo de acceso público universal y financiamiento solidario, que articula las diferentes modalidades de servicios públicos y privados, en el campo del cuidado y desarrollo infantil, para fortalecer y ampliar las alternativas integrales de atención infantil. Los servicios de RNADI son complementarios y no sustituyen a los servicios de educación preescolar que brinda directamente el Ministerio de Educación Pública. Garantiza el derecho de todos los niños de cero a seis años, a participar en el Programa en pos de su desarrollo integral, de acuerdo con las diferentes necesidades y según los diferentes tipos de asistencia que requieren ${ }^{15}$.

El programa RNADI aun durante la pandemia provocada por COVID-19, continúa atendiendo a la población infantil, a través de sus tres unidades ejecutoras: Centros de Educación y Nutrición-Centros Infantiles de Atención Integral (CEN-CINAI). Patronato Nacional de la Infancia (PANI) e Instituto Mixto de Ayuda Social (IMAS); y la articulación con otras instituciones del Estado a través de prestadores de servicios que la integran. Esto permite que se le siga manteniendo el servicio a la población que lo necesita en la modalidad de Cuidado y Protección a la Infancia (API) y el servicio de comidas servidas y distribución de alimentos ${ }^{16}$.

\section{Programa Educa a tu Hijo (Cuba)}

El Programa Educa a tu Hijo busca el desarrollo integral de los niños y el fortalecimiento de la formación personal, cognitiva, física, afectiva y social, para permitir su inserción en el contexto cultural; donde serán reconocidos como sujetos diversos y únicos, desde el nacimiento hasta el ingreso a la escuela. Tiene carácter comunitario e intersectorial y mantiene a la familia como núcleo básico. Busca transmitir conocimientos esenciales a las familias para preparar a sus hijos para el ingreso a la escuela. La concepción de este modelo no institucional, prioriza entre sus objetivos fundamentales la 
formación de sus principales protagonistas, constituyéndose en una modalidad docente equivalente a la realizada por la vía institucional y no como un medio para transmitir contenidos seleccionandos a grupos de población específicos. Por tanto, el sistema de educación inicial en Cuba se caracteriza por ser auspiciado, coordinado y regulado por el Ministerio de Educación a través del subsistema de "educación preescolar" en dos modalidades: institucional y no institucional ${ }^{17}$.

\section{Estrategia Infancia Plena (Ecuador)}

En acción desde 2012, para promover el desarrollo integral de los niños menores de 5 años, considerando que las condiciones de vida, estimulación temprana, educación, alimentación y afectividad en la primera infancia, condicionan el futuro de las personas. La estrategia está alineada con el Plan Nacional del Buen Vivir (2013-2017), y busca reducir las inequidades abordando el punto de partida del proceso de desarrollo humano, desde el momento del embarazo. Así, una educación adecuada de las madres, padres y cuidadores, además de una intervención de calidad y oportuna por parte del Estado y el apoyo comunitario, permitirá la erradicación permanente de la pobreza, fortaleciendo capacidades y generando mayores oportunidades en la población. La Constitución de Ecuador establece el derecho de las personas y de las comunidades al acceso seguro y permanente a alimentos saludables, suficientes y nutritivos; reconoce el derecho de la población a vivir en un entorno sano y ecológicamente equilibrado, que garantice la sostenibilidad y el buen vivir. Afirma que el Estado, la sociedad y la familia promoverán prioritariamente el desarrollo integral de la niñez y la adolescencia y garantizarán el pleno ejercicio de sus derechos, y estos derechos prevalecerán sobre los de otras personas; asume que la educación, con acceso universal, es un deber ineludible e inexcusable del Estado. Los niños menores de seis años tienen la garantía de su alimentación, salud, educación y cuidado diario, en un marco de protección integral de sus derechos, garantizando el derecho a la salud y sus condiciones como el derecho al agua, alimentación, educación, cultura física, trabajo de adultos, seguridad social, ambientes saludables y otros que apoyen el buen vivir $^{18}$. 


\section{Sistema de Protección Social Universal (El Salvador)}

Este es considerado un instrumento de política social basado en el enfoque de derechos humanos que potencia el desarrollo humano de las personas y busca garantizar a todos los ciudadanos, especialmente a la población viviendo en peores condiciones de pobreza y exclusión social. Los componentes del programa son: suministro de uniformes, útiles y calzado, comidas escolares, leche, casa para todos, agricultura familiar, programa de apoyo temporal a la renta, pensión básica universal ${ }^{23}$. A pesar de la perspectiva de buscar el bienestar social, es necesario alinear la oligarquía, las fuerzas armadas, el clero, las intervenciones externas en la economía y la política, así como intereses geopolíticos que han generado graves conflictos políticos y sociales, como han sido guerra civil y profunda crisis social en el país.

\section{Política Pública para el Desarrollo Integral de la Primera Infancia (Guatemala)}

Presenta una política cuyo objetivo es lograr que los hombres y mujeres guatemaltecos, desde el momento que inicia la vida en el vientre de la madre hasta los seis años, disfruten de sus servicios básicos. Promueve la construcción de un sistema que garantice la atención a la salud y el desarrollo integral respetando la diversidad cultural del país. Define las áreas de intervención y establece las acciones según las etapas del ciclo de vida.

A pesar de la información contenida en el sitio web del gobierno, el derecho a la alimentación y la lucha contra el hambre y la pobreza extrema, continúan siendo un desafío para Guatemala que busca alcanzar las metas establecidas en los acuerdos internacionales y garantizar el derecho a la alimentación establecido en su Constitución Federal y que afecta principalmente a la infancia maya. Se requiere participación popular para exigir políticas públicas que contribuyan a avanzar en la lucha por la seguridad alimentaria y a romper la cadena intergeneracional de desnutrición y hambre. Estas políticas deben respetar la cultura del pueblo maya y garantizar las condiciones sociales y de salud adecuadas. Las políticas específicas pueden ser encontradas en: https:// www. siteal.iiep.unesco.org/pt/politicas: Decreto Legislativo número 12 - Ley de Educación Nacional; Decreto número 27 - Ley de Protección Integral de la 
Niñez y Adolescencia (PINA); Plan Estratégico de Educación 2016-2020; Plan de Desarrollo K'atun: Nuestra Guatemala 2032 y el Plan Operativo Anual y Ejercicio Fiscal y Mundial 2021-2025.

\section{Programa de Protección Social (Haití)}

La revisión realizada referente a protección social de los niños y niñas en la primera infancia, en el caso particular de Haití, la información disponible en la web que se encuentran en variados documentos que tratan tema sobre protección y promoción de la salud. También en documentos regionales como son la producción de la CEPAL: Sistemas de protección social en América Latina y el Caribe (2013), así como Promoción y protección social de la infancia y adolescencia en Haití (2014), ambos documentos de la CEPAL ${ }^{21}$. Lo cual limita una descripción mejor detallada sobre la protección social de los niños y niñas en la primera infancia.

\section{Política Pública para el Desarrollo Integral de la Primera Infancia (Honduras)}

El Programa PAIPI fue aprobado en 2012, atiende a todos los niños menores de 6 años y tiene como objetivo promover el cumplimiento de los derechos de la primera infancia, la formación del capital humano del futuro, con foco en los derechos y la corresponsabilidad con este grupo de población. Reconoce que el entorno familiar de un niño es fundamental para el desarrollo de sus capacidades y que la intervención temprana, dirigida a remediar algunas diferencias entre familias, contribuye a reducir la desigualdad ${ }^{23}$.

El plan estratégico del PAIPI 2014-2025 establece la meta de que la primera infancia de Honduras reciba una atención integral, para asegurar el cumplimiento de sus derechos. En el área de salud, asegura que el embarazo y la primera infancia se desarrollen en un ambiente saludable: a) atención materno infantil (capacitación domiciliaria, hogares maternos, atención personalizada durante el parto, vacunación, reducción de la mortalidad infantil, atención odontológica); b) acceso a agua potable y saneamiento; c) atención a la población vulnerable (enfermedades de transmisión sexual, equipos itinerantes multidisciplinarios, coordinación de programas de formación). 
En educación se establecen dos componentes para brindar servicios educativos de calidad: a) educación para educadores de primera infancia (capacitación, documentación y certificación de respaldo, plan de información, educación y comunicación sobre la importancia de la atención integral de la primera infancia); b) calidad y cobertura de la educación inicial (currículo, fortalecimiento institucional y expansión de programas alternativos).

En el área de seguridad alimentaria y nutricional, define dos componentes para asegurar el acceso a una alimentación y nutrición óptimas e inocuas: a) seguridad alimentaria (institucionalizar los patrones de crecimiento de la OPS/OMS, espacio de articulación y coordinación de políticas); b) fortalecimiento institucional (prevención de problemas futuros) ${ }^{24}$.

En el área de protección, se establecen dos componentes para crear las condiciones sociales que contribuyan al bienestar de la primera infancia vulnerable: a) garantía de derechos fundamentales (catastro y Sistema Nacional de Registro de la Primera Infancia - RENPI); b) servicios de protección (acogida comunitaria temporal, centros de atención integral compatibles con horario laboral y protección especial). Finalmente, en el área de recreación y formación de valores, se definen dos componentes para impulsar las condiciones necesarias para desarrollar el ocio, la participación y los valores con el aporte de la familia y la comunidad: a) espacios culturales y recreativos (construcción y mejora); b) formación en valores para familias y trabajadores dedicados al cuidado infantil24.

\section{Programa de apoyo para el bienestar de los Niños y Niñas (México)}

Es un programa de apoyo a madres, padres solteros, tutores o cuidadores primarios que trabajan, buscan empleo o estudian, cuyo ingreso per cápita por hogar no supera la Línea de Seguro Social (LB) y declaran no tener acceso a servicios de cuidado infantil a través de instituciones públicas de seguridad social u otros medios. Se ofrece el valor de $\$ 900$ pesos mexicanos mensuales por cada niño menor de tres años y once meses de edad y $\$ 1,800$ pesos mensuales para los menores de seis años con una necesidad especial (discapacidad) certificada por un médico del servicio público de salud ${ }^{26}$. 


\section{Política Nacional de la Primera Infancia "Amor por los más pequeños" (Nicaragua)}

La política de Nicaragua "Amor por los más Pequeños" fue creada en 2011 con el objetivo de fortalecer las articulaciones interinstitucionales de las acciones que se llevan a cabo en relación con la primera infancia, además de presentar todos los programas dirigidos a este sector de la población. En particular: 1) restablecer los derechos humanos de los niños menores de 6 años, las mujeres embarazadas y las mujeres en período de lactancia, así como promover su pleno desarrollo humano; 2) presentar todos los programas, centros y acciones estatales para que sean universales, gratuitos, de calidad, equitativos, con calidez humana, relevancia cultural y social. La política incluye los siguientes componentes: a) Educación: universalidad de la educación inicial y acceso a centros preescolares y de calidad; b) Salud: completa garantía de salud para el binomio madre- hijo (salud prenatal, parto y recién nacido), con servicios especializados y promoción de la salud preventiva; c) Estimulación temprana: consolidar la organización municipal y comunitaria a través de la formación de promotores solidarios para llegar a las familias. Fortalecer el rol de la familia basado en un modelo de crianza responsable; d) Identidad: registro de niños y niñas y promoción de su autoestima y participación; e) Seguridad alimentaria: reducción del déficit nutricional de los niños menores de 6 años, promoción de la lactancia materna, garantía de disponibilidad de alimentos; f) Prevención de la violencia infantil: atención a las víctimas y sanciones a los agresores: programas socioeducativos y atención integral; g) Restricción de derechos: protección de niños en situación de riesgo en la calle, hijos de madres y padres con problemas de adicciones, adolescentes, migrantes, infractores y privados de libertad, niños con una necesidad especial (con discapacidad), viviendo con VIH o SIDA y niños indígenas; $h$ ) Hogares seguros: garantizando el derecho a una vivienda digna y segura ${ }^{26}$.

\section{El Plan Integral de Atención a la Primera Infancia (PAIPI) - (Panamá)}

Iniciado en 2011, para facilitar la adopción de políticas públicas dirigidas a la primera infancia de Panamá. Incluye programas y líneas de acción que 
aseguran el desarrollo integral de niños y niñas de 0 a 6 meses de edad, en la búsqueda de las siguientes estrategias: 1 ) establecer una perpectiva estratégica que coloque a los niños y niñas como centro; 2 ) establecer e implementar estándares de calidad en la atención integral de la primera infancia en su contexto; 3) asegurar atención oportuna pertinente e integral; 4) maximizar la efectividad de los recursos técnicos y económicos invertidos; 5) fortalecer las capacidades de las instituciones para responder de forma efectiva y sustentable al desafío de dar atención integral a la primera infancia; 6) facilitar el fortalecimiento del contexto familiar para que pueda atender integralmente a los niños y niñas de 0 a 6 años, de forma equilibrada, comprometida e informada; 7) fomentar el fortalecimiento comunitario que asegure a niños y niñas de 0 a 6 años para que puedan desarrollarse en un ambiente seguro, que les permita tener acceso a servicios básicos, institucionales y recreativos que faciliten su desarrollo integral ${ }^{27}$.

\section{El Plan Nacional de Desarrollo Integral de la Primera Infancia (Paraguay)}

Creado en 2011, para ser implementado hasta 2020 con el apoyo de UNICEF, con el fin de consolidar políticas públicas a favor de la primera infancia del país (definida hasta los 8 años) en todos los niveles de gobierno, junto con familias, comunidades, organizaciones, sociedad civil y cooperación internacional. El plan busca: a) elevar la calidad de vida de la primera infancia asegurando el pleno acceso a los servicios de salud y nutrición, la documentación necesaria y el ingreso y permanencia en el sistema educativo; b) proteger e incluir a los niños en situación de vulnerabilidad social promoviendo plenamente sus derechos; c) brindar la protección jurídica necesaria para la primera infancia, mediante la articulación de todas las instituciones responsables; d) generar conciencia, a partir de acciones de comunicación y visibilidad. El Plan creó la Comisión Nacional de la Primera Infancia (CONPI), que es el órgano gestor, junto con las comisiones departamentales y municipales de la primera infancia, de los Consejos de la Niñez y la Adolescencia, dentro del Sistema Nacional de Protección y Promoción Integral de la Infancia y Adolescencia ${ }^{28}$. 


\section{Sistema de Atención Integral a la Niñez y la Adolescencia SNAINA (Perú)}

Creado en 1995 y entró en vigencia en 1996 mediante la Ley N26.518, en cumplimiento del Código de la Niñez y la Adolescencia, con el propósito de orientar, integrar, estructurar, coordinar, supervisar y evaluar políticas, planes, programas y acciones a nivel nacional, destinado a la atención integral de la niñez y la adolescencia. En 2002 se lanzó el Plan Nacional de Acción para la Niñez y la Adolescencia 2002-2010, como un documento histórico de las políticas públicas nacionales a favor de la niñez y la adolescencia ${ }^{29}$.

\section{Quisqueya Empieza Contigo (República Dominicana)}

Creado en 2013 con el objetivo de establecer un sistema integral de protección y atención a la primera infancia, buscando organizar, articular, integrar y regular la oferta de servicios en el país, así como ampliar la oferta de cobertura y calidad a través de un conjunto de servicios. Estrategias de atención integral a los niños de 0 a 5 años, sus familias y comunidades. La política tiene ocho líneas de acción: 1) educación inicial; 2) salud y nutrición; 3) detección y atención temprana de necesidades educativas especiales y discapacidad; 4) protección contra el abuso y la violencia; 5) registro de nacimiento e identidad; 6) participación familiar y comunitaria; 7) sensibilización y movilización a favor de la primera infancia; y 8) formación de recursos humanos. Como parte de los objetivos del Plan, se previó un aumento considerable de la cobertura de servicios para la primera infancia a través de los programas: 1) Programa de Centros de Atención Integral a la Primera Infancia (Estancia Infantil), que se ejecuta directamente desde las dependencias gubernamentales. Estos son centros que ofrecen servicios de educación, salud y nutrición a niños desde los 45 días de vida hasta los 4 años y 11 meses; 2) Programa Integral de Atención a la Primera Infancia Familiar y Comunitaria (Centros Comunitarios), que se implementa con la gestión de las organizaciones de la sociedad civil. El programa consta de cuatro estrategias para su implementación: 1) formación de familias en Educación Oportuna (estimulación temprana); 2) atención integral a los niños de 3 y 4 años; 3) atención integral en el hogar; y 4) formación de las familias a través de una red organizada y articulada de prestación de servicios ${ }^{26}$. 


\section{Uruguay Crece Contigo UCC (Uruguay)}

Creado en 2012 con el objetivo de consolidar un sistema de protección integral de la primera infancia a través de una política que garantice la adecuada atención y protección a la mujer embarazada y el desarrollo integral de los niños menores de 4 años, desde la perspectiva de los derechos. Combina acciones focalizadas y universales. Incluye las siguientes acciones: a) acciones socioeducativas: campañas mediáticas, pack de bienvenida (material educativo y didáctico que se entrega a todos los hospitales públicos y privados participantes del país y las familias participantes; b) generación de conocimiento: realización de la encuesta nacional salud, nutrición y desarrollo infantil, convenio con la Universidad de la República para investigar temas prioritarios de la UCC y evaluación externa; c) fortalecimiento de capacidades institucionales: apoyo técnico para la revisión de estándares y criterios de atención en salud y para la construcción de un proyecto curricular común para la educación inicial de niños de 0 a 6 años, contratando 30 recursos humanos para fortalecer egresados en control del embarazo y nutrición, fortalecimiento de sistemas de información; d) apoyo familiar y trabajo cercano: fortalecer las capacidades de las familias para el desarrollo de buenas prácticas parentales, a través del trabajo en los hogares más vulnerables, realizado por 211 técnicos del área social y de salud. Los Equipos Técnicos de Proximidad (ETC) monitorean a las familias con gestantes y niños menores de 4 años que presentan una situación de riesgo biológico y social ${ }^{30}$.

\section{Conclusión}

La revisión documental muestra que la gran mayoría de los países latinoamericanos han estado luchando por definir políticas dirigidas a la primera infancia, con el lanzamiento de planes integrales, o servicios masivos dirigidos a esta población. Sin embargo, aún existen importantes desafíos para que las iniciativas para garantizar el derecho de la niñez en materia de salud, se traduzcan en mejoras concretas en la situación de los más pequeños, permitiendo así el disfrute del derecho de todos los niños al pleno desarrollo de sus potencialidades. 
Entre los desafíos a enfrentar se encuentra la falta de articulación de las políticas de primera infancia con las demás políticas implementadas. De esta forma se entiende que los gobiernos de los países que forma a Latinoamérica deben deben impulsar iniciativas que evidencien un rol más integrador en la sociedad, así también que actúe como articulador en el sistema evitando duplicación de esfuerzos en servicios, a la vez que garanticen mejor uso de los recursos. Ganar la batalla contra la pobreza infantil debe ser considerado como un desafío para los países a fin de lograr eficiencias económicas y poder alcanzar cobertura universal de los programas implementados. Esto se hace necesario en parte debido a que discapacidades sufridas en la infancia pueden repercutir a lo largo de su vida, expresándose en pérdida de oportunidades en la formación integral del niño o niña con limitado acceso a la escuela, lo que a su vez que contribuye a la perpetuación de la pobreza en la región.

\section{Referencias}

1. Abud S. Infancia, niñez en riesgo, vulnerabilidad infantil, ¿Qué reflejan estos conceptos? Derecho y Soc. 2018;1:51-62.

2. Infancia-UNICEF FDLNUP La convención sobre los derechos del niño.

3. Black PMM, Walker PSP, Fernald LCH, Andersen CT, Digirolamo AM, Lu C, et al. HHS Public Access. 2018;389(10064):77-90.

4. Grantham-McGregor S, Cheung YB, Cueto S, Glewwe P, Richter LSB. International Child Development Steering Group. Developmental potential in the first 5 years for children in developing countries. Lancet. 2007;369(9555):60-70.

5. Children G, Walker SP, Chang SM, Wright A, Osmond C, Grantham-mcgregor SM. Early Childhood Stunting Is Associated with Lower Developmental Levels in the Subsequent. 2015.

6. Lu C, Black MM, Richter LM. HHS Public Access. 2018;4(12).

7. PNUD. Apoyo del PNUD a la implementación del Objetivo de Desarrollo Sostenible 13. 2016;1-16. Disponible en: file:///C:/Users/user/Downloads/SDG_1_ Spanish.pdf.

8. Engle PL, Black MM, Behrman JR, Cabral de Mello M, Gertler PJ, Kapiriri L, Martorell R YM. International Child Development Steering Group. Strategies to avoid the loss of developmental potential in more than 200 million children in the developing world. Lancet. 2007;369(9557):229-42.

9. OPAS/Brasil. Determinantes Sociais e Riscos para a Saúde, Doenças Crônicas Não Transmissíveis e Saúde Mental [Internet]. 2020 [citado 24 de agosto de 
2020]. Disponible en: hhttps://www.paho.org/bra/index.php?option=com_ content\&view=articlectid=5957:no-brasil-paises-das-americas-definem-proximospassos-para-o-enfrentamento-da-epidemia-de-obesidade- infantil\&ltemid=839.

10. Aulicino C, Documento L. Políticas públicas de desenvolvimento infantil en América Latina. Levantamento e análise de experiências. 2016.

11. Ministerio da Saude. Síntese de evidências para políticas de saúde: promovendo o desenvolvimento na primeira infância / Ministério da Saúde, Secretaria de Ciência, Tecnologia e Insumos Estratégicos, Departamento de Ciência e Tecnologia. 2016.

12. Educacao TP. Plano nacional da ação pelos direitos das crianças e adolescentes [Internet]. [citado 24 de agosto de 2020]. Disponible en: https://www. todospelaeducacao.org.br/primeirainfancia/pais_argentina.html.

13. Gobierno de México. Programa de Estancias para Apoyar a Madres Trabajadoras [Internet]. 2016 [citado 24 de agosto de 2020]. Disponible en: https://www.gob. $\mathrm{mx} /$ bienestar/acciones-y-programas/estancias-infantiles-para-apoyar-a-madrestrabajadoras.

14. Dipres. Sistema de Protección Integral a la Infancia2020 [Internet]. [citado 24 de agosto de 2020]. Disponible en: http://www.dipres.gob.cl/597/w3multipropertyvalues-24543-25190.html

15. Presidencia de la República de Costa Rica PI. Equidad para la primera infancia, De cero a Siempre [Internet]. 2012. Disponible en: http://www.deceroasiempre. gov.co/Prensa/CDocumentacionDocs/Equidad-Primera-Infancia.pdf.

16. REDCUDI. Red Nacional de Cuido y Desarrollo Infantil [Internet]. [citado 24 de agosto de 2020]. Disponible en: https://redcuidoinfantil.go.cr/.

17. Latina A de PI para A. Plan de atención integral a la primera infancia - PAIPI [Internet]. Experiencias de los Países. 2015 [citado 24 de agosto de 2020]. Disponible en: https://www.todospelaeducacao.org.br/primeirainfancia/espais_panama.html.

18. Gobierno de Ecuador. Estrategia Nacional Intersectorial para la primera infanciainfancia plena [Internet]. [citado 24 de agosto de 2020]. Disponible en: https:// www.todaunavida.gob.ec/primera-infancia/.

19. Latina A de PI para A. Política pública de desarrollo integral de la primera infancia Guatemala [Internet]. 2016 [citado 24 de agosto de 2020]. Disponible en: https:// siteal.iiep.unesco.org/pt/bdnp/309/politica-publica-desarrollo-integral-primerainfancia-guatemala-invierte-desarrollo.

20. UNESCO. Políticas y regulaciones [Internet]. [citado 24 de agosto de 2020]. Disponible en: https://siteal.iiep.unesco.org/pt/politicas?pais=8cteje=2.

21. Lamaute-brisson NC. Sistema de Protección Social en América Latina y el Caribe, Haití [Internet]. 2013. Disponible en: https://repositorio.cepal.org/bitstream/ handle/11362/4050/1/S2013067_es.pdf.

22. CEPAL. Fortalecimiento de la protección social de Haití [Internet]. 2015 [citado 24 de agosto de 2020]. Disponible en: https://www.cepal.org/pt-br/noticias/discutenfortalecimiento-del-sistema-de-proteccion-social-de-haiti-en-conferencia-enpuerto. 
23. Honduras G de la R de. Ricardo Cardona [Internet]. Segunda. Tegucigalpa; 2015. 19-25 p. Disponible en: https://ceniss.gob.hn/PoliticasPublicas/PAIPI.pdf.

24. UNESCO/HONDURAS. Política pública para el Desarrollo Integral de la Primera Infancia. 2018; Disponible en: https://siteal.iiep.unesco.org/sites/default/files/ sit_accion_files/hn_0307.pdf

25. Brasil G de. Brasil cariñoso [Internet]. Fondo Nacional de Desarrollo Educativo. 2016 [citado 25 de agosto de 2020]. Disponible en: https://www.fnde.gov.br/index. php/programas/brasil-carinhoso/sobre-o-plano-ou-programa/sobre-o-brasilcarinhoso.

26. El Diálogo, Fundación María Cecilia, Todos por la educación R. política nacional de primera infancia «amor para los más chiquitos y chiquitas» Nicaragua [Internet]. 2016 [citado 25 de agosto de 2020]. Disponible en: https://www. todospelaeducacao.org.br/primeirainfancia/es-paises.html.

27. UNESCO/SITIAL/PANAMÁ. Plan de Atención Integral de la Primera Infancia, PAIPI [Internet]. 2018 [citado 27 de agosto de 2020]. Disponible en: https://siteal.iiep. unesco.org/sites/default/files/sit_accion_files/siteal_panama_0067.pdf.

28. Paraguay M de E y C. Plan nacional de atención integral [Internet]. Paraguay; 2011. Disponible en: https://www.unicef.org/paraguay/media/1756/file/resumenprimera-infancia.pdf.

29. Cisneros SP, Social D. Sistema Nacional de Atención Integral al Niño y al Adolescente - SNAINA Plan Nacional de Acción por la Infancia y Adolescencia PNAIA 2002 - 2010 Visión : [Internet]. 2008. Disponible en: https://www2.congreso. gob.pe/Sicr/Comisiones/2007/ComRevNinAdo.nsf/34069c3bb71c123b05256f47 0062fea7/200F3DC04DE2CA7405257466007BC363/\$FILE/SNAINA-PNAIA.pdf.

30. Social M de D. Uruguay Crece Contigo. Disponible en: https://www.gub.uy/ ministerio-desarrollo-social/uruguay-crece-contigo-ucc. 


\section{Capítulo 6}

\section{POLÍTICAAS PÚBLICAS DE NUTRICIÓN EN AMÉRICA LATINA Y EL CARIBE: REFLEXIONESSOCIALESYANTROPOLÓGICAS}

\section{María Elena Díaz Sánchez ${ }^{1}$}

${ }^{1}$ Antropóloga. Doctora en Ciencias de la Salud y Postgrado en Antropología Sociocultural y Gestión de la Información. Investigador titula y jefe del Laboratorio de Antropología Nutricional del Centro de Nutrición e Higiene de los Alimentos del Instituto Nacional de Higiene, Epidemiología y Microbiología de La Habana y profesor de la Universidad Médica de La Habana.

Resumen: $\quad$ Este capítulo discute el tema de las políticas públicas en el contexto de la Nutrición para la Región de América Latina y el Caribe desde una perspectiva antropológica, brindando herramientas metodológicas y teóricas para explorar el significado de las políticas, sus implicaciones culturales desde una perspectiva holística. Se discuten los obstáculos para la formulación de políticas públicas que contemplen procesos sociales, prácticas culturales, aplicadas a situaciones de conflicto con base en los fundamentos del estudio antropológico, en el lenguaje y discursos de los formuladores de políticas, ecos del régimen socioeconómico imperante y los impactos en la sociedad victimizada por la política neoliberal exigida por los dominadores, reforzando la crisis económica, política y social en la Región, aumentando la pobreza, el hambre y la desnutrición, con el incremento del sobrepeso y la obesidad de forma alarmante, además de la deficiencia de micronutrientes. Llama la atención sobre la existencia de normas, aspectos legales, acuerdos y garantías sobre derechos sociales que los programas deben considerar y no violar, pero que no siempre se cumplen, permitiendo la permanencia de la inseguridad alimentaria de la niñez en América Latina y el Caribe.

Palabras clave: Alimentación infantil;; Políticas de salud; Antropología cultural. 
Cuando nos encaminamos a discursar sobre el tema de las políticas públicas en el contexto de la Nutrición para la Región de América Latina y El Caribe con una mirada antropológica, es relevante considerar algunas precisiones.

La formulación de la política pública en la actualidad ha devenido en una actividad sumida en procesos sociales, prácticas culturales, aplicada a situaciones en conflicto; esto implica decisiones, acciones, acuerdos, instrumentos con la participación de las autoridades y otros actores sociales para prevenir o solucionar un problema. Se ha declarado en la literatura que, si este trabajo de formulación de políticas se define como prácticas socioculturales y formas organizacionales para generarlas, ya estamos en las bases del estudio antropológico ${ }^{1,2}$.

A La respuesta a diversos cuestionamientos sobre el análisis de una política pública realizado por Shore ${ }^{1}$ conlleva la consideración de su objeto de estudio, las acciones que genera, los contextos institucionales y socioculturales en que se implementan, el lenguaje y discurso que utilizan los hacedores, las decisiones que se toman, las reglas que origina, el impacto que tienen sobre los beneficiarios y la forma en que estos responden. Ese autor nos reafirma que la Antropología proporciona aproximaciones propias sobre el estudio de las políticas públicas, en las cuales además de los elementos conceptuales y de carácter metodológico, que ayudan a comprender su funcionamiento y proveen una comprensión crítica de los procesos que estructuran a la sociedad, están los regímenes de poder y sus relaciones con otros actores sociales, por citar algunos, los funcionarios, administrativos, facilitadores y sobre todo, el último eslabón de la cadena, que son los sujetos a quienes se dirigirán las acciones políticas. Ante tal pluralidad de situaciones se pueden identificar brechas de las descripciones de las políticas entre personas externas al proceso, tales como académicos y analistas con los participantes que las diseñan, además del impacto que estos contrastes pueden crear en las personas que la reciben.

Pero las políticas reflejan concepciones del mundo, que son ecos del régimen socioeconómico imperante y representado por los estados; por ejemplo, en la mayoría de los países de América Latina y El Caribe se sigue una línea neoliberal en el desarrollo de sus políticas sociales. Por lo tanto, al constituirse las políticas como herramientas de intervención y acción social 
pueden imponer su orden, ya que dentro de sus funciones está legitimar las decisiones tomadas por la autoridad administrativa máxima, que es el aparato estatal, se ejerce entonces una voluntad política, de acuerdo a visiones e intereses y se relaciona con la complejidad cultural en la que está inmersa la sociedad civil, pero no siempre son exitosas. Estas estrategias dependen de la inestabilidad del ciclo político de los países, por lo que su proyección puede ser temporal y declinar.

Los abordajes antropológicos permiten analizar la racionalidad de las políticas públicas, que son prácticas culturales situadas, atravesadas por actores sociales como el Estado, agencias humanitarias, Banco Mundial, Naciones Unidas, sociedad civil, etc. y en su diseño se manifiestan relaciones de poder, pero su fin es tratar de resolver una problemática social.

Según Huerta ${ }^{3}$ el proceso político se distingue por su ámbito público, el logro de sus metas y un poder diferenciado. De acuerdo con este planteamiento, el poder se encuentra en una relación que logra obediencia de la otra parte interactuante, pero con una solicitud de obligaciones posteriores y en este sentido, constituye un medio simbólico que legitima lo gubernamental ${ }^{4}$ Hay aquí una relación donde el sector que se empodera tiene el control de los recursos económicos y busca el dominio de lo social y lo simbólico ${ }^{5}$, sobre la población silenciada, articulándose un discurso hegemónico y en esta interacción los sujetos asumen identidades colectivas ${ }^{2}$. Por eso el análisis de las políticas públicas, requiere el acercamiento antropológico, etnográfico, multisituado para comprender los diferentes puntos de vista de los actores involucrados en su relación, desde una mirada global (Estado vs poblaciones), o local, con la interpretación de la comunidad, lo que permite percibir la complejidad de estos procesos.

La antropología en una de sus líneas de trabajo se ocupa del estudio de categorías de complejidad sociocultural, que son de utilidad para analizar las políticas públicas que desarrollan los Estados con otros actores sociales y que estas funcionen con efectividad para los beneficiarios que las requieren. La antropología constituye así un instrumento de aplicación, desde la visión académica y desde la práctica, que puede contribuir con sus métodos de trabajo a las estrategias organizativas y de evaluación de impacto, entre otras, en la misión del Estado e instituciones humanitarias para la ejecución de las políticas públicas, dirigidas a los ciudadanos. 
El estado es una institución generada por personas, que tiene dentro de sus funciones administrar, priorizar y distribuir recursos, definir e implementar políticas sociales, que sean dirigidas a mejorar el nivel de vida de la población vulnerada, que en términos de derechos humanos le corresponde estar protegida y en este accionar se crean nuevas categorías para describir a las personas (por ejemplo: ciudadano, campesino, escolar, desplazado, mujer, etc.).

La antropología provee herramientas metodológicas y teóricas para explorar el significado de las políticas, sus implicaciones culturales desde una visión holística; puede ayudar en la implementación de estrategias, comprobando si las acciones beneficiarían real y directamente a los grupos de ciudadanos de mayor vulnerabilidad con un enfoque de derechos, respetando sus creencias e imaginarios sociales; pero aun en una etapa anterior, puede contribuir en el análisis de la construcción de la política en sí (si es procedente o no), las dificultades de su aplicación, las características de los actores directos encargados de su implementación, en cuanto a la honestidad, efectividad de sus funciones y el liderazgo como facilitadores, entre otros aspectos importantes para su desarrollo.

Finalmente se puede afirmar que las diversas técnicas antropológicas, basadas en la investigación cualitativa ${ }^{6}$ están preparadas también para evaluar el impacto de las intervenciones, a partir de los planes y programas que generan las políticas, mediante un trabajo interpretativo que puede ser realizado sobre las encuestas, entrevistas, grupos de discusión, estudios de casos y en algunas ocasiones, a dependencia del tipo de acciones desarrolladas, es posible también una valoración física o antropométrica de los individuos.

Una antigua crítica a la aproximación antropológica ha sido la limitación de los trabajos en áreas o comunidades puntuales, aunque proporcionan una mayor riqueza del conocimiento de la complejidad sociocultural. Sin embargo, desde hace ya bastante tiempo se reconoce en estos espacios la etnografía "multilocal"7 que implica la aplicación de los estudios en diferentes lugares, zonas o pueblos, aportando más información a sobre una temática en particular, con instrumentos menos extensos para el trabajo de campo.

Esos elementos planteados contribuyen a saber, junto con aspectos que pueden ser de índole económico, jurídico, entre otros, si determinada política pública cumplió el cometido para el cual fue concebida y en el caso contrario, 
permitirían orientar cuales serían las modificaciones o nuevas líneas de trabajo a realizar. En otras palabras, obtendríamos un saber colectivo como retroalimentación de una o determinadas políticas públicas aplicadas a una población o poblaciones meta, por lo que es muy importante saber con certeza el argumento de esas personas que tienen sus derechos humanos y ciudadanos vulnerados.

Dentro de las políticas públicas desarrolladas en los países de América Latina y El Caribe, las relacionadas con la alimentación y nutrición han sido muy frecuentes, por el gran problema de la inseguridad alimentaria existente, provocado por el acceso desigual a los alimentos, sobre todo entre las poblaciones más empobrecidas.

Lo anterior se ha ido produciendo desde el siglo pasado en el contexto de acuerdos y cambios neoliberales de los gobiernos que tienen este modelo, paralelamente a las dificultades en el mercado laboral, con la caída de los salarios, la desocupación, entre otras muchas situaciones. Estas políticas en América Latina se conocen bien, porque se replicaron en diferentes países de la Región y aparecen publicadas en diversos reportes ${ }^{8,11}$.

Las políticas alimentarias son consideradas, como asistenciales por sus objetivos, criterios de elección y segmentación de la población beneficiaria ${ }^{10}$ Esta conceptualización en su adaptación a los tiempos modernos está basada, como señalaron Soldano y Adrenacci ${ }^{12}$ en que la política asistencial ha entregado bienes y servicios a una parte de la sociedad que no integró el mercado laboral, o que su situación irregular no satisfacía las necesidades básicas de la vida en sociedades de mercado. Otros enfoques tienen que ver con las relaciones hegemónicas de poder, haciéndose cada vez más tangibles las desigualdades sociales.

En el desarrollo de la política pública, también en el plano de la alimentación, desde el Estado o con el enfoque sectorial se impone un conjunto de decisiones, conflictos o situaciones de los diversos actores en su complejidad que hay que analizar; por otra parte, existen además normas, aspectos jurídicos, pactos y garantías en torno a los derechos sociales que los programas deben considerar y no violentar, por lo que no es suficiente que se firmen acuerdos en relación a los derechos, sino que se cumplan. Los vínculos entre la política pública y el derecho no son claros y por eso no necesariamente se diseñan conforme a Adrenacci ${ }^{12}$. En cuanto 
a las necesidades alimentarias, a pesar de que constituyen un factor de supervivencia, no siempre las políticas profundizan para obtener un resultado positivo, a fin de satisfacer las carencias de los grupos sociales con más precariedad, violentándose así el enfoque de derecho.

En América Latina inicialmente se desarrollaron programas nacionales de asistencia alimentaria, como medidas compensatorias en contextos de carencia, acompañadas por políticas de inclusión social, relacionadas con los ingresos, trabajo asalariado, educación, salud y otras, destacándose posteriormente algunos países por abastecimiento y donaciones de productos alimentarios, subsidios, así como intervenciones directas de programas de alimentación complementaria, suplementación y educación en aspectos de nutrición, dirigidas a los más vulnerables, no siempre bien seleccionados. El paso hacia otras estrategias con programas más selectivos de complementación y suplementación favoreció una implementación de corto plazo, beneficiosa para los ejecutores de las políticas respecto a los costos, pero de difícil medición del impacto, sin monitoreo y evaluación, prevaleciendo en sectores urbanos ${ }^{10}$ también se prestó atención a la vigilancia nutricional en la Región.

Otro aspecto muy importante discutido fue la falta de racionalidad en las gestiones organizativas de las prestaciones en territorios con escenarios de diferente gravedad y la existencia a la vez de una gran cantidad de programas en funcionamiento; dada la complejidad de las situaciones alimentarias los expertos han planteado que los programas asistenciales, que generan un marco para la mejoría, se tornaron en asistencialistas, relacionados a esquemas de continuidad y mantenimiento de la desigualdad ${ }^{13}$ En el decurso de los eventos en la Región fueron aumentando esas intervenciones alimentarias de carácter asistencial, hasta convertirse en el espacio de acción estatal por excelencia, frente a otros sectores como el agroalimentario.

Por su parte, el derecho a los alimentos se encuentra reflejado en la Declaración Universal de los Derechos Humanos ${ }^{14}$ y el Estado como garante de ellos en la población debe cumplimentar esta máxima, pero el neoliberalismo existente en la mayoría de los países de América Latina y El Caribe limita la función estatal a asegurar el desarrollo del libre mercado, sin realizar acciones que generen un beneficio global a la ciudadanía. Con ello se ha reforzado la crisis económica, política y social de la Región, aumentó 
la pobreza, el hambre y la desnutrición, con una elevación del sobrepeso y la obesidad en formas alarmantes, manifestándose además estados carenciales de micronutrientes.

No se ha atendido la necesidad de una universalidad de las acciones para asumir el derecho que las personas tienen a una alimentación adecuada en términos de cultura y nutrición. Son graves las violaciones y están lejos de ser vencidas; estas ocurren durante la cadena del proceso alimentario, que incluye la producción y obtención de alimentos de la naturaleza, transformación, intercambio, consumo y nutrición ${ }^{15}$ teniendo un impacto en las relaciones sociales y el entorno.

El papel de las agencias de Naciones Unidas y otras organizaciones no gubernamentales (ONG) se ha visto representado en la implementación de programas de ayuda humanitaria ${ }^{16}$ que han servido para palear, entre otras, las situaciones de crisis alimentaria, pero de ningún modo resuelven el problema.

La desfavorable situación social por la que transita la Región se reconoce a partir de múltiples informes técnicos, administrativos y publicaciones científicas ${ }^{17,18,19}$.

Diversos reportes relatan la evolución de la problemática alimentarionutricional de la región, a través de las confirmaciones obtenidas por los programas de asistencia alimentaria ${ }^{15,20,21}$. En los últimos tiempos se reitera que el hambre y la desnutrición han cobrado un alto impacto en la calidad de vida de la población, se han elevado los costos sanitarios, sociales, económicos y hay fuertes evidencias de una doble carga de malnutrición.

Aunque se ha reportado una rápida disminución de las prevalencias del retardo del crecimiento y la desnutrición actual en los niños, las cifras alcanzadas pueden enmascarar las inequidades en los países de la Región ${ }^{22}$. Los datos actualizados en el observatorio de nutrición de la Organización Mundial de la Salud (OMS) para niños menores de 5 años confirman este planteamiento (retardo del crecimiento, año 2020: 6,3\% [3,7-10,0]; desnutrición, año 2019: 0,8\% [0,5-1,4]), subrayándose también los valores destacados del sobrepeso en estas edades (año 2019: 7,3\% [6,1-8,7]). De igual forma se indica que las Américas es ya considerada la región con más sobrepeso y obesidad del mundo, con una prevalencia en los mayores de 18 años de 63,4\% [61,365,3 ] para el sobrepeso (año 2016) y casi una de cada 3 personas con obesidad 
(año 2016: 29,0\% [27,1-31,0]). La anemia (datos del año 2016) está presente en el $19,1 \%$ [13,9-26,5] de las mujeres con edad reproductiva y en los niños pequeños alcanza valores de $22,7 \%$ [16,8-30,1], todo esto acompañado del incremento de enfermedades crónicas no transmisibles ${ }^{23}$.

Para revertir este escenario se necesita una transformación de los Sistemas Alimentarios hacia otros modelos sustentables que aseguren una adecuada nutrición; para esto se deben formular políticas públicas alimentarias, donde el Estado y los otros actores sociales garanticen la Seguridad Alimentaria y el bienestar nutricional en todas las edades y grupos de ciudadanos.

En los regímenes económicos-políticos actuales que imperan en la Región, los alimentos, antes de cumplir su papel en la satisfacción de las necesidades de la población, se intuyen como mercancía, tienen un precio y son consumidos mientras exista una capacidad de compra. Si no hay posibilidades para los individuos identificados como consumidores, existe entonces una brecha que hay que saldar, no con intervenciones alimentarias asistencialistas, sino con una transformación profunda intersectorial de los Sistemas Alimentarios; realmente éstos son los responsables de proporcionar alimentos a la población, incrementando la disponibilidad, el acceso y el consumo, con diversidad en la dieta, segura y culturalmente apropiada.

El modelo neoliberal imperante en muchos países de la Región considera un sistema alimentario de tipo corporativista, con intereses y métodos de gestión económica encaminados a ejercer una estrategia de despojo, con cambios culturales y de consumo en función de un empoderamiento de las corporaciones que monopolizan toda la cadena alimentaria, restringiendo las alternativas de pequeños productores y consumidores ${ }^{15}$. Por otra parte, se insiste en que el campesinado tiene prácticas productivas obsoletas, imponiendo el uso de semillas certificadas en vez de las originarias, su pensamiento modernizador encamina a la destrucción de la agricultura tradicional. Recomiendan así globalizar los gustos y el consumo, manifiestan el control al difundir por diferentes vías la comida chatarra estableciendo una competencia con respecto a las comidas tradicionales. A pesar de la innegable problemática alimentaria actual defienden el libre mercado como fuente de la riqueza y el progreso. Ese sistema alimentario corporativo interviene en las decisiones acerca de la producción, transformación y consumo de los alimentos, reduciendo la capacidad de los otros actores sociales que 
deberían participar en esas disposiciones; en su accionar también ganan la participación multilateral de agencias de cooperación y organizaciones regionales, al constituirse en donadores financieros.

En esta situación tan compleja tiene lugar el abuso de consumo de alimentos ultraprocesados, pobres en nutrientes, pero altos en azúcar, sal o grasas ${ }^{25,25}$, que se asocian al incremento de las enfermedades crónicas no transmisibles, con énfasis en la obesidad.

Al contextualizar asistencia alimentaria, mediante políticas públicas en distintos países de la Región en la lucha contra la pobreza, en el marco de un enfoque de derechos, y ya desde el siglo pasado, se invoca a la Seguridad Alimentaria en los acuerdos, reglamentaciones, convenios para implementar los programas ${ }^{10}$ y se han publicado evidencias de la situación, planificación y resultados al respecto, con diferentes perspectivas de análisis ${ }^{26-30}$.

El concepto de Seguridad Alimentaria ha sufrido muchos cambios ${ }^{31}$; planteándose que algunas de estas modificaciones han dificultado acciones concretas de las políticas alimentarias. La consolidación conceptual que ha venido ocurriendo es una consecuencia del recrudecimiento de la problemática presentada en el orbe; ha evolucionado de una manera holística y con mayor rigor debido a su utilización en disímiles escenarios, con la contribución de los diferentes actores vinculados al proceso, podemos citar, entre otros, a los gobiernos, la sociedad civil, la investigación científica y también han sido relevantes las agencias multinacionales. En este avatar de situaciones se han ido identificando los factores que inciden en la inseguridad alimentaria presente en el mundo contemporáneo.

La mayoría de las definiciones de la Seguridad Alimentaria contienen como objetivo primordial el logro de una vida saludable y activa, que permita el desarrollo integral de las personas y sociedades. En este sentido, se invoca un enfoque de derechos al plantearse que las personas deban tener un acceso físico, social yeconómico permanente a una alimentación segura, nutritiva y en cantidad suficiente para satisfacer sus necesidades nutricionales y poder desarrollar una vida activa y saludable, (publicado en documentos de la FAO, 2011) (2 $^{32}$ Relacionado a este marco conceptual, en las políticas de Seguridad Alimentaria se tocan aspectos macro y microeconómicos en tres ejes, que involucran a la disponibilidad y acceso a los alimentos, consumo, aprovechamiento y utilización biológica de los mismos, así como la de calidad e inocuidad. 
En este sentido vale apuntar los argumentos del foro ONG durante la Cumbre Mundial sobre la Alimentación del 2002. En los documentos disponibles de esa reunión ${ }^{33}$ se aprecia el rechazo por los movimientos sociales a los problemas no resueltos en la eliminación del hambre y el fallo de las políticas aplicadas en los países; se expuso abiertamente la monopolización y concentración desenfrenadas de recursos y procesos productivos en manos de unas pocas empresas de grandes proporciones, así como el aumento de la productividad a corto plazo utilizando organismos modificados genéticamente, entre otros planteamientos, razones por las cuales se acrecentó la inseguridad alimentaria.

En ese escenario se abogó por la Soberanía Alimentaria, por la primacía del derecho de las personas y las comunidades hacia los alimentos, con el apoyo y la promoción de los mercados y productores locales con respecto a la producción para la importación y exportación de los alimentos. Es decir, cuando la sociedad como un todo participe en la formulación de las políticas y estrategias que garanticen el sistema alimentario (producción, transformación, elaboración, distribución, preparación, comercialización y consumo de los alimentos) en la dimensión temporal y espacial correspondiente, según contextos socioeconómicos y culturales específicos.

La Soberanía Alimentaria muestra una conceptualización más amplia al incluir una posición de derechos dentro de su enunciado, considerar las prácticas culturales de los ciudadanos y respetar el entorno, tomándose como marco estratégico de diferentes movimientos sociales; fue desarrollada por la Vía Campesina (LVC), discutida durante la Cumbre de la FAO de 1996 y posteriormente fue modificándose hasta la Declaración de Nyéléni en el foro de Soberanía Alimentaria del $2007^{34}$ Así la definición declara el derecho de pueblos de obtener alimentos sanos y culturalmente apropiados producidos mediante métodos ecológicos y sustentables, así como de definir sus propios Sistemas Alimentarios y agrícolas.

Se han señalado aspectos comunes entre Seguridad Alimentaria y Soberanía Alimentaria, pero también perspectivas diferentes entre sistemas agroalimentarios con marcos alternativos, siendo estos contrastes relativos las visiones epistémicas correspondientes a cada definición ${ }^{35}$ Desde estas aproximaciones es que plantean que la Seguridad Alimentaria se relaciona con la agronomía y ciencias naturales, concentrando el conocimiento a 
nivel individual o doméstico para identificar cultivos considerados eficientes según contenido nutricional, condiciones y costos de producción, pero esta participación local es aminorada oficialmente por los modos de producción con el conocimiento técnico, tras los adelantos agrícolas, semillas mejoradas, nuevos productos, etc.

Por su parte, la Soberanía Alimentaria la asocian más a la ecología y ciencias sociales, tiende a suscitar una visión multidisciplinaria de los sistemas agrícolas, que se complementa con el nivel local, considerando métodos de cultivo, la producción campesina, hábitos y preferencias alimentarias; propone cambios en los patrones de consumo, transportación y procesamiento y otros, con el fin de mejorar los procesos agrícolas, defender la pequeña y mediana agricultura, en contraposición con la industria.

Las estimaciones más actualizadas de la FAO en el período 2012-2014 indican que 37 millones de personas padecen hambre en América Latina, 15\% menos que en trienio 1990-1992, pero la situación está lejos de ser controlada, no obstante haberse reducido a la mitad, en correspondencia con la meta establecida por los Objetivos de Desarrollo del Milenio (ODM). Para revertir esta situación se propuso el desarrollo de diversas políticas públicas de gran impacto sobre las poblaciones más vulnerables, afirmándose que en la Región existen alimentos suficientes para cubrir las necesidades, pero se dificulta el acceso a los mismos ${ }^{36}$.

La Agenda 2030 para el Desarrollo Sostenible propone un límite de 15 años para eliminar la pobreza y el hambre, para lo cual se convoca a todos los países a trabajar coordinadamente en conjunto y eliminar las causas que mantienen a las personas en condición de inseguridad alimentaria y malnutrición, con el compromiso de la FAO en el acompañamiento de las acciones ${ }^{37}$.

Para entender la repercusión de los Sistemas Alimentarios a nivel del diseño e implementación de políticas, programas, monitoreo y evaluación, la gobernanza y soporte financiero, se plantea la necesidad de una mayor información sobre las intervenciones que fomentan el bienestar nutricional, así como estudios multisectoriales de estilos de vida saludables; con esos propósitos se consideraron datos de 33 países miembros de la CELAC ${ }^{21}$ Del análisis de intervenciones se observó la promoción y uso de alimentos nutritivos, empleo de guías alimentaria, diversidad de la dieta, cultura culinaria 
tradicional, etiquetado nutricional y regulación de publicidad de alimentos ultraprocesados; igualmente se identificaron actividades de beneficio directo a la población (entrega periódica de alimentos, transferencias de dinero, educación nutricional, etc.), actividades para garantizar el funcionamiento del programa (comités técnicos, capacitaciones, monitoreo, supervisión, evaluación del estado nutricional, etc.) y actividades de fortalecimiento de programas (vinculación entre programas, gestión de políticas públicas, rescate de tradiciones, empoderamiento de ciudadanos, etc.).

Estos resultados permiten avizorar que los países de América Latina y el Caribe están trabajando para promover comportamientos alimentarios más adecuados, a la vez que han ido ampliando sus políticas públicas, por lo que existe una potencialidad para para mejorar el bienestar nutricional, a pesar de las cargas de malnutrición combinadas existentes.

En cuanto a políticas públicas para mejorar el bienestar nutricional en la infancia, aunque persisten varias formas de malnutrición ${ }^{38}$ en la actualidad se hace énfasis en el sobrepeso y la obesidad ${ }^{39}$ por el incremento de las prevalencias en la Región ${ }^{23}$ con un enfoque multisectorial que combine el consumo de alimentos saludables, la actividad física y la disminución del tiempo en pantalla por abuso de productos informáticos, limitación de la publicidad y otros factores negativos del Entorno Alimentario, que caractericen el ambiente obesogénico en que se desarrolla.

Para que las políticas públicas en el combate contra la obesidad sean efectivas, por ejemplo, en la etapa escolar y la adolescencia, debemos estudiar las percepciones y representaciones de los niños y sus familiares sobre el problema en su imaginario colectivo; la intervención educativa sobre los alimentos y nutrición es esencial, dentro del enfoque de derechos, acompañada de existencia y legitimidad de productos saludables para el consumo. Pero evaluar el impacto sobre el crecimiento y estado nutricional a corto, mediano y largo plazo mediante el monitoreo contribuirá a mostrar el éxito de los programas. El estudio de la complejidad cultural de la familia es importante en el abordaje de las políticas públicas de nutrición en la infancia, para promover prácticas alimentarias seguras a punto de partida de guías alimentarias y en los primeros 1.000 días de la vida, impulsar la lactancia materna exclusiva. Desde una perspectiva hegemónica, la infancia constituye la transición hacia la adultez y exige un modelo familiar; es una 
etapa de gran plasticidad por el crecimiento y desarrollo, donde se inculcan hábitos, costumbres, en resumen, estilos de vida con los que evolucionará el individuo hacia un resultado final ya más difícil de transformar.

En los momentos actuales, el azote de la pandemia de COVID-19 está repercutiendo en los sistemas alimentarios, se manifiestan interrupciones en el proceso productivo, que afecta la distribución y el acceso a los alimentos. A largo plazo la seguridad alimentaria tendrá un impacto de enormes proporciones, que se sentirá en los países más perjudicados por las crisis, los marginados y vulnerados ${ }^{40}$. Se compromete así el cumplimiento de la meta para el 2030, por lo que se propone trabajar fuertemente en la movilización de los gobiernos, la sociedad civil y otros actores sociales para formular políticas públicas adecuadas, que fomenten la Seguridad Alimentaria.

\section{Referencias}

1. Shore C. La antropología y el estudio de la política pública: Reflexiones sobre la "formulación" de las políticas. Antípoda 2010;10 (enero-junio):21-49.

2. Ramírez, MC. La antropología de la política pública. Antípoda 2010;10 (enerojunio):13-17.

3. Huerta MG. Procesos interculturales y construcciones sociales: apuntes para una antropología de las políticas públicas. Iberoamérica Social: revista-red de estudios sociales, 2016; VI, pp. 118 -134. [citado 16 de mayo 2020]; Disponible en http://iberoamericasocial.com/procesos-interculturales-construcciones-socialesapuntes-una-antropologia-las-politicas-publicas

4. Swartz M, Turner $V$, Tuden, A. Antropología política: una introducción. Alteridades, 1994;4(8):101-126.

5. Huerta MG. Los múltiples sentidos de las políticas públicas. Una propuesta etnográfica para su análisis, VII Jornadas Santiago Wallace de Investigación en Antropología Social. Sección de Antropología Social. Instituto de Ciencias Antropológicas. Facultad de Filosofía y Letras, UBA, Buenos Aires, 2013. [citado 29 de mayo 2020]; Disponible en: https://www.aacademica.org/000-063/219.

6. Fick, U. Introducción a la Investigación Cualitativa. 3ra Ed. Madrid: Ediciones Morata. 2012.

7. Marcus G. Ethnography in/of the World System: The Emergence of Multi-sited Ethnography", Ann Rev Anthropol 1995;24:95-117.

8. Barquera S, Rivera-Dommarco J, Gasca-García A. Políticas y programas de alimentación y nutrición en México. Salud Publica Mex 2001;43:464-77. 
9. Vivero Pol JL, Ramírez P. Leyes, políticas e instituciones contra el hambre en el contexto latinoamericano. En: Vivero JL, Erazo J, editores. Derecho a la Alimentación, Políticas Públicas e Instituciones contra el Hambre. Santiago: Ediciones LOM; 2009. p. 123-171.

10. Sartasiero LH. Las políticas sociales en el caso de la satisfacción de necesidades alimentarias. Trabajo y Sociedad 2012;159-176.

11. Pereyra I. Políticas públicas em Uruguay y la autonomía de las personas, Rev. Cubana Salud Púb. 2019;45(1):e1238.

12. Soldano D, Andrenacci L. Aproximación a las teorías de la política social a partir del caso argentino. En: Andrenacci L (compilador). Problemas de política social en la Argentina contemporánea. Buenos Aires: Editorial Prometeo. 2005. p. 21-89.

13. Álvarez, S. Los discursos minimistas sobre las necesidades básicas y los umbrales de ciudadanía como reproductores de la pobreza. En: Álvarez, Sonia (Compilador.) Trabajo y producción de la pobreza en Latinoamérica y el Caribe: estructuras, discursos y actores. Buenos Aires: CLACSO; 2005. p. 239-273.

14. Naciones Unidas. Declaración universal de los derechos humanos. Naciones Unidas. [Actualización 2020; citado 15 de junio 2020]; Disponible en: https://www. un.org/es/udhrbook/.

15. Morales González JC, Salcedo Fidalgo H, Medina Bernal JL, Rodríguez Navarro SA, Romero Niño IP, Holguín Reyes P. Perspectivas sobre Derecho a la Alimentación y Nutrición Adecuadas. Colombia, FIAN. Año 1, Número 1, 2018. 111p.

16. Martínez-Mauri M. Una mirada antropológica a las Organizaciones no gubernamentales. En: Antropología Social. Algunos debates actuales. Editorial UCO. 2010; 141-202.

17. Martínez R, Palma A, Atalah E, Pinheiro AC. Inseguridad alimentaria y nutricional en América Latina y el Caribe. Comisión Económica para América Latina y el Caribe (CEPAL). Programa Mundial de Alimentos (PMA). Naciones Unidas. 2009.

18. Jiménez-Benítez D, Rodríguez-Martín A, Jiménez-Rodríguez R. Análisis de determinantes sociales de la desnutrición en Latinoamérica. Nutr Hosp 2010; 25(Supl 3):18-25.

19. Comisión Económica para América Latina y el Caribe (CEPAL), "Ruralidad, hambre y pobreza en América Latina y el Caribe", Documentos de Proyectos (LC) TS.2018/119), Santiago, 2018. 65p.

20. González M, Pasarin L, Malpeli A, Políticas sociales de alimentación. X Jornadas de Sociología. Facultad de Ciencias Sociales, Universidad de Buenos Aires, Buenos Aires, 2013. [citado 13 de junio 2018]; Disponible en: http://www.aacademica. org/000-038/498.

21. Molina Barrera V, Mejicano Robles G, Alfaro Villatoro N, Rivas Siliézar RM, Hernández-Garbanzo Y, Rapallo Fernández R, et al. Intervenciones de Fomento al Bienestar Nutricional en América Latina y el Caribe: oportunidades para fortalecer las políticas y programas de alimentación y nutrición. Rev Esp Nutr Comunitaria 2018;24(4):1-16. 
22. Grajeda R, Hassell T, Ashby-Mitchell K, Uauy R, Nilson E. Regional Overview on the Double Burden of Malnutrition and Examples of Program and Policy Responses: Latin America and the Caribbean. Ann Nutr \& Metab 2019; 75:139-143. DOI: 10.1159/000503674.

23. WHO Global Health Observatory data repository. Global and regional trends by WHO Regions, 1990-2025 [updated 2020; [cited 2020 Jun 27]; Available from https://apps.who.int/gho/data/view.main.

24. Pan American Health Organization. Ultraprocessed food and drink products in Latin America: Trends, impact of obesity, policy implications. Washington: PAHO. 2015.

25. Ezzahra Housni F, Magaña González CR, Macías Macías A, Aguilera Cervantes VG, Bracamontes del Toro H. La Antropología Nutricional y el estudio de la dieta. Actualización en Nutrición 2016;17(3):87-93.

26. Zamora Valdés $P$, Rodríguez Oisiac L, Pinheiro Fernandes $A$, Ivanovic Willumsen AC, Cofre Sasso C, Pizarro Quevedo T. Política Nacional de Alimentación y Nutrición. Ministerio de Salud. Santiago. Chile. 2017.

27. CEPAL (Comisión Económica para América Latina y el Caribe), CAC/SICA (Consejo Agropecuario Centroamericano del Sistema de la Integración Centroamericana) y SIECA (Sistema de Integración Económica de Centroamérica). Seguridad alimentaria y nutricional en Centroamérica y la República Dominicana: Explorando los retos con una perspectiva sistémica, LC/MEX/TS.2017/29, Ciudad de México. 2017. 185p.

28. Leavy MP, Szulc AP, Anzelin I. Niñez indígena y desnutrición. Análisis antropológico comparativo de la implementación de programas alimentarios en Colombia y Argentina. Cuadernos de Antropología Social 2018; 48:39-54.

29. Sistema de información de tendencias educativas en América Latina (SITEAL). Política de Seguridad Alimentaria y Nutricional 2011-2021. [Actualización 2018; citado 21 de junio, 2020]; Disponible en: www.siteal.iiep.unesco.org.

30. FAO, OPS, WFP y UNICEF. Panorama de la seguridad alimentaria y nutricional en América Latina y el Caribe 2019. Santiago. 135p.

31. Cárcamo Mallen RW, Álvarez Macías A. La Seguridad Alimentaria y las Políticas Públicas. Una visión conceptual. Sociedades Rurales. Producción y Medio Ambiente 2014;14(27):97-126.

32. Organización de Naciones Unidas para la Agricultura y la Alimentación. La Seguridad Alimentaria: Información para la toma de decisiones. 2011. [citado 26 de junio 2020]; Disponible en: http://www.fao.org/docrep/ 014/al936s/al936s00.pdf.

33. Organización de Naciones Unidas para la Agricultura y la Alimentación. Cumbre Mundial sobre la alimentación. Anexo III. FAO, junio 2002. [citado 28 de junio 2020]; Disponible en: http://www.fao.org/3/Y7106s/Y7106S02. htm\#P516_72987.

34. Nyéléni Forum. Declaración de Nyéléni 2007. [citado 29 de junio, 2020]; Disponible en: https://nyeleni.org/spip.php?article291. 
35. Waldmueller JM, Rodríguez Avalos L. La soberanía alimentaria más allá de la técnica: Una aproximación global hacia su monitoreo intercultural. Rev Centro Andino Est Internacionales 2015;15:253-286.

36. Organización de Naciones Unidas para la Agricultura y la Alimentación. Seguridad alimentaria y nutricional en América Latina y el Caribe. 2020. [Actualización 2020; citado 27 de junio 2020]; Disponible en: http://www.fao.org/americas/ prioridades/ seguridad-alimentaria/es/

37. Naciones Unidas (UN). Objetivos de Desarrollo Sostenibles 2015. Agenda 2030 para el Desarrollo Sostenible. [citado 29 de junio 2020]; Disponible en: https:// www. un.org/sustainabledevelopment/es/development-agenda/.

38. Programa Mundial de Alimentos (PMA). Política em materia de Nutrición. Tema 4. Primer período de sesión extraordinaria de la Junta Ejecutiva directiva. Roma, 20- 23 de febrero, 2017.

39. Araneda J, Pinheiro AC, Rodríguez L. Una mirada actualizada sobre los Ambientes Alimentarios y obesidad. Rev Chil Salud Pública 2020;24(1): 67-71.

40. Johnsen JT, Buckner L, Ray S. Knowledge synthesis and translation in global food and nutrition security to evaluate and accelerate priority actions. bmjnph 2020; 0:1- 2. doi:10.1136/bmjnph-2020-000104. 


\section{Capítulo 7}

\section{MORTALIDAD INFANTIL EN AMÉRICA LATINA Y EL CARIBE: INTERFAZ CON LAS POLITICAS PÚBLICAS Y SOCIALES}

Maressa Cristiane Malini de Lima'; Janine Pereira da Silva², Eugenia de las Mercedes Aguilar Lema ${ }^{3}$, Faride E. Rodríguez Díaz ${ }^{4}$, Helder Gomes ${ }^{5}$, Valmin Ramos-Silva

${ }^{1}$ Doctora en Genética y Biología Molecular de la Universidad Estadual de Londrina (UEL). Docente del Programa de Post Grado en Políticas Públicas y Desarrollo Local de la Escuela Superior de Ciencias de la Santa Casa de Misericórdia de Vitória (EMESCAM). E-mail: maressa.lima@emescam.br.

2 Doctora en Ciencias de la Salud - Área de concentración Salud infantil y adolescente, de la Universidad Federal de Minas Gerais (UFMG). Docente del Programa de Post Grado en Políticas Públicas y Desarrollo Local de la Escuela Superior de Ciencias da Santa Casa de Misericórdia de Vitória (EMESCAM). E-mail: janine.silva@emescam.br

3 Doctora en Medicina y Cirugía de la Universidad Central del Ecuador, Diplomado Superior en Políticas de Salud y Género, de la Facultad Latino Americana de Ciencias Sociales (FLACSO); Diplomado Superior en Salud y Nutrición Humana, del Instituto de Post Grado de la Universidad Central del Ecuador. E-mail: euge28051204@gmail.com.

${ }^{4}$ Nutricionista-Dietista e Investigadora en el Instituto Conmemorativo Gorgas de Estudios de la Salud. Magister en Salud Publica con Énfasis en Epidemiologia. Docente en la Facultad de Medicina de la Universidad de Panamá. E-mail: faridesther@ hotmail.com, frodriguez@gorgas.gob.pa

${ }^{5}$ Economista. Magíster en Ciencias Económicas. Doctora en Políticas Sociales. Postdoctorado en Políticas Sociales. Universidad Federal de Espirito Santo. Profesor del Programa de Postgrado en Políticas Públicas y Desarrollo Local de la Escuela de Ciencias Santa Casa de Misericórdia de Vitória (EMESCAM). Correo electrónico: helder.gomes@emescam.br

${ }^{6}$ Doctor en Ciencias de la Salud - Área de concentración Pediatria de la Universidad Federal de Minas Gerais (UFMG). Docente del Programa de Post Grado en Políticas Públicas y Desarrollo Local de la Escuela Superior de Ciencias de la Santa Casa de Misericórdia de Vitória (EMESCAM). E-mail: valmin.silva@emescam.br

Resumen:

Introducción. La mortalidad infantil, representada por el número de muertes en menores de un año, por mil nacidos vivos, es un indicador social que refleja y refleja a nivel global, las condiciones de vida y salud, vinculadas a la situación socioeconómica de un país. Objetivo: describir la evolución de la mortalidad infantil en América Latina y el Caribe durante los últimos 18 años. Método: Consultas a bases de datos latinoa- 
mericanas, seguidas de la organización y análisis descriptivo de los datos. Resultados: Cuba es un país que siempre ha tenido tasas de mortalidad infantil mucho más bajas que las recomendadas por la OMS, mientras que Haití, aunque ha reducido las tasas en más del $50 \%$ a lo largo de los años, aún se mantiene con tasas extremadamente altas. Conclusión: Se percibe que las políticas neoliberales implementadas en América Latina contribuyeron al aumento de la pobreza y al empeoramiento de las condiciones de vida de la población. Los países que recurrieron al FMI tienen el peor desempeño en el indicador de mortalidad infantil.

Palabras clave: Mortalidad Infantil; Políticas Públicas de Salud; América Latina.

\section{Introducción}

La tasa de mortalidad infantil es un indicador social representado por el "número de muertes de niños menores de un año, por mil nacidos vivos, en un espacio geográfico determinado, en el año considerado", que se utiliza para "analizar las variaciones geográficas y temporales de la mortalidad infantil; contribuir a la evaluación de los niveles de salud y desarrollo socioeconómico de la población y apoyar los procesos de planificación, gestión y evaluación de las políticas y acciones de salud orientadas a la atención prenatal, el parto y la protección de la salud infantil"1.

La muerte neonatal ( 0 a 27 días de vida), un componente importante de la mortalidad infantil tiene una alta prevalencia global y puede estar asociada con tasas bajas de APGAR ( $<7)$ en el quinto minuto después del nacimiento, complicaciones durante el parto, defectos de nacimiento o infecciones, baja educación materna, prematuridad ( $<37$ semanas), menos de tres visitas prenatales, bajo peso al nacer (<2500g) y negro / mestizo / color ${ }^{2,3}$.

Las mujeres y los recién nacidos son más vulnerables durante e inmediatamente después del parto, y se estima que la mortalidad en este grupo es de 2,8 millones cada año, principalmente por causas prevenibles. Sin embargo, desde el año 2000, ha habido una caída en la tasa de mortalidad infantil $(50,0 \%)$ y materna (30,0\%), cuya mortalidad está asociada, en particular, a un mejor acceso a servicios de salud de calidad. Aun así, de acuerdo con la meta propuesta en la Agenda 2030 de Desarrollo Sostenible, 
los Estados Miembros se han comprometido a reducir la tasa de mortalidad materna a menos de 70 casos por cada 100.000 recién nacidos vivos para 2030. En cuanto a los recién nacidos, el objetivo significa tener menos de 12 casos por cada mil nascimientos 4 .

Así, la mortalidad infantil es un indicador importante de bienestar ${ }^{5}$, calidad de vida y servicios de salud, saneamiento básico y educación en una ciudad, país o región4. Las altas tasas de mortalidad infantil han plagado a América Latina y el Caribe durante mucho tiempo y han ido disminuyendo lentamente, sin embargo, en algunos países de la región se han observado pocas mejoras en los últimos 20 años ${ }^{6,7}$.

En este capítulo se presentará la tasa de mortalidad infantil en los países de América Latina y el Caribe en el período 2000, 2006, 2012 y 2018, discutiendo el rol político y social en la génesis del problema, valorando las perspectivas políticas propuestas e implementadas a lo largo de este período. para enfrentar esta cuestión de notoria relevancia para la evolución de los países y pueblos de esta región.

También busca aproximar y fundamentar la nueva tendencia en la producción de conocimiento para integrar las necesidades sociales en la investigación, con el fin de fortalecer el proceso de discusión de políticas públicas y sociales en América Latina y el Caribe, impulsando los procesos y espacios democráticos. para una interacción equitativa en la región ${ }^{8}$. En particular, dado que esta región sigue luchando por desarrollar y fortalecer los procesos de prácticas democráticas, vinculados a las elecciones, la participación y la expansión de los programas sociales, mejorando la capacidad administrativa de los municipios, lo que requiere la captación de conocimientos para reducir las tasas de mortalidad infantil y contribuir al desarrollo humano,

América Latina y el Caribe comprende 33 países: Antigua y Barbuda, Argentina, Bahamas, Barbados, Belice, Bolivia, Brasil, Chile, Colombia, Costa Rica, Cuba, Dominica, Ecuador, El Salvador, Granada, Guatemala, Guyana, Haití, Honduras, Jamaica, México, Nicaragua, Panamá, Paraguay, Perú, República Dominicana, Saint Kitts y Nevis, San Vicente y las Granadinas, Santa Lucía, Surinam, Trinidad y Tabago, Uruguay y Venezuela?.

En esta región, la esperanza de vida y la mortalidad infantil son muy variables, mostrando contrastes entre países y dentro de los países, especialmente cuando se consideran las diferencias regionales, rurales y 
urbanas en las grandes ciudades ${ }^{10}$. A pesar de esto, los países de América Latina y el Caribe han logrado avances sustanciales en términos de reducción de las desigualdades en las intervenciones de salud reproductiva, materna, neonatal e infantil, mortalidad infantil y nutrición. Sin embargo, el 20,0\% más pobre de la población en la mayoría de estos países aún no tiene una calidad de vida mínima y se necesitan más acciones para mejorar la equidad ${ }^{11}$.

Históricamente, la mortalidad infantil siempre ha sido mayor en las zonas rurales y está vinculada al nivel de educación materna, la pobreza y entre los pueblos indígenas. En América Latina, estos grupos no se benefician plenamente de los recursos tecnológicos y el conocimiento en salud ${ }^{12}$, que pueden contribuir a la ocurrencia de la mortalidad infantil. Existe una creciente evidencia que apoya un vínculo entre las desigualdades de ingresos y los resultados de salud ${ }^{13-16}$.

En muchos países, al controlar el ingreso nacional bruto per cápita, la tasa de alfabetización y el gasto en salud, el índice de Gini se asocia de forma independiente con los peores resultados de salud. El índice de Gini representa una escala que varía de cero, que indica la ausencia de desigualdad, a uno, que representa la máxima desigualdad ${ }^{17}$. $Y$ estos resultados, que incluyen altas tasas de mortalidad infantil, son aún peores en los países que son deudores del Fondo Monetario Internacional (FMI). En América Latina, por cada punto porcentual de aumento en el índice de Gini, la tasa de mortalidad infantil aumenta en 0,467 muertes por cada 1.000 nacidos vivos, manteniendo constantes todas las demás variables. Por tanto, es necesario combatir las desigualdades de ingresos y repensar el papel de las instituciones financieras internacionales que dictan las políticas exteriores ${ }^{14}$.

Desde los primeros años del siglo XXI, la profundización de la crisis económica mundial ha terminado por mostrar problemas estructurales crónicos, que no siempre son visibles, especialmente después de las políticas de control de la inflación ampliamente promovidas en el continente en la década de 1990, siguiendo el llamado Consenso de Washington.

El Consenso de Washington fue un movimiento de un grupo de economistas de diferentes países que, motivados por organismos multilaterales (BIRF, FMI, etc.), formularon un modelo de estabilización monetaria a fines de la década de 1980 , cuya base era la paridad fija de monedas. nacio- 
nales de países endeudados con el dólar estadounidense. El modelo pedía apertura comercial a las importaciones y deuda pública para la acumulación de reservas en dólares. En consecuencia, la orientación fue la adopción de medidas de ajuste fiscal, la privatización de empresas y servicios estatales y la desregulación de los flujos de capital. De hecho, estaba en marcha una nueva división internacional del trabajo, con la imposición imperialista de una nueva etapa de especialización productiva para las naciones dependientes ${ }^{18}$.

O Más recientemente, la política social, la austeridad fiscal, la recesión, la crisis económica y la recalificación del Estado van en aumento, todo ello con el objetivo de reducir la demanda y el derecho de la mayor parte de la sociedad al acceso y funcionamiento del Estado en todos los aspectos, particularmente en lo que respecta al bienestar social ${ }^{19}$.

A pesar de todos los ataques a las políticas sociales, la pérdida de derechos es innegable que ha habido una reducción de la mortalidad infantil, y esto se puede atribuir, entre otros factores, al acceso de la población a la atención primaria y secundaria de la salud, además de las reformas. en el sistema de salud pública y mejoras en las condiciones de salud. Esto refuerza la importancia del duelo y el afrontamiento para mantener políticas públicas que contribuyan a reducir la desigualdad social, el acceso a una vivienda de calidad, saneamiento básico y el fomento de la lactancia materna, fundamentales para la reducción de la mortalidad infantil en América Latina y el Caribe ${ }^{10,20,21}$.

Además, las enfermedades diarreicas fueron causas importantes de mortalidad, y la adopción de vacunas contra el rotavirus contribuyó en gran medida a la reducción de estas enfermedades y, en consecuencia, a la mortalidad infantil, incluso en países con baja cobertura de vacunación ${ }^{22,23}$. Asimismo, la aplicación de protocolos de la Organización Mundial de la Salud (OMS) para el tratamiento de la desnutrición aguda severa en niños hospitalizados contribuyó a la reducción de la mortalidad infantil por esta causa $^{13,15,24}$.

A pesar del aporte de estudios de esta naturaleza, existe una limitación asociada a la confiabilidad de los datos difundidos por los países, generando grandes diferencias en el tiempo para evaluar datos entre países centrales y 
periféricos ${ }^{12}$. El propósito de este trabajo es analizar las tasas de mortalidad infantil en América Latina y el Caribe y su interrelación con las políticas públicas y sociales, con el fin de contribuir con subsidios teóricos y prácticos para la (re)planificación de políticas y programas para enfrentar mortalidad infantil en la región. Se trata de una investigación descriptiva, exploratoria y documental, basada en el análisis de los casos de mortalidad infantil en los países de América Latina y el Caribe, en los años 2000, 2006, 2012 y 2018, disponible en base a datos Comisión Económica para América. América Latina y el Caribe?.

\section{Desarrollo}

África Subsahariana, Asia Meridional y Oriente Medio se encuentran entre las regiones con las tasas de mortalidad infantil más altas del mundo, entre los años 1970 y $2003^{25}$. América Latina y el Caribe, en cambio, registró un promedio de $48,8 \%$ de la tasa de mortalidad infantil mundial de 2000 a 2018. A pesar de esta alta tasa de mortalidad, los datos también revelan una tendencia a la baja en esta región y en el mundo (Figura 1).

Figura 1 - Comparación de la tasa de mortalidad infantil en América Latina y el Caribe en relación con el mundo, entre 2000 y 2018.

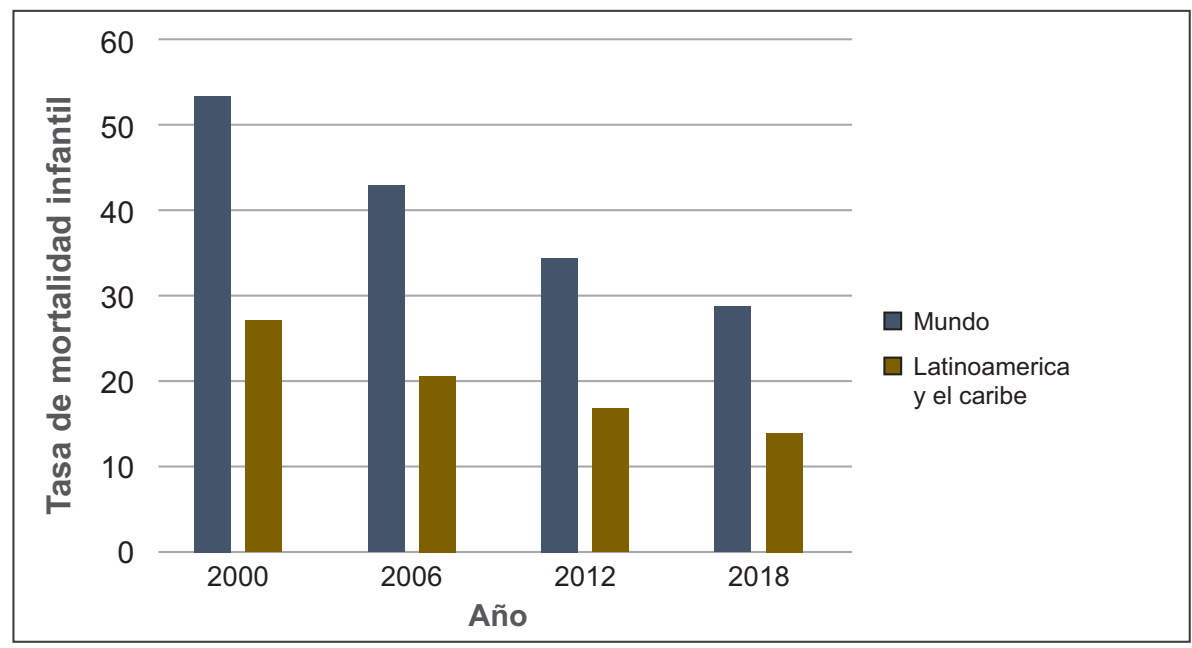

Fonte: Health Nutrition and Population Statistics, $2020^{6}$. 
En 2000, los seis países con mayor riesgo de muerte de un niño en América Latina y el Caribe ${ }^{6}$ estaban representados por Haití $(74,2)$, Bolivia $(55,7)$, Guatemala $(40,6)$, Guyana $(37,1)$, República Dominicana $(33,1)$ y Brasil $(30,4)$, mientras que los de menor riesgo fueron Cuba $(6,8)$, Chile $(9,2)$, Costa Rica $(11,1)$, Dominica $(12,7)$, Bahamas. $(13,0)$ y Antigua y Barbuda $(13,1)$.

Luego de un período de 18 años (2000-2018) ${ }^{6}$ se pudo observar que la mortalidad infantil se mantuvo alta en países como Haití (49.5), República Dominicana y Bolivia (21.8), correspondiendo, aún, a lugares que presentan grandes riesgos para el nacimiento de niños. Se observa un cambio significativo en la tasa de mortalidad en Brasil. Este país logró alcanzar una tasa de mortalidad infantil de 12,8 en 2018.

Otro aspecto importante observado en este estudio fue en relación con el comportamiento de las tasas de mortalidad infantil en Venezuela, Dominica y Granada. En estos países, estas tasas se comportaron con respecto al resto de países de América Latina y el mundo, es decir, se observó un aumento de la mortalidad infantil. En 2018, todos los países con la tasa de mortalidad infantil más baja en 2000 se mantuvieron con tasas de mortalidad por debajo de 10,0 (Tabla 1).

Tabla 1 - Tasa de mortalidad infantil en América Latina y el Caribe, en los años 2000, 2006, 2012 y 2018

\begin{tabular}{|l|r|r|r|r|r|}
\hline TAXA DE MORTALIDAD INFANTIL / AÑO & \multicolumn{4}{c|}{ \% REDUCIÓN } \\
\hline PAísES & \multicolumn{1}{|c|}{$\mathbf{2 0 0 0}$} & \multicolumn{2}{|c|}{$\mathbf{2 0 0 6}$} & \multicolumn{1}{c|}{$\mathbf{2 0 1 2}$} & \multicolumn{2}{c|}{$\mathbf{2 0 1 8}$} & $\begin{array}{c}(\mathbf{2 0 0 0}- \\
\mathbf{2 0 1 8}\end{array}$ \\
\hline Antígua e Barbuda & 13,1 & 9,7 & 6,7 & 5,0 & 61,8 \\
\hline Argentina & 17,5 & 14,4 & 11,8 & 8,8 & 49,7 \\
\hline Bahamas & 13,0 & 11,9 & 9,9 & 8,3 & 36,2 \\
\hline Barbados & 13,7 & 14,2 & 13,1 & 11,3 & 17,5 \\
\hline Belize & 20,0 & 17,6 & 15,2 & 11,2 & 44,0 \\
\hline Bolívia & 55,7 & 40,6 & 29,2 & 21,8 & 60,9 \\
\hline Brasil & 30,4 & 20,7 & 15,4 & 12,8 & 57,9 \\
\hline Chile & 9,2 & 7,6 & 7,2 & 6,2 & 32,6 \\
\hline Colômbia & 21,1 & 17,8 & 14,9 & 12,2 & 42,2 \\
\hline Costa Rica & 11,1 & 8,9 & 8,4 & 7,6 & 31,5 \\
\hline Cuba & 6,8 & 5,4 & 4,4 & 3,7 & 45,6 \\
\hline
\end{tabular}




\begin{tabular}{|c|c|c|c|c|c|}
\hline \multicolumn{4}{|c|}{ TAXA DE MORTALIDAD INFANTIL / AÑO } & \multicolumn{2}{|c|}{ \% REDUCIÓN } \\
\hline PAÍSES & 2000 & 2006 & 2012 & 2018 & $\begin{array}{l}(2000- \\
2018)\end{array}$ \\
\hline Dominica & 12,7 & 14,5 & 22,7 & 32,9 & $-159,1 \#$ \\
\hline Equador & 24,3 & 18,6 & 14,4 & 12,2 & 49,8 \\
\hline El Salvador & 27,2 & 20,0 & 15,0 & 11,8 & 56,6 \\
\hline Granada & 13,3 & 12,5 & 12,9 & 13,7 & $-3,0 \#$ \\
\hline Guatemala & 40,6 & 33,0 & 26,8 & 22,1 & 45,6 \\
\hline Guiana & 37,1 & 32,9 & 29,4 & 25,1 & 32,4 \\
\hline Haiti & 74,2 & 63,8 & 56,8 & 49,5 & 33,3 \\
\hline Honduras & 30,3 & 23,6 & 18,6 & 15,1 & 50,2 \\
\hline Jamaica & 19,0 & 16,9 & 14,9 & 12,4 & 34,7 \\
\hline México & 22,2 & 16,9 & 14,1 & 11,0 & 50,5 \\
\hline Nicarágua & 29,9 & 21,1 & 16,6 & 15,7 & 47,5 \\
\hline Panamá & 21,8 & 19,0 & 16,0 & 13,1 & 39,9 \\
\hline Paraguai & 27,9 & 24,4 & 20,7 & 17,2 & 38,4 \\
\hline Peru & 29,6 & 19,5 & 14,3 & 11,1 & 62,5 \\
\hline República Dominicana & 33,1 & 29,6 & 27,5 & 24,1 & 27,2 \\
\hline São Cristóvão e Névis & 19,0 & 13,7 & 11,4 & 9,8 & 48,4 \\
\hline San Vicente e Granadinas & 19,4 & 19,7 & 17,6 & 14,8 & 23,7 \\
\hline Santa Lúcia & 15,4 & 16,1 & 16,3 & 14,9 & 3,3 \\
\hline Suriname & 30,1 & 24,9 & 20,4 & 16,9 & 43,9 \\
\hline Trinidad e Tabago & 25,4 & 23,2 & 19,7 & 16,4 & 35,4 \\
\hline Uruguai & 14,8 & 11,7 & 8,5 & 6,4 & 56,8 \\
\hline Venezuela & 18,4 & 15,4 & 14,8 & 21,4 & $-16,3 \#$ \\
\hline América Latina e Caribe ${ }^{\star}$ & 27,2 & 20,5 & 16,6 & 14,0 & 61,8 \\
\hline
\end{tabular}

Fuent: CEPAL, 20207. * Estimación basada en 33 países. \# El índice negativo indica el porcentaje de empeoramiento de la tasa de mortalidad infantil.

La persistente alta mortalidad infantil en América Latina y el Caribe se ve reforzada por las crisis económicas y la degradación ambiental que han generado desempleo e inflación ${ }^{26,27}$. Asimismo, la baja inversión en infraestructura, la falta de abastecimiento de agua y alcantarillado, que garantizarían la mejora en la calidad de vida de la población, fueron desatendidas y contribuyeron a la permanencia de enfermedades que se asociaron con el aumento de la mortalidad infantil en el siglo XXI. Otro factor importante está 
asociado al bajo compromiso con la implementación de políticas públicas para mejorar los niveles de lactancia materna exclusiva, al menos hasta los cuatro meses, en esta región ${ }^{28}$.

Todo este proceso puede estar justificado por la política neoliberal, orientación contraria a la inversión en políticas sociales que, por requerimiento del FMI, se utilizó en los países de América Latina y el Caribe para negociar la deuda externa de estos países. Esta política, como se esperaba, generó impactos negativos en los indicadores socioeconómicos y altos costos sociales (Cuadro 2), como el acceso deficiente a los servicios de infraestructura básica, el aumento de las desigualdades sociales, el desempleo y el empleo precario, interfiriendo así en los indicadores. del desarrollo humano 29 .

En este sentido, el endurecimiento de la trampa de la deuda pública terminó por implicar la reproducción ampliada de los problemas fiscales internos en cada país. Paradójicamente, la búsqueda de soluciones a estos graves problemas, basada en la austeridad fiscal, frente a promover la posibilidad de nuevas fuentes de financiamiento para las políticas sociales, terminó por generar una presencia aún más fuerte de la lógica privada en la gestión de los servicios públicos ${ }^{18}$.

Tabla 2 - Gasto corriente total en salud como proporción del PIB en los años 2000, 2006, 2012 y 2018.

\begin{tabular}{|l|c|c|c|c|}
\hline \multicolumn{5}{|c|}{ GASTO EN SALUD (\% PIB) } \\
\hline PAísES & $\mathbf{2 0 0 0}$ & $\mathbf{2 0 0 6}$ & $\mathbf{2 0 1 2}$ & $\mathbf{2 0 1 8}$ \\
\hline Antígua e Barbuda & 4,5 & 4,7 & 5,2 & 4,5 \\
\hline Argentina & 8,5 & 7,6 & 8,5 & 9,1 \\
\hline Bahamas & 4,0 & 5,4 & 6,0 & 5,8 \\
\hline Barbados & 5,3 & 6,6 & 7,8 & 6,8 \\
\hline Belize & 4,1 & 4,6 & 5,4 & 5,6 \\
\hline Bolívia & 4,4 & 4,8 & 5,4 & 6,4 \\
\hline Brasil & 8,3 & 8,3 & 7,7 & 9,5 \\
\hline Chile & 7,0 & 6,0 & 7,0 & 9,0 \\
\hline Colômbia & 5,7 & 6,4 & 6,8 & 7,2 \\
\hline Costa Rica & 6,6 & 7,0 & 7,9 & 7,3 \\
\hline Cuba & 6,6 & 8,3 & 9,3 & 11,7 \\
\hline Dominica & 5,2 & 5,2 & 5,8 & 5,9 \\
\hline
\end{tabular}




\begin{tabular}{|l|c|c|c|c|}
\hline \multicolumn{5}{|c|}{ GASTO EN SALUD (\% PIB) } \\
\hline PAísES & $\mathbf{2 0 0 0}$ & $\mathbf{2 0 0 6}$ & $\mathbf{2 0 1 2}$ & $\mathbf{2 0 1 8}$ \\
\hline Equador & 3,3 & 5,7 & 8,5 & 8,3 \\
\hline El Salvador & 8,9 & 7,9 & 7,5 & 7,2 \\
\hline Granada & 5,3 & 6,0 & 5,9 & 4,8 \\
\hline Guatemala & 5,7 & 6,6 & 6,0 & 5,8 \\
\hline Guiana & 3,9 & 5,0 & 4,9 & 4,9 \\
\hline Haiti & 6,9 & 5,5 & 9,7 & 8,0 \\
\hline Honduras & 6,4 & 8,1 & 8,6 & 7,9 \\
\hline Jamaica & 5,8 & 4,5 & 5,0 & 6,0 \\
\hline México & 4,4 & 5,7 & 5,8 & 5,5 \\
\hline Nicarágua & 5,2 & 6,0 & 7,6 & 8,6 \\
\hline Panamá & 7,0 & 6,6 & 6,6 & 7,3 \\
\hline Paraguai & 5,5 & 4,2 & 6,5 & 6,7 \\
\hline Peru & 4,5 & 4,5 & 4,8 & 5,0 \\
\hline República Dominicana & 4,9 & 4,0 & 5,9 & 6,1 \\
\hline São Cristóvão e Névis & 4,7 & 4,9 & 5,2 & 5,0 \\
\hline San Vicente e Granadinas & 4,3 & 3,8 & 4,7 & 4,5 \\
\hline Santa Lúcia & 5,4 & 5,7 & 5,6 & 4,5 \\
\hline Suriname & 6,3 & 6,3 & 4,6 & 6,2 \\
\hline Trinidad e Tabago & 4,2 & 4,2 & 4,9 & 7,0 \\
\hline Uruguai & 10,0 & 8,4 & 8,8 & 9,3 \\
\hline Venezuela & 7,3 & 8,1 & 6,4 & 1,2 \\
\hline
\end{tabular}

Fuente: CEPAL, 2020. * Estimación basada en 33 países. \# El índice negativo indica el porcentaje de empeoramiento de la tasa de mortalidad infantil

Así, los inicios de los noventa estuvieron marcados por las políticas neoliberales, mientras que en la década siguiente predominaron los avances sociales, con una pequeña reducción de las desigualdades sociales. Hubo una reducción en la exportación de manufacturas y un aumento en la exportación de productos primarios, de baja composición tecnológica y bajo valor económico, lo que contribuyó a perjudicar la economía y el mantenimiento económico, político y social de la región de América Latina y el Caribe ${ }^{30}$.

Afortunadamente, se observa que la difusión de programas de transferencias monetarias condicionadas, un importante instrumento para 
combatir la pobreza intergeneracional ha sido adoptada por casi todos los países latinoamericanos ${ }^{31}$, lo que trae beneficios inmediatos, pero puede comprometer el fortalecimiento de políticas efectivas. y la permanencia de gobiernos no deseados, que fortalece en la región el mantenimiento de tasas de mortalidad infantil por encima de las recomendadas por la OMS.

Es de destacar que, desde principios del siglo XXI, la crisis del Estado de Bienestar Social ha ampliado el papel del mercado como mecanismo de satisfacción de las necesidades básicas, reduciendo los presupuestos públicos para las políticas sociales. Esto contribuyó al mantenimiento de las crisis económicas y políticas, resultando en un aumento de la vulnerabilidad social, dando lugar a políticas públicas que buscaran superar la lógica asistencialista de la dependencia, produciendo desarrollo y emancipación social, reflejando, entre otros, en mejorar las tasas. de la mortalidad infantil ${ }^{32}$.

El tema de la política es fundamental para abordar los problemas sociales, que incluyen el progreso de la niñez y la juventud y, en consecuencia, de la evolución de los países latinoamericanos ${ }^{31}$. Así, a principios de la década de 2000, hubo una percepción pública de la importancia de los partidos en la vida política de América Latina y, a pesar de la participación de las élites, los partidos a veces siguen siendo legítimos, estructurando la competencia y dando forma a los resultados electorales, orientando ciudadanos y élites en la comprensión de la realidad política, construyendo acuerdos en torno a políticas de gobierno y acciones legislativas efectivas. A pesar de las deficiencias, con algunas excepciones, siguieron estructurando la dinámica política latinoamericana y más de la mitad de la población creía, en ese momento, que la calidad del voto cambiaría las cosas en el futuro, especialmente entre uruguayos y venezolanos ${ }^{33}$.

Entre los países analizados en este estudio, ocho mostraron una reducción superior al $50 \%$ en su tasa de mortalidad infantil, como se destaca en la Figura 2. La reducción promedio en la tasa de mortalidad infantil para estos países fue: Perú (62,50\%), Antigua y Barbuda (61,8\%), Bolivia (60,9\%), Brasil $(57,9 \%)$, Uruguay $(56,8 \%)$, El Salvador $(56,6 \%)$, México $(50,5 \%)$, Honduras $(50,2 \%)$. Estos resultados pueden atribuirse, en parte, a "la voluntad política de mejorar el acceso a servicios de salud de calidad, invertir en la fuerza laboral de salud, introducir atención gratuita para mujeres embarazadas y niños y apoyar la planificación familiar"4. 
Figura 2 - Países de América Latina y el Caribe que presentaron una importante reducción del 50,0\% en la tasa de mortalidad infantil, de 2000 a 2018.

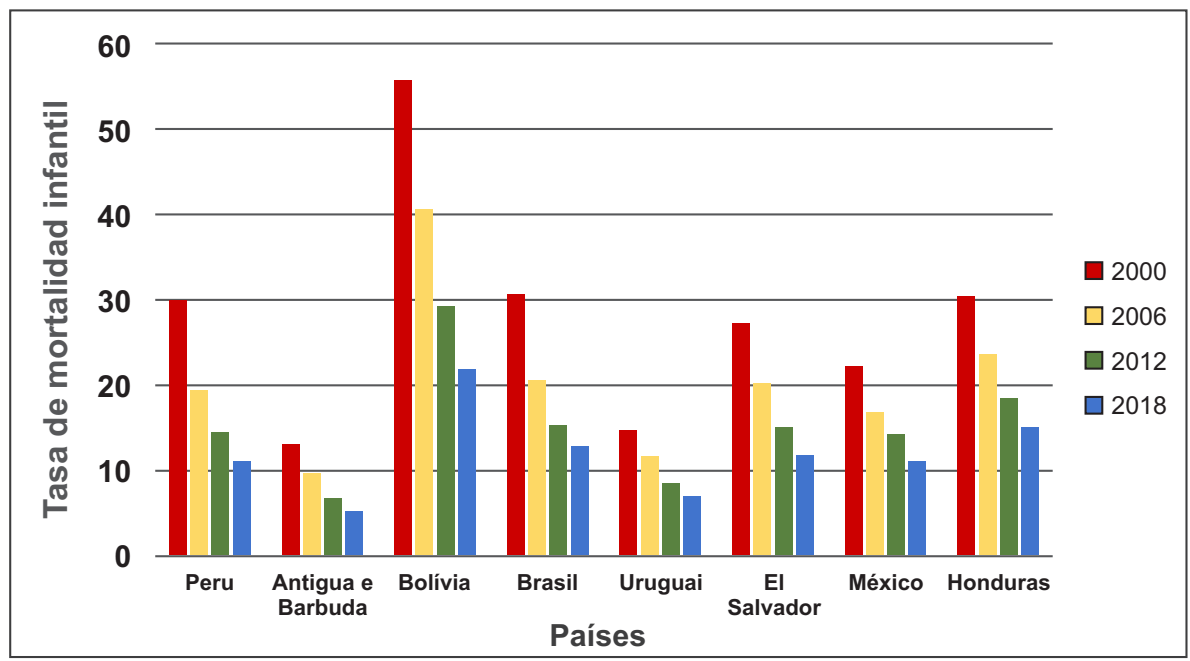

Fuente: Health Nutrition And Population Statistics, $2020^{6}$.

El panorama social de América Latina continúa reflejando la desigualdad de ingresos, la pobreza y la reducción del gasto social, con fuerte influencia de la migración, tema de gran relevancia en la agenda política y social de la región. Se puede observar que la renta $(1,0 \%)$ de los más ricos sigue creciendo. La pequeña mejora en los ingresos de la clase media no se reflejó en la eliminación de vulnerabilidades para la mayoría de la población, quienes permanecieron con bajo nivel educativo, desempleo o empleo de baja calidad, baja cobertura y prestaciones insuficientes en el sistema de jubilaciones y pensiones. Para la efectividad de la igualdad social es necesario establecer un pacto de equidad distributiva y sostenibilidad de la protección social para la práctica de la igualdad social?.

Las instituciones dañinas en muchos de estos países contribuyen a aumentar las desigualdades sociales, lo que tiene un impacto negativo en el proceso de desarrollo económico ${ }^{34}$. En Brasil, a pesar de la alta desigualdad social, la reducción de la mortalidad infantil puede atribuirse a programas de transferencias monetarias condicionadas a los más pobres, inversiones en atención primaria de salud, reducción de las tasas de analfabetismo, bajos niveles de fecundidad y mejoras acceso al suministro de agua y saneamiento básico ${ }^{35}$. 
A principios de la década de 2000, los indicadores demográficos y epidemiológicos en América Latina indicaron similitudes y contrastes en algunos países, percibidos como un retroceso social. Para reducir la publicidad de la oposición, algunos organismos internacionales atribuyeron la pérdida de derechos sociales a la transición demográfica, y no a las políticas de la corte neoliberal ${ }^{36}$.

En la Figura 3, es posible ver el cuadro de la disparidad que se presenta en América Latina y el Caribe. Por un lado, Cuba, con su muy pequeña, mantuvo la tasa de mortalidad y con tendencia a la baja en el período analizado, y por otro lado, Haití, que a pesar de haber disminuido un 33,3\% en este período de 18 años, todavía tiene una tasa de mortalidad cercana a los 50.

Figura 3 - Comparación entre las tasas de mortalidad infantil en Cuba y Haití, de 2000 a 2018

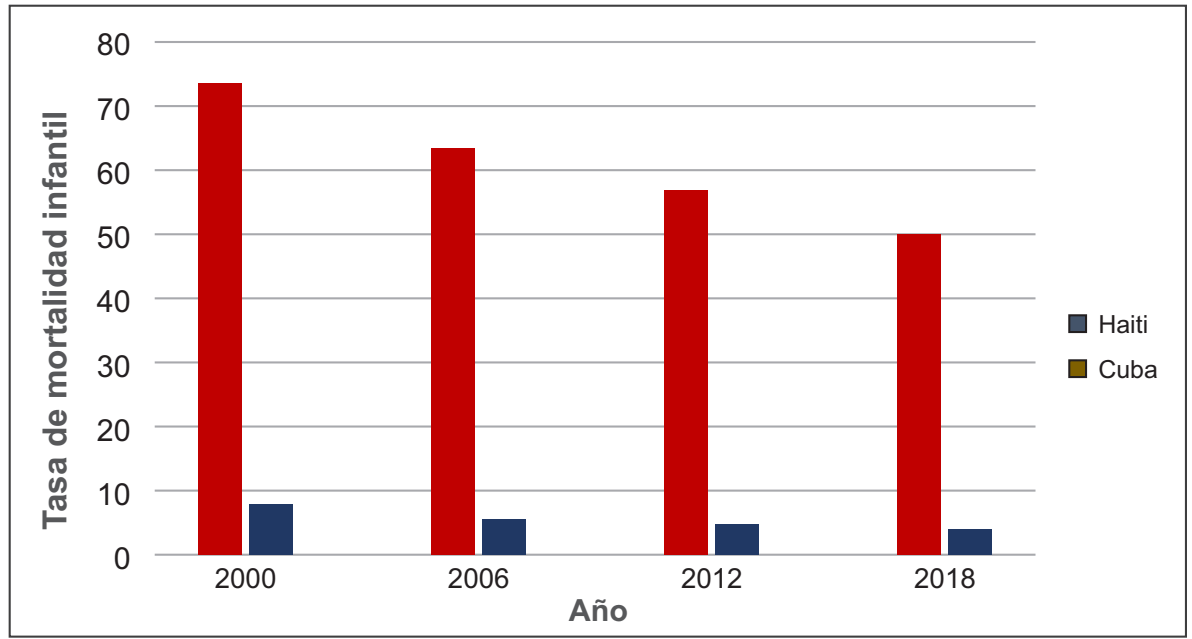

Fuente: Health Nutrition and Population Statistics, $2020^{7}$

Las nefastas consecuencias de la acción del imperialismo salvaje estadounidense y el colonialismo depredador europeo dejaron como herencia para la región de América Latina y el Caribe, influencias de la opresión cultural para la implantación de racismo y la invisibilidad de todas las formas de prejuicio, que reducen la autoestima de las personas, en todos los ciclos vitales. Implantó en el inconsciente colectivo las bases para minimizar la dependencia económica, favoreciendo la implantación 
de políticas públicas que resultaron en el aumento de la pobreza, de la educación y de la baja calidad de la salud y de la pérdida o vulneración de los derechos sociales ${ }^{37}$, que afectaban directamente a la niñez en la Región, reduciendo las posibilidades de una vida sana en un mundo altamente selectivo y competitivo.

\section{Consideraciones finales}

En definitiva, la crisis económica mundial ha dejado en evidencia problemas estructurales crónicos, a veces invisibles, en respuesta a las políticas públicas de control de la inflación desde 1990. Muchos países de la región incluso han logrado ocultar muchas de sus dificultades para financiar planes de desarrollo a través de tras la melodía de las agencias multilaterales (FMI, BIRF, etc.), que forzaron la idea de convertir artificialmente las naciones subdesarrolladas en economías emergentes, dado el auge de la demanda china de productos básicos. Es interesante que, aun con el surgimiento de gobiernos progresistas en algunos países de América Latina, en el período, la exacerbación de la trampa de la deuda impidió cualquier posibilidad de avanzar con los planes (neo) de desarrollo que pretendían poner en marcha. Así, a diferencia de los discursos formales, las políticas de austeridad fiscal marcan la pauta de la política macroeconómica.

El control del gasto en políticas esenciales siguió siendo una prioridad del modelo, ya que se mantuvo la conversión continua de la deuda externa privada en deuda pública interna, cuyos pagos parciales de intereses crecientes destruyeron la ya precaria capacidad para impulsar nuevas inversiones y promover políticas públicas esenciales., que podría sostener y mejorar la calidad de vida en general. Así, el endurecimiento de la trampa de la deuda pública terminó por implicar la reproducción extendida de los problemas fiscales internos en cada país. Paradójicamente, la búsqueda de soluciones a estos graves problemas, basada en la austeridad fiscal, frente a promover la posibilidad de nuevas fuentes de financiamiento para las políticas sociales, terminó generando una presencia aún más llamativa de la lógica privada en la gestión de los servicios públicos.

En el caso de las políticas de salud, en particular, esta perspectiva proporcionó la subcontratación de servicios a organizaciones y fundaciones 
sociales e, incluso, el avance de la tramitación de propuestas de privatización de unidades a favor del gran capital. Dentro de esta lógica, el acceso a los servicios esenciales de salud es cada vez más restrictivo, desde la infraestructura preventiva, como la vinculada al saneamiento ambiental, hasta la atención primaria y procedimientos de diagnóstico y tratamiento más intensivos. En este contexto, se ven obstaculizados los avances en la atención preventiva y la atención de emergencia, que vienen mostrando resultados positivos en la reducción de la mortalidad infantil en América Latina y el Caribe. Es necesario enfrentar esta tendencia que apunta a un escenario camuflado de conversión definitiva del prenatal y posparto en privilegios para quienes pueden pagarlos, de manera inmediata, al momento de brindar estos servicios, como un prerrequisito para la madre y el niño. deben cumplirse.

\section{Referencias}

1. BRASIL. Ministério da Saúde/CENEPI: Sistema de Informações sobre Mortalidade (SIM) e Sistema de Informações sobre Nascidos Vivos (SINASC). Disponível em: http://tabnet.datasus.gov.br/cgi/idb2000/fqc01.htm. Acesso em: 10 ago. 2020.

2. CARVALHO, P. I. et al. Fatores de risco para mortalidade neonatal em coorte hospitalar de nascidos vivos. Epidemiol. Serv. Saúde, v.16, n. 3, p. 185-194, jul./ set. 2007. doi: 10.5123/S1679-49742007000300005.

3. Mortalidade Materna e na Infância - Mulheres e crianças estão sobrevivendo cada vez mais.disponível em https://www.unicef.org/brazil/comunicados-de-imprensa/ mortalidade-materna-e-na-infancia-mulheres-e-criancas-estao-sobrevivendocada-vez-mais.

4. FUNDO DAS NAÇÕES UNIDAS PARA A INFÂNCIA (UNICEF); ORGANIZAÇÃO MUNDIAL DA SAÚDE (OMS). 2019. UNICEF e OMS dizem que taxas de mortalidade materno-infantil nunca foram tão baixas. Disponível em: https://news.un.org/pt/ story/2019/09/1687532. Acesso em: 10 ago. 2020.

5. GERRING, J. et.al. Electoral Democracy and Human Development. Paper prepared for presentation at the ECPR joint sessions of workshops, Pisa, April 24-28, 2016. Disponível em: https://ecpr.eu/Filestore/PaperProposal/0a4557bb-f171-42f3882a- cb6ba37456c9.pdf. Acesso em: 10 ago. 2020.

6. HEALTH NUTRITION AND POPULATION STATISTICS, 2020. Disponível em https:// databank.worldbank.org/source/health-nutrition-and-population-statistics. Acesso em 14 OUT 2020. 
7. Comissão Econômica para a América Latina e o Caribe (CEPAL), Panorama Social da América Latina, 2019. Resumo executivo (LC/PUB.2020/1-P), Santiago, 2020. Disponível em: https://repositorio.cepal.org/bitstream/handle/11362/45090/1/ S1900909_pt.pdf. Acesso em: 10 ado. 2020.

8. PELLEGRINI FILHO, A. Pesquisa em saúde, política de saúde e eqüidade na América Latina. Ciência \& Saúde Coletiva [online], v. 9, n. 2, p. 339-350, 2004. doi: 10.1590/ S1413-81232004000200011.

9. TOUCHTON, M.; SUGIYAMA, N. B.; WAMPLER, B. DEMOCRACIA EM AÇÃO: indo além das eleições para melhorar o bem-estar. Caderno $\mathrm{CRH}$, Salvador, v. 33, p. 01-17, e020006, jul. 2020. doi: 10.9771/ccrh.v33i0.33273.

10. BÄHR, J.; WEHRHAHN, R. Life expectancy and infant mortality in Latin America. Soc Sci Med, v.36, n. 10, p. 1373-1382, mai. 1993. doi:10.1016/0277-9536(93)90230-2.

11. RESTREPO-MÉNDEZ, M. C. et al. Progress in reducing inequalities in reproductive, maternal, newborn, and child health in Latin America and the Caribbean: an unfinished agenda. Rev Panam Salud Publica, v. 38, n. 1, p. 9-16, 2015.

12. BEHM, H.; PRIMANTE, D. A. Infant and child mortality in Latin America. Notas Poblacion, v. 6, n. 16, p. 23-44, abr. 1978. doi: pubmed.ncbi.nlm.nih.gov/12335524/.

13. CHUANG, Y. C. et al. The inter-relationship among economic activities, environmental degradation, material consumption and population health in lowincome countries: a longitudinal ecological study. BMJ Open, v. 5, n. 7, e006183, jul. 2015. doi:10.1136/ bmjopen-2014-006183.

14. FERRE, J. C. Economic Inequalities in Latin America at the Base of Adverse Health Indicators. Int J Health Serv, v. 46, n. 3, p. 501-522, jun. 2016. doi:10.1177/0020731416653428.

15. HOSSAIN, M. et al. Efficacy of World Health Organization guideline in facilitybased reduction of mortality in severely malnourished children from low and middle income countries: A systematic review and meta-analysis. J Paediatr Child Health, v. 53, n.5, p. 474-479, jan./mai. 2017. doi:10.1111/jpc.13443.

16. TEJADA, C. A. O. et al. Crises econômicas, mortalidade de crianças e o papel protetor do gasto público em saúde. Ciênc. saúde coletiva, Rio de Janeiro, v. 24, n. 12, p. 4395-4404, nov./dez. 2019. doi: 10.1590/1413-812320182412.25082019.

17. WOLFFENBÜTTEL, A. O que é? - Índice de Gini. Desafios do Desenvolvimento. Instituto de Pesquisa Econômica Aplicada. ed. 4, ano 1, 2004. Disponível em: https:// www.ipea.gov.br/desafios/index.php?option=com_content\&id=2048: catid=28. Acesso em: 10 ago. 2020.

18. GOMES, Helder. Endividamento, histórico de lutas e propostas alternativas nos países da América Latina e do Caribe. São Paulo: Jubileu Sul Américas. 2020.

19. Vieira, Fabiola Sulpino, et al. "Políticas sociais e austeridade fiscal: como as políticas sociais são afetadas pelo austericídio da agenda neoliberal no Brasil e no mundo." (2018). 
20. SANKAR, M. J. et al. Optimal breastfeeding practices and infant and child mortality: a systematic review and meta-analysis. Acta Paediatr, v.104, n. 467, p.3-13, dez. 2015. doi:10.1111/apa.13147.

21. NISHIMURA, F. Efeito da habitação sobre a mortalidade infantil: evidências de um desenho de regressão descontínua. Análise Econômica, Porto Alegre, v. 38, n. 76, p. 171-196, jun. 2020. doi: 10.22456/2176-5456.81890.

22. OLIVEIRA, L. H. et al. Impact and Effectiveness of 10 and 13 -Valent Pneumococcal Conjugate Vaccines on Hospitalization and Mortality in Children Aged Less than 5 Years in Latin American Countries: A Systematic Review. PLoS One, v. 11, n. 12, e0166736, dez. 2016. doi: 10.1371/journal.pone.0166736.

23. CHAVERS, T. et al. Post-licensure experience with rotavirus vaccination in Latin America and the Caribbean: a systematic review and meta-analysis. Expert Rev Vaccines, v. 17, n. 11, p. 1037-1051, nov. 2018. doi:10.1080/14760584.2018.154 1409.

24. da Silva, Valmin Ramos. "Desnutrição em crianças internadas em Hospital Infantil de Vitória, ES: reflexão histórico-político-social." Rev Med Minas Gerais 2017.26 (1818).

25. Victora, Cesar, and Fernando C. Barros. "A questão da sobrevivência infantil no mundo e sua relevância para as Américas” Cadernos ESP 1.1 (2005): 04-13.

26. Chuang YC, Huang YL, Hu CY, Chen SC, Tseng KC. The inter-relationship among economic activities, environmental degradation, material consumption and population health in low-income countries: a longitudinal ecological study. BMJ Open. 2015;5(7):e006183. Published 2015 Jul 15. doi:10.1136/ bmjopen-2014-006183.

27. Tejada, Cesar Augusto Oviedo, et al. "Crises econômicas, mortalidade de crianças e o papel protetor do gasto público em saúde." Ciência \& Saúde Coletiva 24 (2019): 4395-4404.

28. TEIXEIRA, J. C.; PUNGIRUM, M. E. M. C. Análise da associação entre saneamento e saúde nos países da América Latina e do Caribe, empregando dados secundários do banco de dados da Organização Pan-Americana de Saúde-OPAS. Rev. bras. epidemiol [online], v. 8, n. 4, p. 365-376, 2005. doi: 10.1590/S1415$790 \times 2005000400005$.

29. SILVA, G. F. O custo social das reformas neoliberais: impactos do consenso de Washington em pobreza e desigualdades na América Latina e o Caribe. Trabalho de Conclusão de Curso (Graduação) - Universidade Federal de Santa Catarina, Centro Socioeconômico. Santa Catarina, p. 94. 2019. Disponível em https:// repositorio.ufsc.br/handle/123456789/209690. Acesso em: 10 ago. 2020.

30. SANTOS, T. M. Estudo do desenvolvimento em países da América Latina a partir do comércio exterior (1990-2015). Dissertação (Mestrado) - Universidade Estadual de Campinas, Faculdade de Ciências Aplicadas. São Paulo, p. 122. 2018. Disponível em: http://repositorio.unicamp.br/handle/REPOSIP/332947. Acesso em: 10 ago. 2020. 
31. SANTOS, P. M. A. Mecanismos de difusão de políticas sociais: o caso dos programas de transferência condicionada de rendimentos na América Latina. Dissertação (Mestrado) - Universidade de Lisboa, Instituto Superior de Ciências Políticas. Portugal, p. 116. 2019. Disponível em https://www.repository.utl.pt/ handle/10400.5/18011. Acesso em: 10 ago. 2020.

32. ZAMBAM, N. J.; KUJAWA, H. A. As políticas públicas em Amartya Sen: condição de agente e liberdade social. Revista Brasileira de Direito, v. 13, n. 1, p. 60-85, 2017.

33. Alcántara Sáez, Manuel, and Flavia Freidenberg. "Partidos políticos na América Latina." Opinião Pública 8.2 (2002): 137-157.

34. FERREIRA, C. C.; SALLES, A. O. T. Desenvolvimento econômico e desigualdade social: uma análise a partir do princípio de causação circular cumulativa de Gunnar Myrdal. Revista da Sociedade Brasileira de Economia Política, n. 55, p. 82-116, jan./abr. 2020.

35. SILVA, E. S. A.; PAES, N. A. Programa Bolsa Família e a redução da mortalidade infantil nos municípios do Semiárido brasileiro. Ciênc. saúde coletiva [online], v. 24, n. 2, p. 623-630, 2019. doi: 10.1590/1413-81232018242.04782017.

36. Soares, Laura Tavares Ribeiro. "América Latina: transição epidemiológica ou retrocesso social?." Acta Paul Enferm. 13.special issue 1 (2000): 55-64.

37. VAL, Eduardo Manuel, BELLO, Enzo. O pensamento pós e descolonial no novo constitucionalismo latino-americano. Caxias do Sul, RS: Educs, 2014. https://www. ucs.br/site/midia/arquivos/pensamento_pos.pdf. 



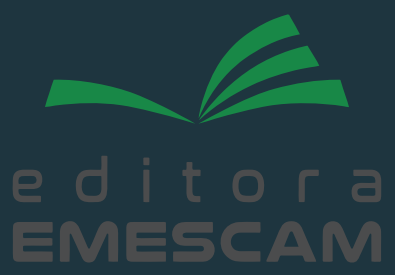

